LA-13935

Approved for public release;

distribution is unlimited.

Probabilistic Assessment of the

Design and Safety of HSLA-100

Steel Confinement Vessels 
Los Alamos National Laboratory, an affirmative action/equal opportunity employer, is operated by the University of California for the United States Department of Energy under contract W-7405-ENG-36.

This report was prepared as an account of work sponsored by an agency of the United States Government. Neither the Regents of the University of California, the United States Government nor any agency thereof, nor any of their employees make any warranty, express or implied, or assume any legal liability or responsibility for the accuracy, completeness, or usefulness of any information, apparatus, product, or process disclosed, or represent that its use would not infringe privately owned rights. Reference herein to any specific commercial product, process, or service by trade name, trademark, manufacturer, or otherwise does not necessarily constitute or imply its endorsement, recommendation, or favoring by the Regents of the University of California, the United States Government, or any agency thereof. The views and opinions of authors expressed herein do not necessarily state or reflect those of the Regents of the University of California, the United States Government, or any agency thereof. Los Alamos National Laboratory strongly supports academic freedom and a researcher's right to publish; as an institution, however, the Laboratory does not endorse the viewpoint of a publication or guarantee its technical correctness. 
LA-13935

Issued: March 2003

Probabilistic Assessment of the

Design and Safety of HSLA-100

Steel Confinement Vessels

Ronald M. Dolin

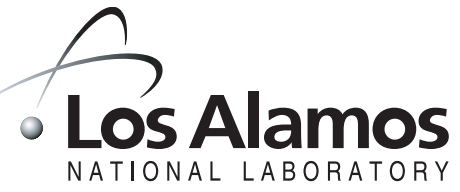





\section{CONTENTS}

TABLES .........................................................................................................................................................................................................vi

FIGURES

SYMBOLS.......................................................................................................................................................................................................................viii

ABSTRACT. ..................................................................................................................................................................................................................

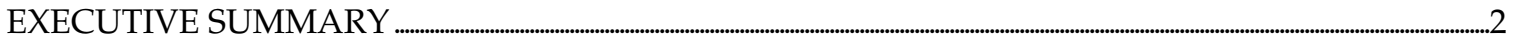

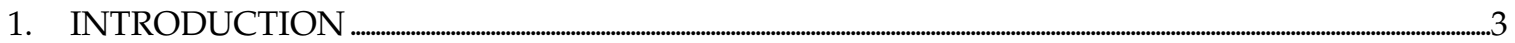

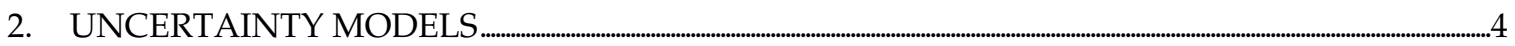

2.1. Uncertainty Distributions for Fragment Geometry ..................................................................................................................... 4

2.2. Uncertainty Distributions for Fragment Velocity...................................................................................................................8

2.3. Uncertainty Distributions for Fragment Orientation................................................................................................10

3. LIKELIHOOD OF OCCURRENCE SIMULATION ……...........................................................................................

3.1. Maximum Likelihood Estimator .........................................................................................................................................17

4. STOCHASTIC SAMPLING SIMULATION ............................................................................................................................19

4.1. DynEx Problem Stochastic Sampling Logical Influence Diagram Model...................................................20

4.1.1. Fragment Geometry ..........................................................................................................................................................21

4.1.2. Fragment Orientation.........................................................................................................................................................22

4.1.3. Fragment Velocity

4.2. Performing a Simulation............................................................................................................................................................................ 24

5. STOCHASTIC SAMPLING SIMULATION CONVERGENCE .................................................................................27

5.1. Performing Multiple Simulations ...............................................................................................................................................34

6. ASSESSING MARGIN AND SAFETY .....................................................................................................................................35

6.1. Likelihood of Occurrence Results Relative to Performance Requirements..............................................36

6.2. Stochastic Sampling Simulation Results Relative to Performance Requirements............................38

6.3. Capability Ratio-Percent of Specification .............................................................................................................40

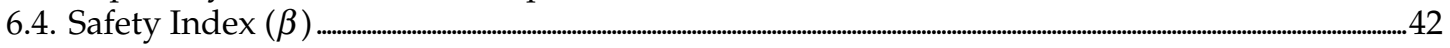

6.5. Engineering Index ...........................................................................................................................................45

7. USING PROBABILISTIC ASSESSMENTS TO VALIDATE NUMERICAL SIMULATION ..............48

7.1. Comparing Numerical Tool Predictions with Probabilistic Predictions............................................48

7.2. Assessing a Numerical Tool's Ability to Infer beyond the Domain for Which It Was Validated ...........................................................................................................................................................................................50

8. SUMMARY OF RESULTS .............................................................................................................................................................51

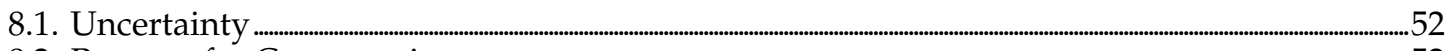

8.2. Reasons for Conservatism ...............................................................................................................................................52

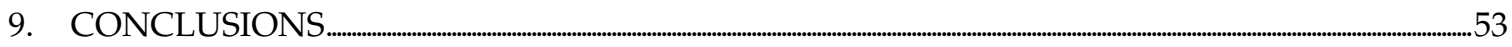

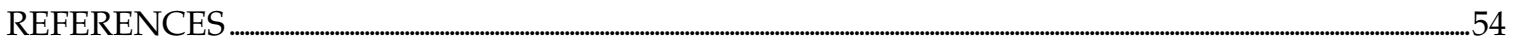

APPENDIX A. DISCRETE PROBABILISTIC ASSESSMENT MATRICES..........................................................55

APPENDIX B. STOCHASTIC SAMPLING LOGICAL INFLUENCE DIAGRAM MODEL ...................59

APPENDIX C. RESULTS OF FORTY STOCHASTIC SIMULATIONS USING DIFFERENT RANDOM SAMPLING SEEDS.......................................................................................................61

APPENDIX D. RESULTS OF FINITE ELEMENT ANALYSES USING THE NUMERICAL

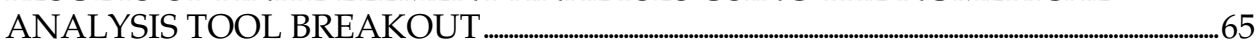




\section{TABLES}

Table 2.1. $\quad$ Likelihood That Fragments of Certain Mass Occur..........................................................................................5

Table 2.2. $\quad$ Likelihood That Fragments Have a Particular Diameter ...............................................................................6

Table 2.3. Discrete Distribution of $L / D$ Ratios When $D=0.25$ Inches...........................................................................7

Table 2.4. Logical Deduction of Perforation for $v_{\text {cr }}$.....................................................................................................................8

Table 2.5. Cumulative Likelihoods That a Fragment Travels with at Least the Specified Velocity ................................................................................................................................

Table 3.1. Fragment Discretization for the Likelihood of Occurrence Simulation........................................12

Table 3.2. Results of the Likelihood of Occurrence Simulations for Three Different Wall Thicknesses ...................................................................................................................................................................................................16

Table 3.3. Joint Probability Matrix for Discrete $L / D$ and $P / L$ Combinations ….......................................................18

Table 3.4. Combined Probability of Perforation for Discrete $L / D$ Combinations ...........................................18

Table 3.5. Combined Probability of Perforation for Discrete $P / L$ Combinations ...........................................18

Table 3.6. Results of Maximum Likelihood Point Estimates for the Three Vessel Thickness Models Considering Worst-Case Scenario .....................................................................................19

Table 4.1. C Critical Velocity Table for HSLA-100 Type Steel...................................................................................................23

Table 4.2. Results of the Stochastic Sampling Simulation for Three Vessel Scenarios................................27

Table 5.1. Convergence Summary for 1" Containment Vessel Thickness Simulations..............................28

Table 5.2. Convergence Summary for 2" Containment Vessel Thickness Simulations..............................28

Table 5.3. Convergence Summary for 5.25" Containment Vessel Thickness Simulations ......................28

Table 5.4. Maximum Worst Probable Point from All Simulations Performed.................................................33

Table 5.5. Results of Forty Unique Stochastic Sampling Simulations Measured with Respect to Their Worst Probable Points ...............................................................................................................................34

Table 6.1. Capability Ratios and Percent of Specification Values for Likelihood of Occurrence Simulations ...................................................................................................................................................................4 41

Table 6.2. Capability Ratios and Percent of Specification Values for the Stochastic

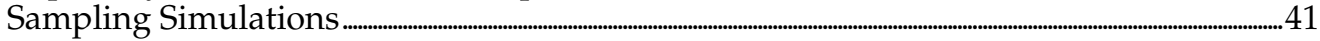

Table 6.3. JAR-25 Relationship between Probability and Severity of Effects....................................................44

Table 6.4. Safety Indices for the Six Numerical Simulations.................................................................................44

Table 7.1. Validation Assessment for the $0.5 \mathrm{~cm}$ Diameter Fragment Impacting a 2" Target ..............49

Table 7.2. Validation Assessment for 0.75 and $1.0 \mathrm{~cm}$ Diameter Fragments Impacting a 2" Target ...................................................................................................................................................................................................50

Table A1. Discrete Probability Assessment for 1 inch Thick Containment Vessel .........................................56

Table A2. Discrete Probability Assessment for 2 inch Thick HSLA-100 Containment Vessel .....................................................................................................................................................................................................56

Table A3. Discrete Probability Assessment for 2 inch Thick HSLA-100 Containment Vessel Encased in a 3.25 inch Steel Safety Vessel ......................................................................................57

Table C1. Results of Forty Simulations Using Different Sampling Sets for the 1 inch Target Thickness Scenario .62

Table C2. Results of Forty Simulations Using Different Sampling Sets for the 2 inch Target Thickness Scenario.

Table C3. Results of Forty Simulations Using Different Sampling Sets for the 5.25 inch Target Thickness Scenario.. . .64

Table D1. Various Penetration Parameters for Fragments Impacting a 2-inch Thick HSLA-100 Steel Plate with a Constant Fragment $D=0.50 \mathrm{~cm}$..............................................................66

Table D2. Various Penetration Parameters for Fragments Impacting a 2-inch Thick HSLA-100 Steel Plate with a Constant Fragment $D=0.75 \mathrm{~cm}$..........................................................67

Table D3. Various Penetration Parameters for Fragments Impacting a 2-inch Thick HSLA-100 Steel Plate with a Constant Fragment $D=1.0 \mathrm{~cm}$ 67 


\section{FIGURES}

Figure 2.1. Probability distribution for fragment mass based on Mott's distribution....................................5

Figure 2.2. Probability distribution for fragment diameter based on experimental

evidence and expert judgment.

Figure 2.3. Depiction of DynEx experiment.

Figure 2.4. Distribution for fragment length-to-diameter ratio, given the fragment has a particular diameter.

Figure 2.5. Probability distribution for likely fragment velocities

Figure 2.6. Cumulative distribution a fragment travels with at least the specified velocity....................10

Figure 2.7. Orientation of a fragment with respect to the containment vessel ...................................................10

Figure 4.1. Influence diagram depicting how the probability of perforation is influenced .......................20

Figure 4.2. Influence diagram for probability of mass................................................................................................................21

Figure 4.3. Influence diagram for determining probability of orientation..................................................................22

Figure 4.4. Influence diagram for determining the probability that a fragment travels at or above its critical velocity.

Figure 4.5. Critical velocity versus fragment $L / D$ ratios for various target thickness to

Figure 4.6. Domain of simulated fragment events relative to actual test events. 23

Figure 5.1. Converging pdf plots for increasing sample sizes for 1" vessel thickness

Figure 5.2. Converging pdf plots for increasing sample sizes for 2" vessel thickness

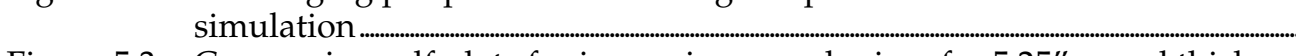

Figure 5.3. Converging pdf plots for increasing sample sizes for $5.25^{\prime \prime}$ vessel thickness simulation.

Figure 5.4. The probability density function for the 1 " vessel using 30,000 samples over

the range from $\mu$ to $\mu+3 \sigma$
Figure 5.5. The cumulative probability

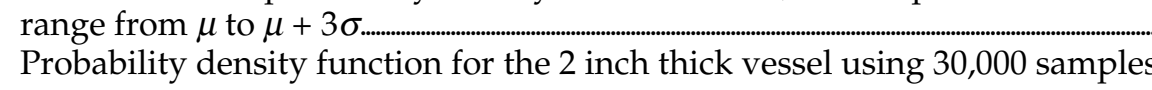

(hability density function for 30,000 samples over the

Figure 5.6. Probability density function for the 2 inch thick vessel using 30,000 samples

Figure 5.7. Cumulative probability density function for the 2 inch thick vessel using

$\begin{array}{ll} & 30,000 \text { samples over the range from } \mu \text { to } \mu+6 \sigma \\ \text { Figure 5.8. Probability density function for the } 5.25 \text { inch thick }\end{array}$ over the range from $\mu$ to $\mu+6 \sigma$..............................................................................................

Figure 5.8. Probability density function for the 5.25 inch thick vessel using 30,000 samples

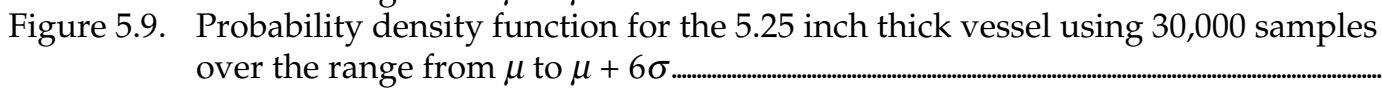

Figure 6.1. Likelihood of occurrence predictions for a 1"containment vessel relative to the

Figure 6.2. Likelihood of occurrence predictions for a 2" containment vessel relativine to the probability of different geometries..............................................................................................

Figure 6.3. Likelihood of occurrence predictions for a 5.25" vessel thickness relative to the probability of different geometries occur ..................................................................................................................................38

Figure 6.4. Stochastic sampling simulation predictions using a 1" thick vessel relative

Figure 6.5. Stochastic sampling simulation predictions using a 2" thick vessel relative to 32 the probability of different geometries occur.

Figure 6.6. Stochastic sampling simulation predictions using a 5.25" vessel thickness

relative to the probability of different geometries occur........................................ 37

Figure 6.7. Engineering index for the containment and safety vessels as computed using the Likelihood of Occurrence model.........................................................................

Figure 6.8. Engineering index for the containment and safety vessels as computed using

Figure B1. Input/output and problem specification graphical user interface for the

Figure B2. Main logical model for the DynEx influence diagram................................................. 60

Figure B2. Main logical model for the DynEx influence diagram 


\section{LIST OF SYMBOLS}

$m_{t} \quad$ total mass of containment vessel material

$m_{f} \quad$ fragment mass

$D \quad$ fragment diameter

$L \quad$ fragment length

a fragment's critical orientation cone angle

$\mathrm{b}_{0} \quad$ target safety index

b safety index determined through simulation

$C_{p} \quad$ capability ratio

$P(p) \quad$ probability of perforation

$P\left(m_{f}\right) \quad$ probability a fragment of mass $m_{\mathrm{f}}$ exists

$P(D) \quad$ probability a fragment's diameter is $D$

$P(L / D \mid D) \quad$ probability a fragment with an $(L / D)$ ratio exists, given its diameter is $D$

$P\left(>v_{\text {cr }}\right) \quad$ probability a fragment's velocity is critical

$P(a) \quad$ probability a fragment is within the critical cone angle orientation

$p_{0} \quad$ target probability of failure

$p \quad$ probability of failure determined through simulation 


\title{
Probabilistic Assessment of the Design and Safety of HSLA-100 Steel Confinement Vessels
}

by

Ronald M. Dolin

\begin{abstract}
This probabilistic approach for assessing the design and safety of the HSLA100 steel confinement vessel used for a DynEx test involved the probability of failure for several scenarios, in which a fragment may penetrate the vessel. The samples involve vessel thicknesses of 1 inch, 2 inches, and 5.25 inches-the combined thicknesses of the 2 inch containment vessel and the 3.25 inch safety vessel. Two simulation approaches were used for each scenario to assess the probability of failure. The Likelihood of Occurrence method simultaneously models all likely fragment events of a test, for which the net probability of failure is the sum of all the fragment events. The Stochastic Sampling method determines the probability of a fragment perforation on the basis of a logical model and takes the overall probability that an experiment results in failure as the maximum probability for any fragment event. With margin and safety assessments taken into account, it was concluded that the one and two inch thicknesses by themselves are inadequate for containing a DynEx test. The 5.25 inch thickness was determined to be safe by the Likelihood of Occurrence method and nearly adequate by the Stochastic Sampling simulation.
\end{abstract}




\section{EXECUTIVE SUMMARY}

This report describes a probabilistic approach for assessing the design and safety of the HSLA-100 steel confinement vessel for particular types of detonations. The probability of failure for three different vessel scenarios is considered. The first scenario is the probability a fragment penetrates through half of the two-inch thickness of the new HSLA-100 steel confinement vessel. This one-inch thickness criteria is equivalent to the full thickness of the current confinement vessel. The second scenario considers the probability a fragment perforates the full HSLA-100 containment vessel thickness. The third scenario estimates the probability a fragment perforates the two-inch thick HSLA-100 containment vessel and the 3.25" thick safety vessel encasing it. The model developed for this scenario is conservative because it assumes a constant combined wall thickness when in fact the gap between the containment and safety vessels acts to reduce the probability of failure.

Two different simulation approaches are used to assess the probability of failure. The first approach assesses probability of failure by simultaneously modeling all likely fragment events of a DynEx test. The probability each event results in perforation and each event's likelihood of occurrence are computed. The net probability of failure is the sum of all the discrete fragment events. The second assessment method is based on stochastic sampling. A logical probability model is generated using a decision analysis influence diagram. The Latin-hypercube sampling technique is used to randomly sample the probable fragment event space. For each randomly selected fragment event the probability of perforation is based on the criteria of the logical model. The overall probability a DynEx experiment results in failure is taken as the maximum probability of failure for all the fragment events.

Variables of a fragment event are the fragment mass, geometry, velocity, and orientation. There is uncertainty associated with each variable. Uncertainty is propagated through both assessment models using probability distributions. A fragment has the highest probability of perforation when its mass is large relative to its length-to-diameter ratio, when it is in the proper orientation relative to the vessel wall, and when it's traveling with sufficient velocity. The probability each of these conditions are met determines an event's likelihood of occurrence. Mathematical formulations for these probability expressions are presented for both approaches.

Probability distributions are based on a synthesis of experimental evidence, theory, and expert judgment. Once fully developed, the probability models are used to help verify and validate the numerical predictions. Using Bayesian methods, confidence in numerical predictions is assessed within the well-defined, well-documented domain so that inferences beyond this domain can be made with confidence using only numerical analysis. The results from the three test scenarios for the two different simulation approaches are tabulated below.

\begin{tabular}{|c|c|c|c|}
\hline & \multicolumn{2}{|c|}{ Probability of Failure } \\
\hline & & $\begin{array}{c}\text { Likelihood of } \\
\text { Occurrence Simulation }\end{array}$ & $\begin{array}{c}\text { Stochastic Sampling } \\
\text { Simulation }\end{array}$ \\
\hline \multirow{3}{*}{$\begin{array}{c}\text { Target } \\
\text { Thickness }\end{array}$} & $1 "$ & 8.90E-03 & $2.20 \mathrm{E}-03$ \\
\hline & $2 "$ & $1.52 \mathrm{E}-05$ & $1.55 \mathrm{E}-04$ \\
\hline & $5.25 "$ & $1.23 \mathrm{E}-13$ & $2.50 \mathrm{E}-09$ \\
\hline
\end{tabular}




\section{INTRODUCTION}

Numerical analysis is used to make predictions and add insight in regimes of interest where physical testing is not possible or permissible for reasons such as time, cost, limited resources, regulation, or complexity. Two properties of any numerical method are they are deterministic and nonstochastic. This is in contrast to the physical world, which is both uncertain and random. Another property of a numerical prediction is for any validated and verified numerical process the same set of input conditions always yields the same set of output responses. In physical processes this is seldom true. No two activities are identical. For example, in physical experiments samples are never the same, conditions vary, as does the gathering, recording, and interpretation of data. All these uncertainties are idealized in numerical processes.

In any numerical simulation there can be found a set of input conditions for which the predicted response is undesirable (e.g., failure occurs). Once this failure threshold is found, each time a numerical analysis is performed using those input parameters the result is the same. The sensitivity of a failure threshold is investigated by varying input parameters and measuring output response. But sensitivity studies only add insight to how an undesirable result is approached within some limited neighborhood. Sensitivity studies do not provide insight into whether or not a response profile is possible or even likely to occur.

While it is important to know the boundaries of a problem's failure domain, it is equally important to understand the likelihood those boundaries are breached. In fact, understanding an event's likelihood of occurrence is quintessential to assessing performance. In the fragment penetration/perforation problem of the HSLA-100 containment vessel, it is always possible to find a set of conditions for which numerical analysis predicts failure. But that knowledge provides only limited utility without additionally knowing the likelihood that the deterministic set of conditions occur.

One aspect of traditional uncertainty quantification studies based on sensitivity is the large number of numerical analyses required. One has to first find the boundaries of the failure domain and then parametrically investigate the sensitivity of the failure neighborhood with many more analyses. From that, a response surface can be populated. When a response surface technique is used the surface is used to assess the problem's response for random input conditions. Response surfaces can be constructed from simple polynomial interpretation all the way up to complex neural or Bayesian networks. Once built, estimation techniques such as Monte Carlo or Latin hypercube are employed to numerically integrate the response surface.

Three distinct simulation approaches are used to estimate the probability that an HSLA-100 containment vessel fails during an experiment. A series of finite element analyses were performed to simulate performance. A classic probabilistic approach for estimating reliability utilized a stochastic sampling simulation using Latin hypercube in conjunction with a logical influence diagram model. A second probabilistic approach was based on using experimental evidence to estimate an event's likelihood of occurrence.

The stochastic sampling and likelihood of occurrence simulations were based on evidence mined from historical archives of similar experiments. The results from these simulations were used to validate the finite element analysis within the limited domain of known scenarios. The goal of the validation effort was to establish confidence in the finite element simulation's ability to make predictions in domains beyond that of previous experiments. This would then allow the performance of the HSLA-100 containment vessel to be inferred with confidence in untested scenarios.

In the subregion of the overall containment vessel's response domain where experimental evidence, theory, and expert judgment are strongest, predictions about an event's probable success or failure are made using the Likelihood of Occurrence and Stochastic Sampling simulations. Finite element analysis is then simulated in that same domain to validate the finite element model, its predictions within that domain, and the numerical simulation process itself. As the investigation proceeds from well-defined, well-documented (WDWD) domains where 
existing knowledge is strongest into domains less understood, reliance on numerical performance predictions increases. In general, the likelihood of an event's occurrence diminishes significantly in these domains.

Failure occurs when a fragment perforates the containment vessel. Three different vessel thickness scenarios are investigated. A one-inch thickness represents the old containment vessel design while a two-inch thickness represents the new HSLA-100 vessel design. A 5.25" thickness represents the new vessel design with an added 3.25" safety vessel encasing it, which is an operational requirement. The Likelihood of Occurrence and Stochastic Sampling simulations compute the probability of failure differently.

\section{UNCERTAINTY MODELS}

Theoretical and experimental evidence is used to define distributions for key parameters describing fragment configuration and event conditions. Probabilistic assessment models are used to capture the uncertainty in key parameters. The uncertainty models strive to simulate possible fragment configurations while propagating parameter uncertainties in a logical manner. A matrix of discrete key parameter sets is defined to investigate the performance domain.

The Likelihood of Occurrence and Stochastic Sampling simulation models follow the same basic logical framework. First, probable fragment geometries are computed. Then each discrete fragment configuration, the number of fragments likely to exist during a DynEx test is determined. The number of those fragments likely to be in a proper orientation is determined. The probability that these properly orientated fragments travel with a velocity sufficient to perforate the containment vessel is then computed. From those calculations, the probability of perforation is assessed. The probability of perforation for any fragment event is independent of the probabilities of perforation for the other fragment configurations.

Three first order parameters dominate failure in the HSLA-100 containment vessel problem. They are fragment

1. geometry,

2. orientation, and

3. velocity.

For these key parameters, there exist combinations for which the probability of perforation is significant. What constitutes a significant probability is defined by the performance requirements. When a combination of key parameters results in a significant probability of failure, the parameter values are said to be critical. Some key parameters are independent, while others are dependent either on other key parameters or on other aspects of the problem. For example, fragment orientation is treated as an independent parameter, while critical velocity depends on fragment geometry. This is because fragments of different sizes and shapes require different velocities to perforate the vessel thickness. The probability that a parameter is in its critical state is described below.

\subsection{Uncertainty Distributions for Fragment Geometry}

Fragments of many different sizes and shapes are possible during a DynEx test. However, some geometries are more likely to occur than others. Using both theory and empirical evidence, a distribution is generated for the probability that fragments of various mass occur. From that, theory, experimental evidence, and expert judgment combine to yield a probability distribution for the probability that a given a fragment diameter occurs. Once a fragment diameter has been determined, a distribution for the probability of having various fragment lengths is generated.

It has been determined by theoretical analysis, experimental evidence, and numerical analysis that fragments below a particular mass cannot penetrate the HSLA-100 steel confinement vessel. 
Using a Mott distribution, [Rodriguez 2000], Table 2.1 shows the probability $P(M)$ that fragments of various discrete mass ranges exist. Mott's distribution is a theoretical approximation to experimental evidence. Historically Mott's distribution underestimates the number of small fragments and overestimates the number of large fragments. Since larger fragments dominate damage, Mott's distribution is conservative. Figure 2.1 shows the probability distribution for $P(M)$.

\section{TABLE 2.1. LIKELIHOOD THAT FRAGMENTS OF CERTAIN MASS OCCUR}

\begin{tabular}{|c|c|}
\hline \multicolumn{2}{|c|}{$\mathbf{P}(\mathbf{M})$} \\
Based on Mott's Distribution \\
\hline Range & $P$ (range) \\
\hline $0.00<m<0.60$ & 0.88500 \\
\hline $0.60<m<1.70$ & 0.06500 \\
\hline $1.70<\mathrm{m}<2.20$ & 0.02000 \\
\hline $2.20<\mathrm{m}<3.00$ & 0.01000 \\
\hline $3.00<\mathrm{m}<4.00$ & 0.01000 \\
\hline $4.00<\mathrm{m}<5.00$ & 0.00600 \\
\hline $5.00<\mathrm{m}<6.00$ & 0.00100 \\
\hline $6.00<\mathrm{m}<7.00$ & 0.00120 \\
\hline $7.00<\mathrm{m}<8.00$ & 0.00080 \\
\hline $8.00<\mathrm{m}<14.0$ & 0.00070 \\
\hline $14.0<\mathrm{m}<17.0$ & 0.00022 \\
\hline $17.0<\mathrm{m}<20.0$ & $3.000 \mathrm{E}-05$ \\
\hline $20.0<\mathrm{m}<25.0$ & $4.000 \mathrm{E}-05$ \\
\hline $25.0<\mathrm{m}<30.0$ & $5.000 \mathrm{E}-06$ \\
\hline $30.0<\mathrm{m}<35.0$ & $4.000 \mathrm{E}-06$ \\
\hline $35.0<\mathrm{m}<40.0$ & $5.000 \mathrm{E}-07$ \\
\hline $40.0<\mathrm{m}<50.0$ & $4.000 \mathrm{E}-07$ \\
\hline $50.0<\mathrm{m}<60.0$ & $5.000 \mathrm{E}-08$ \\
\hline $60.0<\mathrm{m}<70.0$ & $4.000 \mathrm{E}-08$ \\
\hline $70.0<\mathrm{m}<80.0$ & $5.000 \mathrm{E}-09$ \\
\hline $80.0<\mathrm{m}<90.0$ & $4.000 \mathrm{E}-09$ \\
\hline $90.0<\mathrm{m}<100$ & $5.000 \mathrm{E}-10$ \\
\hline $100<\mathrm{m}<110$ & $4.000 \mathrm{E}-10$ \\
\hline $110<\mathrm{m}<120$ & $5.000 \mathrm{E}-11$ \\
\hline $120<\mathrm{m}<150$ & $4.000 \mathrm{E}-11$ \\
\hline $150<\mathrm{m}$ & $5.000 \mathrm{E}-12$ \\
\hline
\end{tabular}

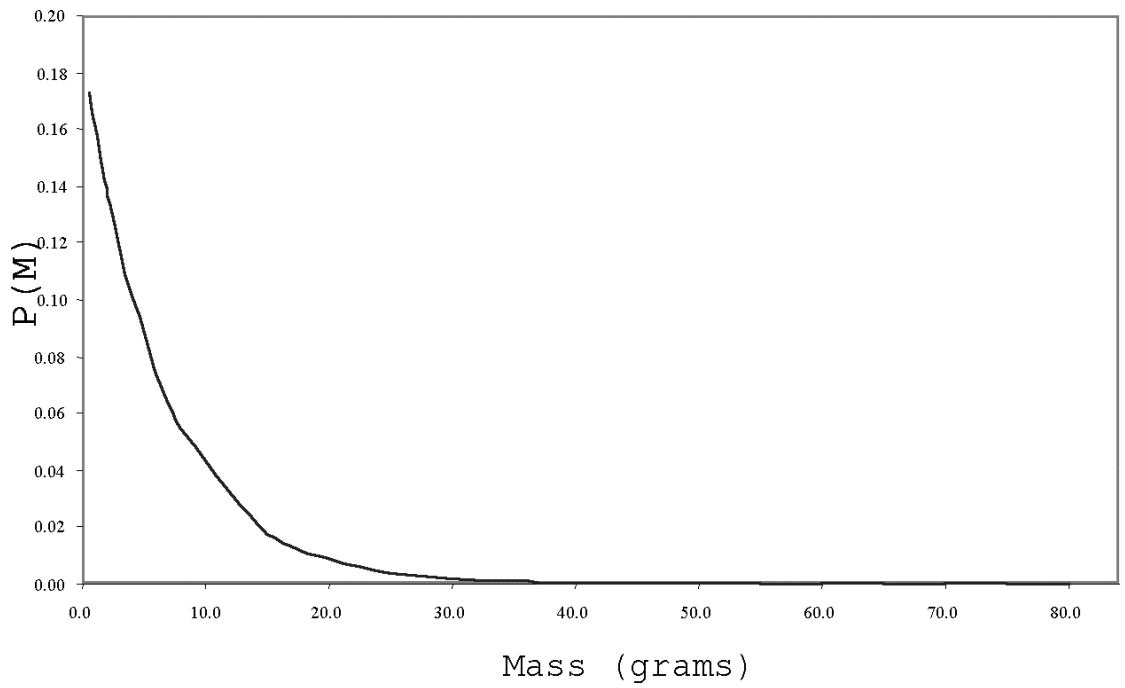

Figure 2.1. Probability distribution for fragment mass based on Mott's distribution.

This probability distribution for fragment mass has been verified from data obtained in both government tests [DOE 1980], and independent experiments performed at the Southwest Research Institute. [Anderson 1992] A beta distribution was used to represent the likelihood that a fragment would have a diameter within some range. The probability of having a specific fragment diameter is represented as $P(D)$. Diameter is always taken as the smaller of either 
nonthickness fragment dimension. Table 2.2 shows the discrete diameter values considered. For each range of diameters, the likelihood of occurrence is given by the beta distribution. Figure 2.2 shows the shape of this distribution. The beta parameters $\alpha$ and $\beta$ were adjusted to give the distribution best capturing what was observed in experiments and predicted by theory.

TABLE 2.2. LiKelihoOd ThAT FRAgMENTS HAVE A PARTICUlAR DiAMETER

\begin{tabular}{|c|c|c|c|}
\hline P(D): & \multicolumn{3}{c|}{$\begin{array}{c}\text { A Beta Distribution with } \\
\text { alpha }=3 \text { and beta }=5\end{array}$} \\
\hline$D$ & Beta & Range & $P(D)$ \\
\hline 0.25 & 0.2436 & $0.00<D<0.25$ & 0.2436 \\
\hline 0.50 & 0.7734 & $0.25<D<0.50$ & 0.5298 \\
\hline 0.75 & 0.9871 & $0.50<D<0.75$ & 0.2137 \\
\hline 1.00 & 1.0000 & $0.75<D<1.00$ & 0.0129 \\
\hline
\end{tabular}

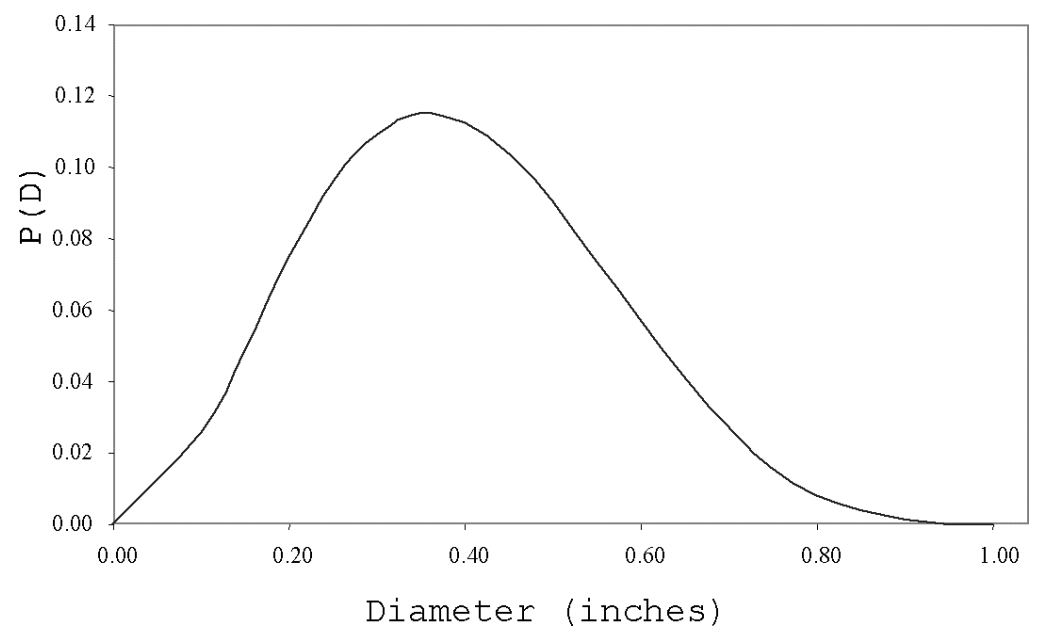

Figure 2.2. Probability distribution for fragment diameter based on experimental evidence and expert judgment.

As Figure 2.3 illustrates, when a DynEx experiment is performed, thousands of fragments impact the HSLA-100 steel confinement vessel. The simplified high explosive geometry is shown as a flat plate but in general, more complex geometries are modeled. Mott's distribution is used to estimate the way that fragments are parsed out on the basis of mass. Combining experimental evidence with expert judgment, the manner in which fragment diameters distribute themselves can be determined. The probability that a fragment has diameter $D$ is defined as $P(D)$.

Given that a fragment has a diameter $D$, the conditional probability, $P(L / D \mid D)$, that it has a given length-to-diameter ratio can be determined. Table 2.3 shows values of a beta distribution used to describe the likelihood that various $L / D$ ratios occur given a fragment of diameter $D$. The shape of this beta probability distribution is based on experimental evidence and expert judgment. Notice that the distribution has been segregated into ten discrete possibilities. This was done to define a discrete matrix of likely fragment events for the numerical probability model.

Table 2.3 is populated with a distribution for diameters of $D=0.25$ inches, showing the probability a fragment has a specific $L / D$ ratio given $D=0.25$. Other columns have been included to highlight the fact that an engineer may want to determine the probability that a fragment has a specific $L / D$ ratio dependent on $D$. In that case a different distribution would be used for each discrete $D$. For now we have chosen to make $P(L / D \mid D)$ independent of $D$. Figure 2.4 shows the distribution for $P(L / D \mid D)$. This distribution is based on experimental evidence and expert judgment. 

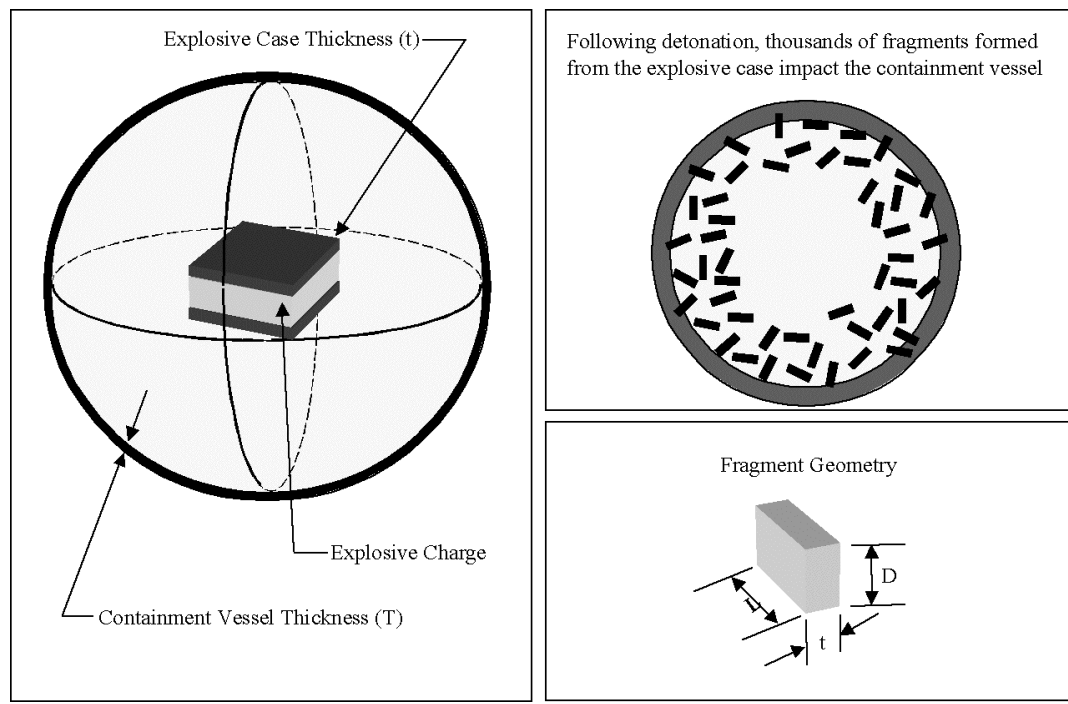

Figure 2.3. Depiction of DynEx experiment.

TABLE 2.3. DisCRETE DistRIBUTION OF L/D RATIOS WHEN $D=0.25$ INCHES

\begin{tabular}{|c|c|c|c|c|}
\hline \multirow{2}{*}{$P(L / D \mid D)$} & \multicolumn{3}{l}{$\begin{array}{l}\text { A Beta Distribution with } \\
\text { alpha }=0.3 \text { and beta }=5.3\end{array}$} \\
\hline \multirow{2}{*}{$L / D$} & \multicolumn{3}{|c|}{$P(\mathrm{~L} / \mathrm{D})$} & \\
\hline & $\mathrm{D}=0.25$ & $\mathrm{D}=0.50$ & $\mathrm{D}=0.75$ & $\mathrm{D}=1.00$ \\
\hline 1 & 0.7000 & & & \\
\hline 3 & 0.0700 & & & \\
\hline 4 & 0.0400 & & & \\
\hline 6 & 0.0200 & & & \\
\hline 7 & 0.0110 & & & \\
\hline 8 & 0.0070 & & & \\
\hline 10 & 0.0030 & & & \\
\hline 12 & 0.0010 & & & \\
\hline 14 & 0.0003 & & & \\
\hline 16 & 0.0001 & & & \\
\hline
\end{tabular}

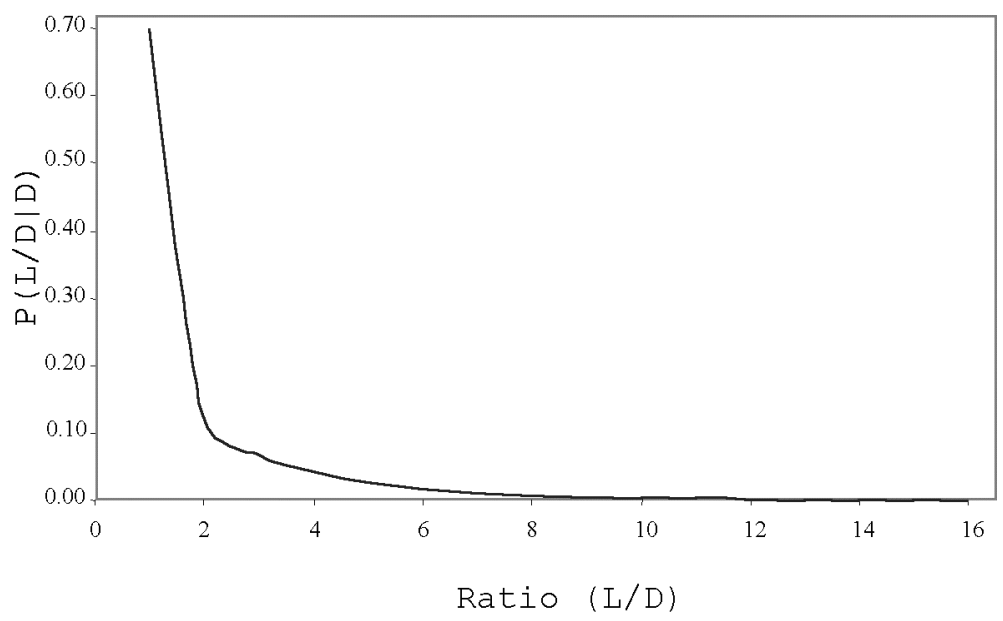

Figure 2.4. Distribution for fragment length-to-diameter ratio, given the fragment has a particular diameter.

There are two reasons for making this independence assertion. First, it has been observed that the most likely $L / D$ ratio is 1 , independent of a fragment's diameter. Second, $P(L / D \mid D)$ and $P(D)$ are coupled by $P(M)$. This is because when we think about the probability that a given fragment 
geometry exists, we start with the probability it has mass $M$. Once the mass is set, we determine a distribution for the likely geometries a fragment possessing that mass can have. Once the distributions for $M$ and $D$ have been accounted for, it is logically consistent to consider a distribution for $(L / D)$ ratios. Further, having a distribution based on $(L / D)$ ratios rather than lengths allows the same distribution for $P(L / D \mid D)$ for the discrete set of diameters considered.

Mathematically, the probability that a given fragment geometry exists during a DynEx experiment can be expressed as

$$
P(D)=P(D \mid M) \cdot P(M) .
$$

Therefore,

$$
\begin{aligned}
P(\text { fragment }) & =P(L / D \mid D) \cdot P(D) \\
& =P(L / D \mid D) \cdot P(D \mid M) \cdot P(M) .
\end{aligned}
$$

\subsection{Uncertainty Distributions for Fragment Velocity}

Perhaps more than any other key parameter, the uncertainty associated with fragment velocity is the least understood. However, by combining theory with experimental evidence and engineering logic, an assessment can be made for a probable velocity distribution. It has been observed during previous experiments that for explosive shaped charges of interest, fragments travel faster near the top and slower near the midsection of the HE charge. Over time a good theoretical approximation for the minimum and maximum velocities has emerged. Near the top, velocity is a maximum $\left(v_{\max }\right)$ and can be approximated using spherical fragment velocity equations. Near the midsection, velocity is a minimum $\left(v_{\min }\right)$ and can be approximated using cylindrical fragment velocity equations. For each specific fragment there exists a critical velocity $\left(v_{\mathrm{cr}}\right)$. Critical velocity is defined as the velocity a fragment has to exceed in order for failure to occur. The velocities $v_{\min }, v_{\max }$ and $v_{\mathrm{cr}}$, depend on the fragment geometry. Critical velocity is additionally dependent on target thickness. Table 2.4 shows the possible logical deductions that can be made regarding $v_{\text {cr }}$.

TABLE 2.4. LOGICAL DEDUCTION OF PERFORATION FOR $v_{\text {cr }}$

\begin{tabular}{|l|c|}
\hline$v_{\text {max }} \prec v_{c r} \succ v_{\text {min }}$ & Not Possible \\
\hline$v_{\text {max }} \cong v_{c r} \succ v_{\text {min }}$ & Slightly Possible \\
\hline$v_{\text {max }} \succ v_{c r} \succ v_{\text {min }}$ & More Possible \\
\hline$v_{\text {max }} \succ v_{c r} \cong v_{\text {min }}$ & Likely \\
\hline$v_{\text {max }} \succ v_{c r} \prec v_{\text {min }}$ & Going Through \\
\hline
\end{tabular}

Table 2.4 asserts that with respect to fragment velocity, if $v_{\text {cr }}$ is greater than both the minimum and maximum possible fragment velocities, perforation is not possible. If $v_{\mathrm{cr}}$ is in the neighborhood of the maximum possible fragment velocity, failure is slightly possible. If the maximum possible fragment velocity $v_{\max }$ exceeds the velocity necessary for failure to occur $v_{\mathrm{cr}}$ failure is more possible. This is because it is now possible that a fragment can be traveling at or above the critical velocity. To turn this possibility into a probability requires an evaluation of the velocity probability density function. As $v_{\mathrm{cr}}$ approaches minimum predicted fragment velocity, the likelihood that a fragment travels at or above its critical velocity increases.

Whenever a fragment travels faster then its critical velocity, it becomes a candidate for failure. What still has to be factored in is the likelihood that such a fragment exists and that it's in a critical orientation. Theory predicts that for the problem at hand the maximum spherical velocity 
is $2 \mathrm{~km} / \mathrm{s}$ and the minimum cylindrical velocity is $1.4 \mathrm{~km} / \mathrm{s}$. It has been observed in experiments that the average fragment velocity is $1.6 \mathrm{~km} / \mathrm{s}$. [Rodriquez 2002] Engineering judgment is that the minimum and maximum velocities are three sigma events. Based on that, the Gaussian distribution shown in Figure 2.5 is generated with a mean of 1.6 and a standard deviation of 0.10 . Table 2.5 shows the cumulative likelihood that a fragment travels with at least the specified velocity. Figure 2.6 shows a plot of this cumulative distribution.

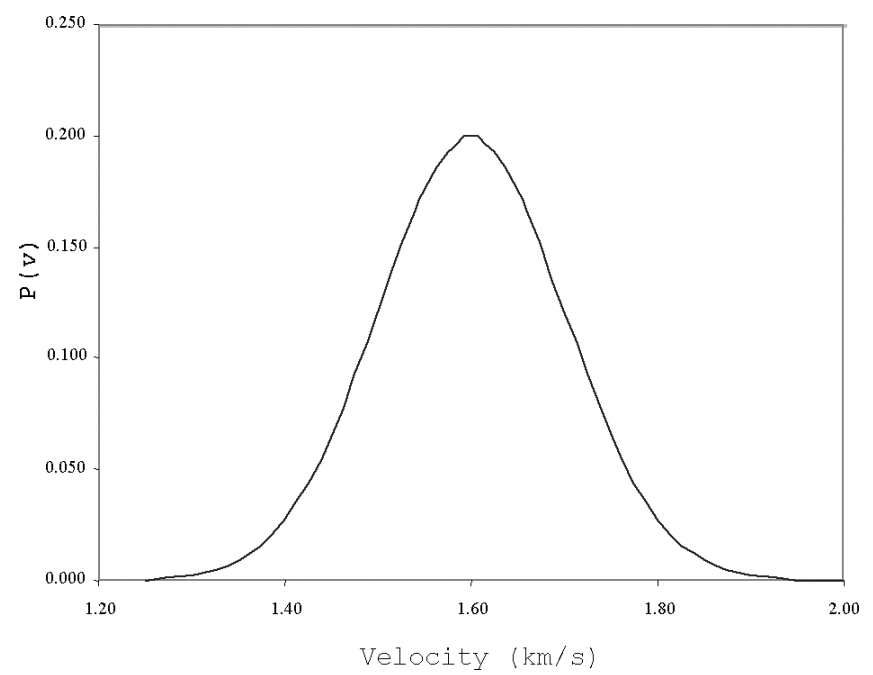

Figure 2.5. Probability distribution for likely fragment velocities.

\section{TABLE 2.5. CUMULATIVE LiKELIHOODS THAT A FRAGMENT TRAVELS WITH AT LEAST THE SPECIFIED VELOCITY}

\begin{tabular}{|c|c|}
\hline \multicolumn{2}{|c|}{$\mathbf{P}(>\mathbf{v})$} \\
Gaussian Distribution \\
\hline $\mathrm{v}$ & $\mathrm{P}(>\mathrm{vcr})$ \\
0.8 & 1.000000 \\
1.0 & 1.000000 \\
1.1 & 1.000000 \\
1.2 & 0.999968 \\
1.3 & 0.998650 \\
1.4 & 0.977250 \\
1.5 & 0.841345 \\
1.6 & 0.500000 \\
1.7 & 0.158655 \\
1.8 & 0.022750 \\
1.9 & 0.001350 \\
2.0 & 0.000032 \\
2.1 & $2.871 \mathrm{E}-07$ \\
2.3 & $1.288 \mathrm{E}-12$ \\
2.4 & $0.000 \mathrm{E}+00$ \\
3.0 & $0.000 \mathrm{E}+00$ \\
\hline
\end{tabular}

Table 2.5 and Figures 2.5 and 2.6 indicate there is nearly a 100 percent probability a fragment, regardless of geometry, travels with a minimum velocity of $1.25 \mathrm{~km} / \mathrm{s}$. There is roughly a $60 \%$ probability a fragment velocity is at least $1.6 \mathrm{~km} / \mathrm{s}$. The maximum spherical velocity prediction of $2 \mathrm{~km} / \mathrm{s}$ has only $0.00757 \%$ probability of occurring. Notice that this distribution does not take into account the dependence that fragment velocity has on fragment geometry. Treating the velocity distribution as an independent parameter is conservative because it is possible for large fragments to be evaluated at velocities higher than they would actually achieve during a DynEx test. The driving reason for taking this conservative approach is that, while it is known that fragment velocity and geometry are dependent, the nature of their relationship is not known. 


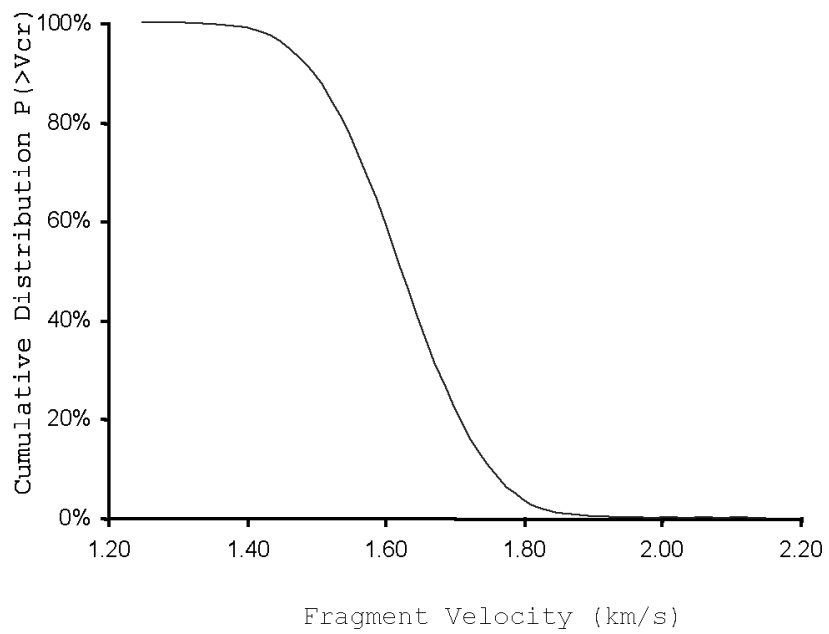

Figure 2.6. Cumulative distribution a fragment travels with at least the specified velocity.

\subsection{Uncertainty Distributions for Fragment Orientation}

As a fragment travels toward the steel confinement vessel, it spins and tumbles. Hyrdodynamic calculations indicate there exists some critical angle of attack that the fragment's leading edge must be within in order for perforation to occur. Because this requirement exists in both the pitch and yaw axes of revolution, one can think of the critical attack angle forming a cone. If $\alpha$ is the critical attack angle, then we are interested in the probability that a fragment's angle of attack in both the pitch or yaw directions is less than or equal to $\alpha$. Due to the random dynamics of fragment movement, all fragment orientations are equally likely. This applies to both the pitch and yaw rotations. This suggests not only a uniform distribution, but it allows pitch and yaw rotations to be combined into a single probability distribution.

Figure 2.7 shows a relative to the fragment's velocity vector as the fragment approaches the containment vessel. There is a geometric component of wall thickness based on the relationship between an outward normal from the containment vessel at the point of impact and the fragment's attack angle. This effective thickness represents the amount of target material the fragment has to perforate. The minimum condition exists when $\alpha=\theta=0$ and the effective thickness equals the containment vessel thickness. Treating all impacts such that the effect target thickness is minimal is conservative, and the effective thickness factor can be omitted from failure predictions.

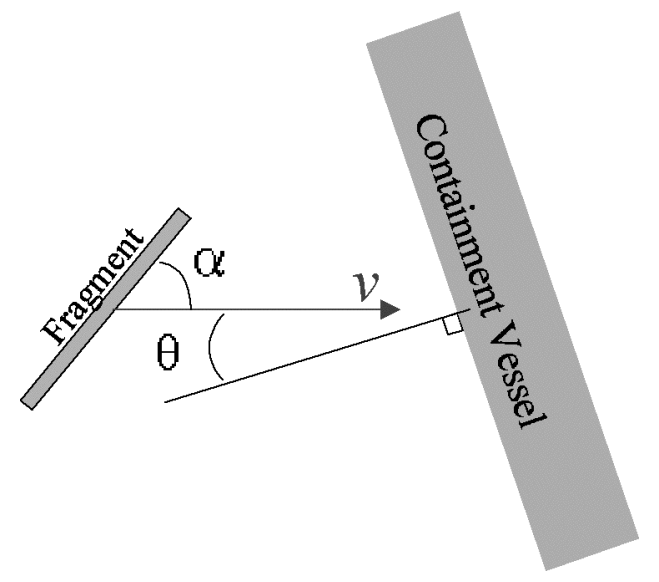

Figure 2.7. Orientation of a fragment with respect to the containment vessel. 
Perforation is possible whenever $\alpha_{\max } \geq \alpha \geq-\alpha_{\max }$, which occurs $(2 \alpha / \pi)$ times. Since any angle of attack is equally likely, the probability distribution for orientation is uniform and can be represented deterministically. From the geometry of fragment orientation,

$$
P(\text { orientation })=P\left(\alpha_{\max } \geq \alpha \geq-\alpha_{\max }\right) .
$$

As a fragment rotates, it is equally likely that the tip and tail reverse. If we consider a one-degree discretization in which every angle is equally likely, then for a given angle $\phi$,

$$
P(\Phi)=\frac{1}{180} \operatorname{deg}=\frac{1}{\pi} \text { radians. }
$$

If the complete range of possible angles between the specified critical attack angles $( \pm \alpha)$ is taken with equal probability,

$$
\begin{aligned}
P(\text { orientation }) & =\left.\sum P\left(\Phi_{i}\right)\right|_{\alpha \geq \Phi \geq-\alpha} \\
& =P(\alpha \geq \Phi \geq 0)+P(0 \geq \Phi \geq-\alpha) \\
& =P(\alpha \geq|\Phi|) \\
& =2 P(\alpha \geq \Phi) \\
& =\frac{2 \alpha}{\pi} .
\end{aligned}
$$

\section{LIKELIHOOD OF OCCURRENCE SIMULATION}

Knowing the probability of perforation for a given fragment event is of marginal utility without additionally knowing the likelihood that the fragment event occurs. Taking that logic one step further, knowing the combined probability of perforation for a given fragment event along with its likelihood of occurrence provides only limited insight into the probability that an overall DynEx test will be successful. To adequately assess a DynEx test's probability of failure, the probability that every possible fragment event likely to occur causes failure needs to be computed.

The foremost feature of the Likelihood of Occurrence simulation model is that an entire DynEx test is captured simultaneously. During a DynEx test thousands of fragments are generated. Each fragment tumbling toward the containment vessel wall is referred to as a fragment event. Many fragment events possess fragments of similar geometry. These fragment events can be grouped together into what is referred to as a fragment configuration. All the different fragment configurations taken at once comprise a DynEx test. This is referred to as the Likelihood of Occurrence Event $\left(E_{\text {Lofo }}\right)$, where

$$
\text { Event } E_{\text {LofO }} \equiv \text { Entire DynEx test results. }
$$

The amount of explosive coupled with the mass and shape of the explosive casing account for the number of fragments generated during a DynEx test, as well as their probable geometries and velocities. The various containment vessel thickness configurations account for how deeply each fragment must penetrate in order to perforate, which in turns accounts for a fragment's critical velocity. Recall from chapter two, critical velocity is the velocity a fragment of length $L$ has to achieve in order to perforate a target of thickness $P$.

The Likelihood of Occurrence mathematical model considers a $4 \times 10$ matrix of discrete fragment configurations. For each discrete fragment configuration, many variables are computed. They include

- fragment length $(L)$,

- ratio of the containment vessel thickness to fragment length $(P / L)$, and

- fragment mass. 
Using the probability mass function for fragment mass described in Chapter 2, the probability that a fragment of some discrete mass exists can be computed. Table 3.1 shows the discretization of the thousands of fragment events in the mathematical model into 40 fragment configurations. For each discrete fragment configuration, the number of fragments likely to exist during a DynEx test is determined. Next the number of those fragment events likely to be in the proper orientation is computed. Once done, the probability that these properly orientated fragments travel with a velocity sufficient to perforate the containment vessel is assessed. From those calculations, the discrete fragment configuration's probability of perforation is determined.

TABLE 3.1. FRAGMENT DisCRETIZATION FOR THE LIKELIHOOD OF OCCURRENCE SIMULATION

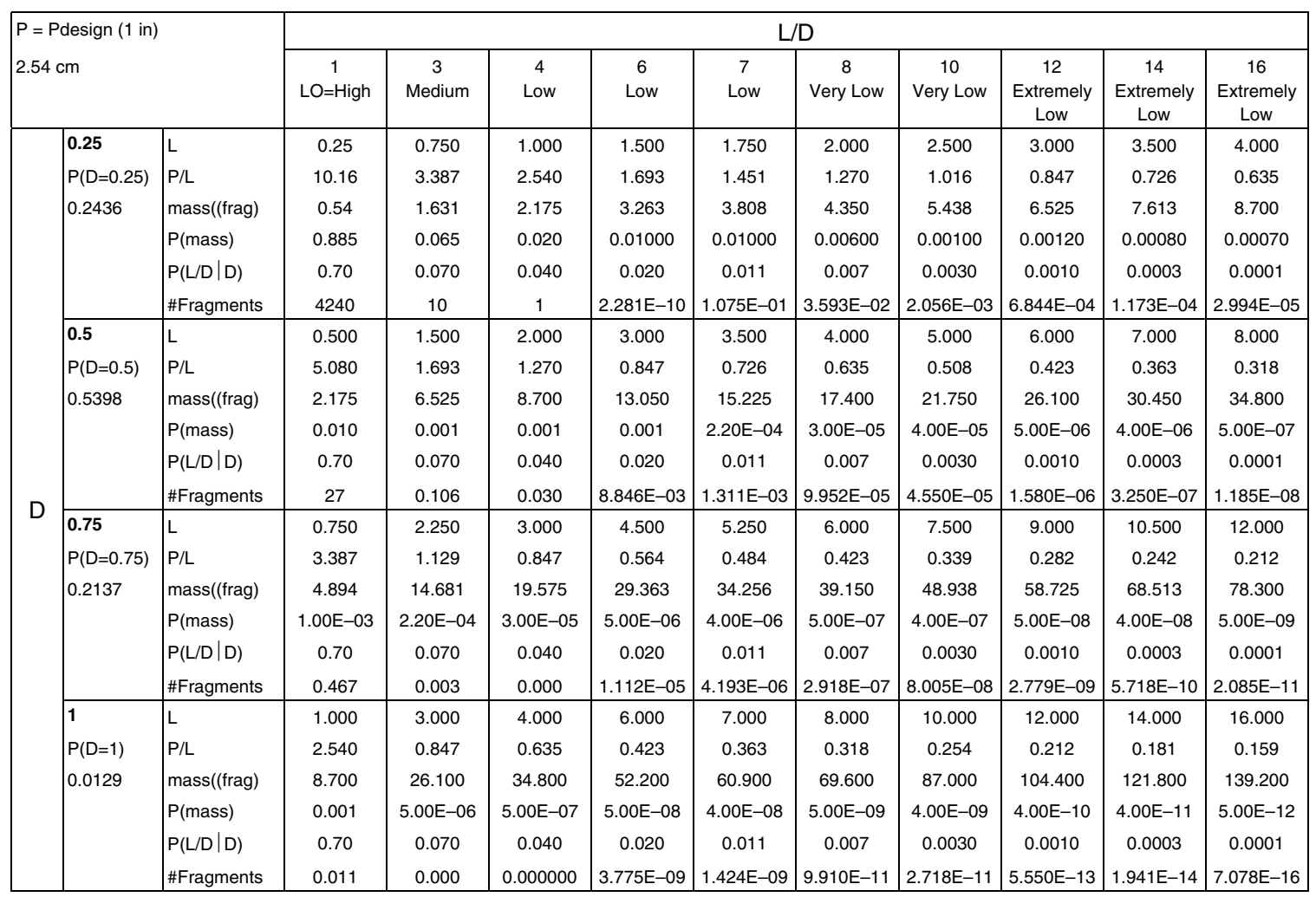

The probability of perforation for each discrete fragment configuration is independent of the probabilities of perforation for the other fragment configurations. Applying the multiplication rule for conditional probability, the overall probability of failure is then determined by summing the discrete probabilities of perforation, for example, by summing the discrete probabilities of perforation in Table 3.1.

Consider the discrete fragment configuration where the fragment diameter is $0.25 \mathrm{~cm}$ and the length to diameter ratio equals one. This configuration is row one and column one of the matrix in Table 3.1. Given $L / D=1$, and $D=0.25 \mathrm{~cm}$, the fragment length, $L=0.25 \mathrm{~cm}$. Using a containment vessel thickness of $P=1$ inch, the ratio of thickness to fragment length is

$$
\frac{P}{L}=\frac{2.54 \mathrm{~cm}}{0.25 \mathrm{~cm}}=10.16 .
$$

The mass of a fragment in this discrete geometry configuration is

$$
\text { mass }_{\text {fragment }}=\delta \cdot t_{\text {case }} \cdot D \cdot L=0.540,
$$

where 


$$
\begin{aligned}
\delta & =\text { density of the explosive casing material, } \\
t_{\text {case }} & =\text { thickness of the explosive casing material, } \\
D & =\text { fragment diameter, and } \\
L & =\text { fragment length. }
\end{aligned}
$$

Using the probability density functions for $P(D)$ and the conditional probability $P(L / D \mid D)$ given in Figures 2.2 and 2.3, respectively, when $D=0.25 \mathrm{~cm}$, the beta probability $P(D)=0.2436$. For a length to diameter ratio of 1 , the beta probability $P(L / D \mid D)=0.70$. The number of fragments likely to exist with this geometry is given as

$$
\text { \# fragments }=\left[\frac{\text { mass }_{\text {case }}}{\text { mass }_{\text {fragment }}}\right] \cdot\left[\frac{P(\text { mass })}{\sum_{i=1}^{\# d g} P_{i} \text { (mass) }}\right] \cdot P(L / D \mid D) \cdot P(D)=4,240 \text {, }
$$

where

$$
\begin{aligned}
\# \text { fragments } & =\text { number of fragments having this in the given configuration, } \\
\text { mass }_{\text {case }} & =\text { mass of the explosive case } \\
\text { mass }_{\text {fragment }} & =\text { mass of a fragment in this fragment configuration, } \\
P(\text { mass }) & =\text { likelihood a fragment with this mass occurs } \\
\sum P_{i}(\text { mass }) & =\text { total likelihood of all discrete fragment masses, } \\
\# d g & =\text { number of discrete fragment geometries in the model, } \\
P(L / D \mid D) & =\text { probability the fragment } L / D \text { ratio occurs given } D \text { occurs, and } \\
P(D) & =\text { probability a fragment with the given diameter } D \text { occurs. }
\end{aligned}
$$

Many fragments have the same geometry. The ratio of the mass of the case to the mass of a fragment indicates how many fragments could be made from the case if all the fragments possessed the same geometry. The probability that a fragment has that geometry is given by $P$ (mass). Since this mathematical model consider discrete geometries, $P$ (mass) is normalized with respect to the sum of all the discrete $P$ (mass)'s to get a distribution. The product of the number of possible fragments that could be generated and the probability such a fragment could exists yields a probable estimate for the number of fragments in a discrete geometry configuration.

For the amount of explosive and the mass of the explosive casing, the Mott's distribution estimates that 41,500 fragments are generated during a DynEx test. However, the preponderance of fragment geometries have mass, diameter, and length values far below the smallest discrete values considered in the configuration matrix of Table 3.1. The knowledge base of experimental, antidotal, and analytical evidence suggests that fragments possessing diameters less than $0.25 \mathrm{~cm}$ and length-to-diameter ratios less than 1 do no damage to the HSLA-100 containment vessel. Hence, they are not included in the mathematical model. Of all the possible 41,500 fragments that can occur during a DynEx test, 4,279 fragments exist that would, given the right conditions (i.e., critical orientation and velocity), perforate the containment vessel. What needs to be determined then is the likelihood that any of those fragments will achieve their critical orientation and velocity.

Notice in the discrete configuration matrix shown in Table 3.1 that $99 \%$ of the probable fragments have $D=0.25 \mathrm{~cm}$ and $L / D=1$. The remaining 39 fragment configurations constitute the tail region of the probable fragment distribution. The mass of the 37,221 fragments considered too small to cause damage is not neglected in the discrete model. Their mass is made proportionally available to the 40 fragment configurations. This results in overestimating the likelihood that the larger and potentially damaging fragments occur. 
As previously discussed, critical orientation is independent of fragment mass and geometry. It has been determined from hydrodynamic simulation that only those fragments whose angle of attack relative to the containment vessel are within a cone whose angle is $+\alpha$ radians can cause damage. Since all angles are equally likely to occur, a uniform distribution is used to assess the likelihood that a given angle of attack occurs.

Angles of attack nearly orthogonal to the containment vessel wall require less fragment velocity to perforate the containment vessel than angles of attack near the outer boundary of the cone (i.e., $\pm \alpha$ ). This is because the effective wall thickness of the containment vessel is minimal. Fragments that impact the containment vessel at an angle perforate at a nonorthogonal angle. This means that they have more containment vessel material to perforate than orthogonal impacts. By treating all angles of attack within the $\pm \alpha$ cone as orthogonal, a conservative estimate of the probability of failure results. This is because the minimal effective thickness of the containment vessel is used. The probability that a fragment is within the $\pm \alpha$ cone angle of attack when it impacts the containment vessel wall is given as

$$
P(\alpha)=\frac{2 \alpha}{\pi} .
$$

When $\alpha$ equals 20 radians, the number of fragments within the $L=D=0.25 \mathrm{~cm}$ fragment configuration likely to be in a critical orientation is

$$
\begin{aligned}
\text { \# candidates } & =P(\alpha) * \# \text { fragments } \\
& =\frac{2 \alpha}{\pi} \cdot\left[\frac{\text { mass }_{\text {case }}}{\text { mass }_{\text {fragment }}}\right] \cdot\left[\frac{P(\text { mass })}{\sum_{i=1}^{\# d g} P_{i} \text { (mass) }}\right] \cdot P(L / D \mid D) \cdot P(D) \\
& =\frac{2 \alpha}{\pi} \cdot 4,240 \\
& =942 .
\end{aligned}
$$

This means that for the example, out of the 41,500 fragments generated during a DynEx test, 4,240 probably have diameter $D=0.25 \mathrm{~cm}$ and length $L=0.25 \mathrm{~cm}$. Of those 4,240 fragments, 942 are probably going to be in an orientation that could potentially perforate the containment vessel. However, in order for perforation to occur, these 942 fragments have to be moving with a sufficiently fast velocity.

The Southwest Research Institute has compiled extensive empirical knowledge on the velocities that various sized fragments have to obtain in order to perforate different thickness of material. [Anderson 1992], [Rodriguez 2000] The critical relationship between fragment geometry and containment vessel thickness is the relationship between fragment length and containment vessel thickness. For various ratios of target thickness to fragment length, curves of constant $(L / D)$ can be plotted that indicate critical velocity. This is shown in Figure 2.7. Critical velocity is defined as the minimum speed a fragment with dimensions $L$ and $D$ has to be traveling to perforate a target of thickness $P$. For $L=D=0.25 \mathrm{~cm}$ and $P=2.54 \mathrm{~cm}$, the critical velocity is $5 \mathrm{~km} / \mathrm{s}$.

The probability that a fragment obtains its critical velocity depends on the conditions of the experiment. Namely, critical velocity depends on the amount of explosive used in the DynEx test, the shape of the explosive charge, the thickness of the explosive case, and case's material properties. For the test scenarios considered here, the probability distribution for velocity is given in Figure 2.5.

Theory and empirical evidence suggest that fragment velocity is dependent on a fragments starting location with respect to the explosive case. Larger fragments are known to travel slower than smaller fragments. Based on the geometry of the DynEx test explosive charge, the minimum 
estimated fragment velocity is $1.4 \mathrm{~km} / \mathrm{s}$. The average fragment velocity is thought to be $1.6 \mathrm{~km} / \mathrm{s}$, and the maximum fragment velocity is estimated to be $2.0 \mathrm{~km} / \mathrm{s}$. Expert opinion is that a Gaussian distribution reasonably predicts probable velocities. [Rodriguez 2000] The Gaussian distribution best matching the estimated fragment velocities has a mean of $1.60 \mathrm{~km} / \mathrm{s}$ and a standard deviation of $0.10 \mathrm{~km} / \mathrm{s}$.

The probability that a fragment travels at a velocity greater than $5 \mathrm{~km} / \mathrm{s}$ is one minus the cumulative probability that it travels at a velocity of $5 \mathrm{~km} / \mathrm{s}$ or less. Figure 2.5 shows the cumulative probability distribution for critical velocities. The probability that a fragment travels at a velocity greater than $5 \mathrm{~km} / \mathrm{s}$ is $P\left(>v_{\text {cr }}\right)=0.0$. This implies that it is not possible for a fragment with the given geometry to achieve a velocity sufficient to perforate the $2.54 \mathrm{~cm}$ thick containment vessel.

The overall probability that a fragment of dimension $L$ and $D$ perforates a target of thickness $P$ is the number of candidate fragments in the $L-D$ configuration times the probability that any one of them achieves a speed equal to or greater than the critical velocity. For the $L=D=0.25 \mathrm{~cm}$ discrete fragment configuration with a containment vessel thickness $P=2.53 \mathrm{~cm}$, the probability of perforation can be expressed as

$$
\begin{aligned}
P(\text { perforation })_{L, L / D} & =\# \text { candidates } \cdot P\left(v_{\text {fragment }}>v_{\mathrm{cr}}\right) \\
& =\frac{2 \alpha}{\pi} \cdot\left[\frac{\text { mass }_{\text {case }}}{\text { mass }_{\text {fragment }}}\right] \cdot\left[\frac{P(\text { mass })}{\sum_{i=1}^{\# d g} P_{i}(\text { mass })}\right] \cdot P(L / D \mid D) \cdot P(D) \cdot P\left(v_{\text {fragment }}>v_{\text {cr }}\right) \\
& =0.0 .
\end{aligned}
$$

For the dynamics of this example, it is not possible for a fragment to achieve the necessary $5 \mathrm{~km} / \mathrm{s}$. Since smaller sized fragments would require even higher velocities, our earlier assertion that small fragments can be neglected from the mathematical model seems valid.

The entire DynEx device's overall probability of failure is the sum of the discrete fragment configuration probabilities of perforation. If $N$ is the number of discrete fragment configurations,

$$
\begin{aligned}
N & =(\# \text { diameters considered }) \cdot(\# L / D \text { ratios considered }) \\
& =\# D^{\prime} \mathrm{s} \cdot \#(L / D)^{\prime} \mathrm{s} \\
& =4 \cdot 10=40 .
\end{aligned}
$$

The overall probability of failure is then

$$
\begin{aligned}
P(\text { failure }) & =\sum_{i=1}^{N} P_{i} \text { (perforation) } \\
& =\left\{\frac{2 \alpha \cdot m_{\text {case }}}{\pi \sum_{i=1}^{N} P\left(m_{i}\right)}\right\} \cdot \sum_{i=1}^{n}\left\{\left[\frac{P\left(m_{i}\right)}{m_{i}}\right] \cdot P\left(L_{i} / D_{i} \mid D_{i}\right) \cdot P\left(D_{i}\right) \cdot P\left(v_{i(\text { fragment })}>v_{i(\text { cr })}\right)\right\} \\
& =1.944 \times 10^{5} \cdot \sum_{i=1}^{n}\left\{\left[\frac{P\left(m_{i}\right)}{m_{i}}\right] \cdot P\left(L_{i} / D_{i} \mid D_{i}\right) \cdot P\left(D_{i}\right) \cdot P\left(v_{i(\text { fragment })}>v_{i(\text { cr })}\right)\right\} \\
& =0.00886,
\end{aligned}
$$

where 


$$
\begin{aligned}
\sum_{i=1}^{N} P_{i} \text { (perforation) } & =\text { sum of all the discrete probabilities of perforation, } \\
m_{\text {case }} & =\text { mass of the explosive case, } \\
m_{i} & =\text { mass of a fragment with the } i \text { th discrete set of conditions, } \\
P\left(m_{i}\right) & =\text { probability a fragment with mass } m_{i} \text { exists, } \\
\sum_{i=1}^{N} P\left(m_{i}\right) & =\text { sum of all the discrete mass probabilities, } \\
P\left(D_{i}\right) & =\text { probability a fragment with the } i \text { th discrete diameter exists, } \\
P\left(L_{i} / D_{i} \mid D_{i}\right) & =\text { probability } i \text { th discrete } D \text { and } L / D \text { conditions exists, and } \\
P\left(v_{i(\text { fragment })}>v_{i(\text { cr })}\right) & =\text { probability } i \text { th discrete fragment set travels faster than its critical velocity. }
\end{aligned}
$$

Appendix A contains the discrete fragment configuration matrices for the three containment vessel scenarios. A probabilistic assessment for the one- and two-inch thick containment vessel scenarios is given. The combined 2 inch thick containment vessel encased by the 3.25 inch thick safety vessel scenarios is also presented. Table 3.2 contains the result of the Likelihood of occurrence simulation for all three scenarios. Tables A1, A2, and A3 contain the discrete assessments for each scenario.

TABLE 3.2. RESUlTS OF THE LIKELIHOOD OF OCCURRENCE SiMULATIONS FOR THREE DIFFERENT WALL THICKNESSES

\begin{tabular}{|c|c|}
\hline Target Thickness & $\begin{array}{c}\text { Probability of Failure for Likelihood } \\
\text { of Occurrence Simulation }\end{array}$ \\
\hline $1^{\prime \prime}$ & $8.90 \mathrm{E}-03$ \\
\hline $2^{\prime \prime}$ & $1.52 \mathrm{E}-05$ \\
\hline $5.25^{\prime \prime}$ & $1.23 \mathrm{E}-13$ \\
\hline
\end{tabular}

The probability of failure is defined as the sum of the discrete-fragment-configurations probability of perforation. This means that failure is a cumulative metric. Had this been the sort of problem where only the worst-case probability of perforation was considered, a maximum value approach for predicting the probability of failure would have been adopted. Had this been a reliability type problem, the discrete results would have been normalized. However, this model defines the entire DynEx test as a single event. While the most probable fragment event dominates the failure prediction, other less likely fragment events contribute to the net probability of failure.

If the effects of tumble interactions on orientation and the likelihood that fragments impact the containment vessel at coincident locations are neglected, each fragment acts independently of the other fragments and can thus be thought of as an exclusive event. These two assumptions are reasonable. Because orientation is random, even if fragments interact on their way to the vessel wall, there is no predisposition for a particular orientation. Because the explosive case is small relative to the diameter of the containment vessel and because empirical evidence suggests fragment trajectories expand evenly outward, the space between fragments increases with distance.

Since all probable fragments are accounted for in the mathematical model, each fragment's probability of perforation contributes to the net probability of failure. The Likelihood of Occurrence mathematical model treats all exclusive fragment events as happening simultaneously rather than as one event happening repeatedly with minor parameter deviations (as is the case with the Stochastic Sampling model). 
The mathematical model assumes a DynEx test is akin to a Bayesian probability problem. If

$$
\begin{aligned}
& e_{i} \equiv \text { the event "fragment } i \text { occurs" and } \\
& p \equiv \text { the event "fragment perforates target thickness," }
\end{aligned}
$$

then

$$
\begin{aligned}
& L\left(e_{i}\right) \equiv \text { the likelihood } i \text { th fragment occurs and } \\
& P\left(p \mid e_{i}\right) \equiv \text { probability } i \text { th fragment perforates target thickness when it occurs. }
\end{aligned}
$$

And we can write the mutually exclusive events using a Bayesian formulation. By applying the multiplication rule for conditional probability, sometimes referred to as the rule of elimination, [Higgins 1995] and [Walpole 1989]

$$
P\left(p \cap e_{i}\right)=L\left(e_{i}\right) \cdot P\left(p \mid e_{i}\right)
$$

and

$$
\begin{aligned}
P(\text { failure }) & =P\left(p \cap e_{1}\right)+P\left(p \cap e_{2}\right)+\ldots+P\left(p \cap e_{n f}\right) \\
& =L\left(e_{1}\right) \cdot P\left(p \mid e_{1}\right)+L\left(e_{2}\right) \cdot P\left(p \mid e_{2}\right)+\ldots+L\left(e_{n f}\right) \cdot P\left(p \mid e_{n f}\right),
\end{aligned}
$$

where

$$
\begin{aligned}
P(\text { failure }) & =\text { net probability of failure and } \\
n f & =\text { number of fragment events. }
\end{aligned}
$$

From the earlier derivation given for the discrete mathematical model,

$$
P(\text { failure })=\sum_{i=1}^{N} P_{i}(\text { perforation })=\sum_{i=1}^{n f} L\left(e_{i}\right) \cdot P\left(p \mid e_{i}\right) \text {. }
$$

Equation (3.11) is the same as the equation used by the Likelihood of Occurrence model. Separate $N$ and $n f$ indices are required because in the discrete mathematical model the likelihood of occurrence formula contained all the fragments with a particular geometry configuration. Therefore, only the probabilities of perforation for the $N$ discrete different types of fragment configurations needed to be summed. In the formula given above there are $n f$ total fragments grouped in $N$ geometric sets. In other words, in the mathematical model there are $n f$ fragments having the potential to cause failure. Many of those $n f$ fragments are the same size. In fact, there are $N$ distinct geometric configurations. The difference in the how the probabilities are computed depends on how the different formulas do their combinatorics.

\subsection{Maximum Likelihood Estimator}

The method of maximum likelihood is used to obtain a point estimate for an unknown parameter $(\theta)$. In the DynEx problem the unknown parameter $\theta_{1}$ is taken to be the mean of the $(L / D)$ ratio most likely to be involved in a perforation. The unknown parameter $\theta_{2}$ is taken as the mean of the $(P / L)$ ratio most likely to be involved in a perforation. The likelihood function $L(\theta)$ provides the key linkage of the parameters and the sample data.

If $X$ is a random variable whose values $x_{i}$, where $i=1,2, \ldots, n$, have a probability density function $f(x: \theta)$, then the likelihood function of the data values is

$$
L(\theta)=\left.f\left(x_{i}, \theta\right)\right|_{i=1, n} .
$$


The maximum likelihood estimator of $\theta$ is the value of $\theta$ maximizing $L(\theta)$. If the random variables are discrete, $L(\theta)$ is an estimator maximizing the probability of occurrence of the data values. In the DynEx problem then

$$
\begin{aligned}
& L\left(\theta_{1}\right)=\text { the }(L / D) \text { ratio having the most likely probability of perforation and } \\
& L\left(\theta_{2}\right)=\text { the }(P / L) \text { ratio having the most likely probability of perforation. }
\end{aligned}
$$

Table 3.3 shows the joint probability mass function matrix derived from the data in Table A2 in Appendix A. This data represents the results of the Likelihood of Occurrence simulation of a 2 in. thick vessel. The fields of the probability mass function matrix in Table 3.1 depicts the probability for perforation for various discrete $(L / D)$ and $(P / L)$ combinations. Since the discrete joint probability of perforation values shown do not form a distribution, the marginals are normalized. Table 3.4 shows the combined probability of perforation for each of the discrete $L / D$ combinations. Table 3.5 shows the combined probability of perforation for each of the discrete $P / L$ combinations.

TABLE 3.3. Joint Probability MAtrix FOR Discrete L/D AND P/L COMBINATIONS

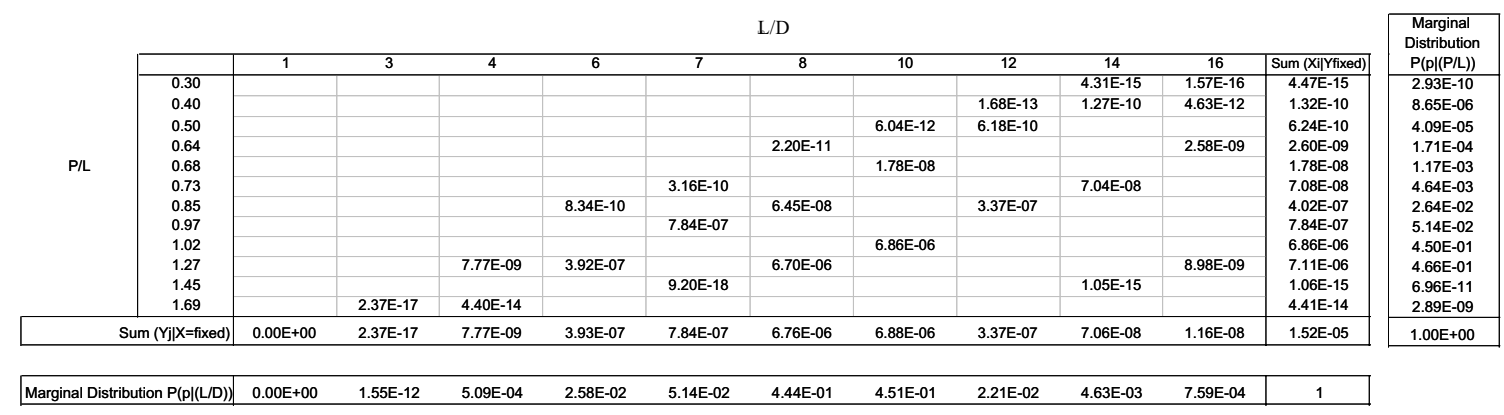

\begin{tabular}{|c|c|c|c|c|c|c|c|c|c|c|c|c|}
\hline L/D Ratios & $x$ & 1 & 3 & 4 & 6 & 7 & 8 & 10 & 12 & 14 & 16 & Sum \\
\hline & $f(X)=P(p)$ & $0.00 E+00$ & $2.37 \mathrm{E}-17$ & 7.77E-09 & $3.93 \mathrm{E}-07$ & $7.84 \mathrm{E}-07$ & $6.76 E-06$ & $6.88 \mathrm{E}-06$ & 3.37E-07 & 7.06E-08 & 1.16E-08 & 1.52448E-05 \\
\hline & $N(P(p))$ & $0.00 E+00$ & 1.55E-12 & $5.09 \mathrm{E}-04$ & $2.58 \mathrm{E}-02$ & 5. $14 \mathrm{E}-02$ & 4.44E-01 & 4.51E-01 & 2.21E-02 & 4.63E-03 & 7.59E-04 & 1 \\
\hline Mean $N(P(p))$ & & $0.00 E+00$ & 4.66E-12 & 2.04E-03 & 1.55E-01 & 3.60E-01 & 3. $55 \mathrm{E}+00$ & $4.51 \mathrm{E}+00$ & 2.66E-01 & $6.48 \mathrm{E}-02$ & 1.21E-02 & 8.920 \\
\hline Variance & & $0.00 E+00$ & $5.45 \mathrm{E}-11$ & $1.23 \mathrm{E}-02$ & $2.20 \mathrm{E}-01$ & $1.90 \mathrm{E}-01$ & $3.75 \mathrm{E}-01$ & $5.27 \mathrm{E}-01$ & 2. $10 \mathrm{E}-01$ & $1.19 \mathrm{E}-01$ & 3.80E-02 & 1.691 \\
\hline ird Deviation & & 1.300 & & & & & & & & & & \\
\hline
\end{tabular}

TABle 3.4. Combined Probability of Perforation For Discrete L/D COMBINATIONS

\begin{tabular}{|c|c|c|c|c|c|c|c|c|c|c|c|c|c|c|}
\hline \multirow[t]{3}{*}{ P/LRatios } & $\mathrm{Y}$ & 0.3 & 0.4 & 0.5 & 0.635 & 0.677 & 0.726 & 0.847 & 0.968 & 1.016 & 1.27 & 1.451 & 1.693 & Sum \\
\hline & $g(Y)=P(p)$ & 4.47E-15 & $1.32 \mathrm{E}-10$ & $6.24 \mathrm{E}-10$ & $2.60 \mathrm{E}-09$ & $1.78 E-08$ & $7.08 \mathrm{E}-08$ & $4.02 E-07$ & $7.84 \mathrm{E}-07$ & $6.86 \mathrm{E}-06$ & 7.11E-06 & $1.06 \mathrm{E}-15$ & $4.41 \mathrm{E}-14$ & $1.52 E-05$ \\
\hline & $N(P(p))$ & $2.93 \mathrm{E}-10$ & $8.65 E-06$ & 4.09E-05 & $1.71 \mathrm{E}-04$ & $1.17 \mathrm{E}-03$ & $4.64 \mathrm{E}-03$ & $2.64 E-02$ & $5.14 \mathrm{E}-02$ & $4.50 \mathrm{E}-01$ & $4.66 E-01$ & $6.96 \mathrm{E}-11$ & 2.89E-09 & 1 \\
\hline Mean & & $8.80 \mathrm{E}-11$ & $3.46 \mathrm{E}-06$ & $2.05 \mathrm{E}-05$ & $1.08 E-04$ & $7.90 \mathrm{E}-04$ & $3.37 \mathrm{E}-03$ & 2.23E- -22 & $4.98 \mathrm{E}-02$ & 4.57E-01 & $5.92 E-01$ & $1.01 E-10$ & $4.89 \mathrm{E}-0.9$ & 1.126 \\
\hline Variance & & $2.00 \mathrm{E}-10$ & $4.56 \mathrm{E}-06$ & $1.60 \mathrm{E}-05$ & 4.12E- -05 & $2.35 \mathrm{E}-04$ & $7.42 \mathrm{E}-04$ & $2.05 E-03$ & 1.28E-03 & $5.44 \mathrm{E}-03$ & $9.68 E-03$ & $7.36 \mathrm{E}-12$ & $9.30 \mathrm{E}-10$ & 0.019 \\
\hline ard Deviation & & 0.140 & & & & & & & & & & & & \\
\hline
\end{tabular}

TABLE 3.5. COMBINED PROBABILITY OF PERFORATION FOR DisCRETE P/L COMBINATIONS

From Table 3.4, the mean $(L / D)$ value, measured with respect to probability of perforation, is $E(X)=8.920$. The corresponding standard deviation is $S_{X}=1.30$. From Table 3.5, the $(P / L)$ most expected to be involved in a fragment perforation is $E(Y)=1.126$. The corresponding standard deviation for $(P / L)$ is $S_{Y}=0.140$. Hence, the maximum likelihoods estimated by the likelihood functions are

$$
\begin{aligned}
& L\left(\theta_{1}\right)=E(X)=8.9200 \text { and } \\
& L\left(\theta_{2}\right)=E(Y)=1.1226 .
\end{aligned}
$$


From these estimators the fragment geometry most likely to perforate a 2 " thick containment vessel is $D=0.5 \mathrm{~cm}$ and $L=4.46 \mathrm{~cm}$. Given this geometry, the worst-case probability of perforation is given below. The worst-case scenario is defined as all the explosive case material forming fragments that have the geometry most likely to cause perforation. For the above likelihood estimators, the worst case scenario is

$$
\begin{aligned}
D & =0.5 \mathrm{~cm}, \quad L=4.5 \mathrm{~cm}, \\
\text { fragment mass } & =(\delta)(t)(D)(L)=19.575 \mathrm{gm}, \\
P(\text { fragment mass }) & =3 \times 10^{-5}, \text { from Mott's distribution, } \\
P(L / D \mid D) & =P(9.0 \mid 0.5)=0.0046, \\
\# \text { fragments } & =\left(\frac{\text { case mass }}{\text { fragment mass }}\right) *\left(\frac{P_{i}(\text { mass })}{\sum P(\text { mass })}\right) * P(D) * P(L / D \mid D) \\
& =\left(\frac{15,500}{19,575}\right) *\left(\frac{3 \times 10^{-5}}{1.015}\right) *(0.5298) *(0.0046)=5.704 \times 10^{-5}, \\
\# \text { candidates } & =(\# \text { fragments })(P(\text { orientation })) \\
& =5.704 * 10^{-5} *\left(\frac{2 \alpha}{\pi}\right)=1.2675 \times 10^{-5}, \\
\text { critical velocity } & =1.7 \mathrm{~km} / \mathrm{s}, \\
P\left(>v_{\text {cr }}\right) & =0.1587, \text { and } \\
P(\text { perforation }) & =(\# \text { candidates }) * P\left(>v_{\text {cr }}\right)=2.01 \times 10^{-6} .
\end{aligned}
$$

The most likely estimators for the 1" and 5.25" vessel thickness scenarios are given in Table 3.6.

TABLE 3.6. RESULTS OF MAXIMUM LIKELIHOOD POINT ESTIMATES FOR THE THREE VESSEL THICKNESS MODELS CONSIDERING WORST-CASE SCENARIO

\begin{tabular}{|c|c|c|c|c|c|}
\cline { 2 - 6 } \multicolumn{1}{c|}{} & \multicolumn{5}{|c|}{ Likelihood Estimates of Probability of Perforation } \\
$\begin{array}{c}\text { Vessel } \\
\text { Thickness }\end{array}$ & $\begin{array}{c}\text { Likelihood } \\
\text { Estimator for } \\
(\boldsymbol{L} / \boldsymbol{D})\end{array}$ & $\begin{array}{c}\text { Likelihood } \\
\text { Estimator for } \\
(\boldsymbol{P} / \mathbf{L})\end{array}$ & $\begin{array}{c}\text { Fragment } \\
\text { Diameter } \\
(\mathbf{c m})\end{array}$ & $\begin{array}{c}\text { Fragment } \\
\text { Length } \\
(\mathbf{c m})\end{array}$ & $\begin{array}{c}\text { Probability of } \\
\text { Perforation } \\
\boldsymbol{P}(\text { failure })\end{array}$ \\
\hline $1^{\prime \prime}$ & 4.220 & 1.337 & 0.450 & 1.900 & $6.93 \mathrm{E}-03$ \\
\hline $2^{\prime \prime}$ & 8.920 & 1.123 & 0.507 & 4.524 & $2.01 \mathrm{E}-06$ \\
\hline $5.25^{\prime \prime}$ & 15.532 & 1.137 & 0.755 & 11.728 & $5.00 \mathrm{E}-13$ \\
\hline
\end{tabular}

\section{STOCHASTIC SAMPLING SIMULATION}

The Stochastic Sampling simulation model assesses the probability of failure by determining the frequency at which failures occur. In this approach random fragment geometries are sampled and their respective probabilities of perforation are determined. The parameter distributions described in Chapter two are used in the Stochastic Sampling model. However, the approach used to determine the net probability of failure is different. The primary difference between the Stochastic Sampling simulation model presented here and the Likelihood of Occurrence model presented in Chapter 3 is how each model defines an event. Recall that for the Likelihood of Occurrence simulation, $E_{\text {Lofo }}$ defined as the entire DynEx test as an event. In the Stochastic Sampling simulation model, an event is defined as

$$
E_{S S}=\text { Single fragment response. }
$$


A logical influence diagram is used to capture the structure of the Stochastic Sampling mathematical model. Influence diagrams are commonly used in decision analysis problems. Influence diagrams contain boxes of various shapes to indicate function and arrows connecting the boxes to indicate when one box is influenced by another box.

\subsection{DynEx Problem Stochastic Sampling Logical Influence Diagram Model}

Figures B1 and B2 in Appendix B, show the logical model for the DynEx problem. Figure 4.1 is a detail from Figure B2 depicting the logical way a fragment's probability of perforation is influenced. According to the logical model, the probability that a random fragment perforates the containment vessel is influenced by the probability that the fragment exists, is in the correct orientation, and is traveling with sufficient velocity. Each of these factors are uncertain and are described in terms of probability distributions.

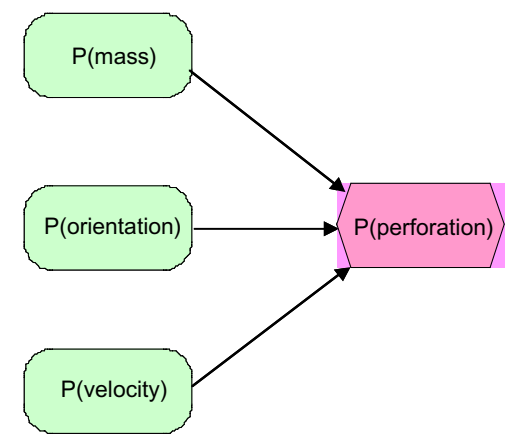

Figure 4.1. Influence diagram depicting how the probability of perforation is influenced.

The probability that a fragment exists depends on the probability that a specific fragment geometry occurs. The probability that a fragment is in the correct orientation is based on the uniform distribution describing the way fragments tumble toward their target. The probability that a fragment is traveling with sufficient velocity depends on many scenario specific parameters, such as target thickness and fragment geometry.

The stochastic sampling model assumes that a series of fragments are randomly selected on the basis of distributions for diameter $D$ and the length-to-diameter $(L / D)$ ratio. The influence diagram models what happens for each random fragment event. For a fragment to perforate the containment vessel wall, the fragment must exit, it must be in a critical orientation, and it must be traveling at or above a certain velocity based on its geometry. Mathematically it can be shown if

$$
\begin{aligned}
M_{i} & =\text { event } i \text { th fragment of given mass exists, } \\
O_{i} & =\text { event } i \text { th fragment's orientation is critical, and } \\
V_{i} & =\text { event } i \text { th fragment's velocity is at or above its critical velocity, }
\end{aligned}
$$

then

$$
\begin{aligned}
P_{i} \text { (perforation) } & =P\left(M_{i} \cap O_{i} \cap V_{i}\right) \\
& =P\left(M_{i}\right) \cdot P\left(O_{i}\right) \cdot P\left(V_{i}\right) \\
& =P(\text { mass }) \cdot P(\text { orientation }) \cdot P(\text { velocity }) .
\end{aligned}
$$

There exist combinations of these three first order parameters for which the probability of perforation is significant. The probability that a first order parameter is in such a critical state for a given fragment event is described below. 


\subsubsection{Fragment Geometry}

Fragments of various sizes and shapes are possible during a DynEx test. However, some fragment geometries are more probable than others. The uncertain components of fragment geometry are diameter $(D)$ and length to diameter ratio $(L / D)$. Theory, experimental evidence, and expert judgment combine to produce probability distributions for both $(D)$ and $(L / D)$. Those distributions were presented in Chapter 2. In the Stochastic Sampling model, $(D)$ and $(L / D)$ are treated as uncertain parameters and stochastically sampled on the basis of their respective probability distributions. Figure 4.2 shows a portion of the Stochastic Sampling model's influence diagram for assessing the probability that a specific fragment mass occurs.

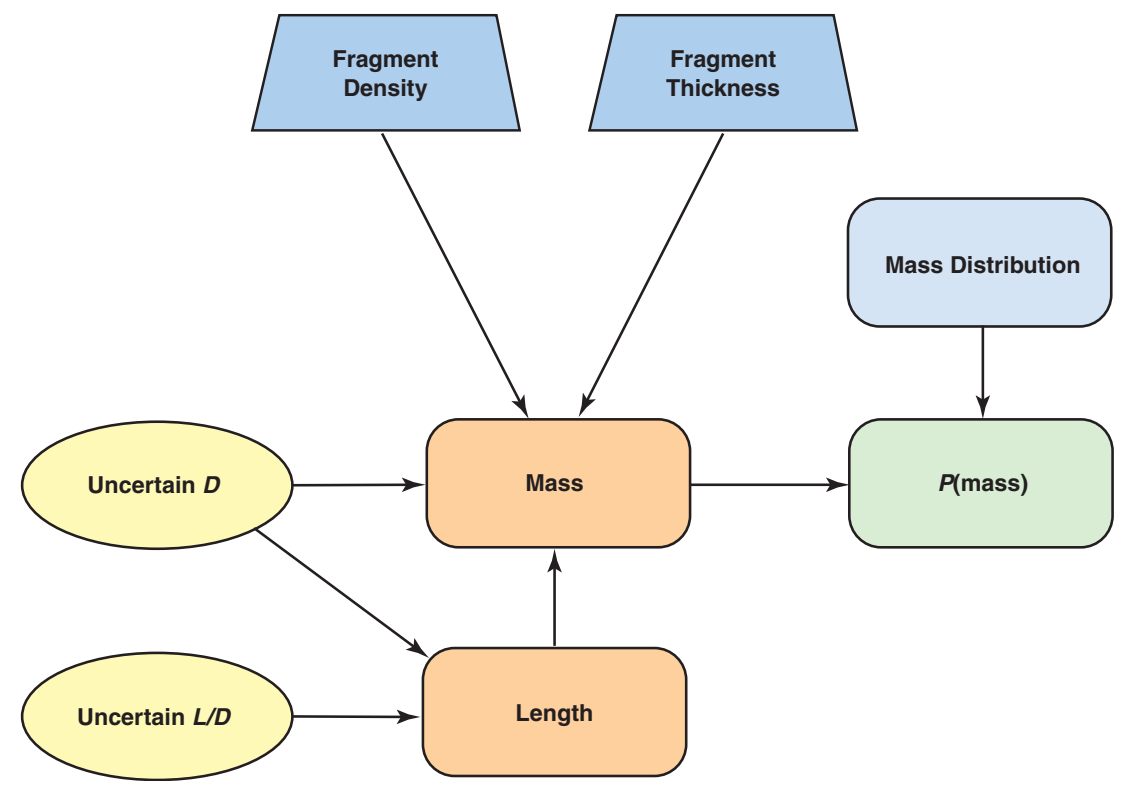

Figure 4.2. Influence diagram for probability of mass.

Oval shaped nodes in the influence diagram depict uncertain random variables. Rounded corner rectangular-shaped nodes depict computed parameters. The orange rounded-corner rectangularshaped nodes depict parameters computed from other problem parameters. The green nodes represent probabilistic calculations. The light blue rounded-corner rectangular-shaped nodes represent known parameter distributions. Nodes shaped like frustums depict constant parameters.

In the influence diagram shown in Figure 4.2, fragment density $(\delta)$ and thickness $(t)$ are userdefined constants. The model assumes that the explosive case does not thin before or during fragmenting and that the manufactured density of the case is homogenous and remains constant during expansion. Using Monte Carlo type stochastic sampling techniques, in particular, the Latin-hypercube method, different combinations of $(D)$ and $(L / D)$ are randomly generated. Each random pair of $(D, L / D)$ parameters constitutes a fragment event. By the logic of the influence diagram, fragment length is computed from the $D, L / D$ parameter pair, where $L=(L / D)^{*} D$. The equation for a fragment's mass is defined as

$$
M=\delta t L D
$$

With the mass of a given fragment determined, the probability that such a fragment could exist is computed using the mass distribution given in Figure 2.1. The shape of this probability density function is called Mott's distribution and is used to estimate the probability that fragments within various mass ranges occur $(\mathrm{P}(M))$. Historically Mott's distribution underestimates the likelihood of small fragments and over estimates the likelihood of large fragments. [Rodriguez 2000] Since larger fragments dominate damage, Mott's distribution is conservative. 


\subsubsection{Fragment Orientation}

Before beginning a simulation, a value for the cone angle is specified. As described in Chapter 2, the cone angle represents the angle between the tip of the fragment and the normal to the containment vessel wall at the point of impact. The Stochastic Sampling model assumes all fragments whose angle of attack is inside the cone angle are perpendicular to the containment vessel wall. Since nonperpendicularities decrease the effectiveness of the fragment's ability to perforate the containment vessel, this assumption leads to conservative estimates of perforation. Figure 4.3 shows the influence diagram for the probability of a fragment being in the orientation necessary to cause damage.

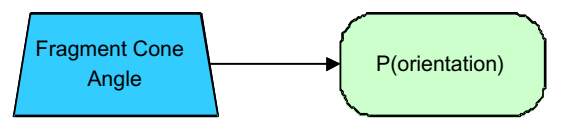

Figure 4.3. Influence diagram for determining probability of orientation.

All fragment orientations are assumed equally probable. Hence, a uniform distribution is used to represent the probability density function for fragment orientation. If $\alpha$ is the user specified cone angle given in degrees, then $\pm \alpha$ is the range of interest, and the possible range of rotation is $0 \leq \alpha \leq 180$. If $180<\alpha<360$, the fragment is in a reverse orientation and the tail becomes the tip. Since any orientation is equally probable,

$$
\begin{aligned}
P(\text { orientation }) & =(2 \alpha) / \pi \\
& =2 *(\alpha * \pi / 180) / \pi \\
& =\alpha / 90 .
\end{aligned}
$$

\subsubsection{Fragment Velocity}

Each unique fragment has an associated velocity necessary for perforation to occur. This critical velocity depends on both fragment geometry and the thickness of the containment vessel. Figure 4.4 shows the logic influence diagram for computing the probability that a given fragment travels at or above its critical velocity.

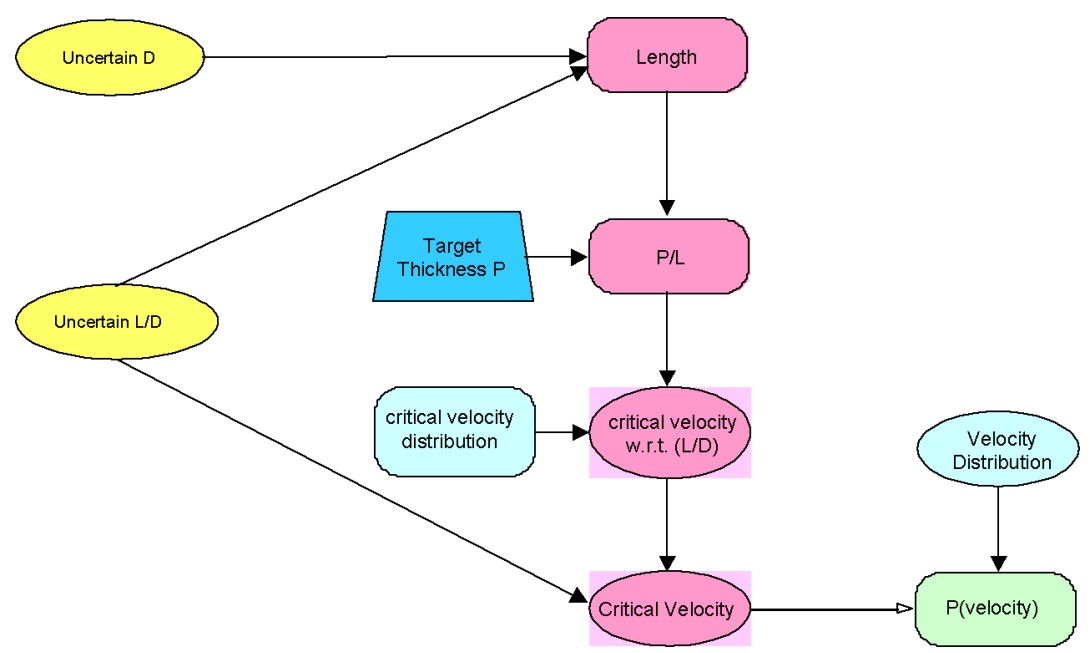

Figure 4.4. Influence diagram for determining the probability that a fragment travels at or above its critical velocity. 
As shown in Section 4.1.1, a fragment's length is directly computed from the random variables. Namely,

$$
L=(L / D) * D
$$

At the start of a simulation, target thickness $(P)$ is specified. For the HSLA-100 containment vessel, $P$ is the radial wall thickness of the vessel. For spherical vessels with a sufficiently large diameter, the radial thickness is equivalent to a flat wall thickness. With fragment length $L$ known, the ratio of target thickness to fragment length $(P / L)$ is used to determine the critical velocity. The critical velocity distribution node of the influence diagram represents a table of experimental data compiled by Southwest Research Institute relating combinations of $(P / L)$ and $(D / L)$ for materials similar in performance to HSLA-100 steel. [Anderson 1992]

The influence diagram computes critical velocity in two steps. In the first step the critical velocity is determined with respect to the fragment's specific $(L / D)$. In this step a single $(P / L)$ curve is generated for possible combinations of $(L / D)$. The curve is defined using cubic polynomial interpolation. In the second step the critical velocity is determined as the point along the $(P / L)$ curve corresponding to the fragment's $(L / D)$. Table 4.1 shows the tabular critical velocities generated from the Southwest Research Institute data. Figure 4.5 shows various $(P / L)$ curves for $(D / L)$ ratios versus critical velocity. Reading along the proper $(P / L)$ curve to the fragment's $(L / D)$ ratio provides an estimate for the velocity necessary for a fragment to perforate a target of thickness $P$.

TABLE 4.1. CRITICAL Velocity TABLE FOR HSLA-100 TYPe StEEL

\begin{tabular}{|c|c|c|c|c|c|c|c|c|c|c|c|c|c|c|}
\hline & \multicolumn{13}{|c|}{$P / L$} \\
\hline & & 0.00 & 0.25 & 0.50 & 0.75 & 1.00 & $\begin{array}{l}1.25 \\
\end{array}$ & 1.50 & 1.75 & 2.00 & 2.25 & 2.50 & 2.75 & 3.00 \\
\hline \multirow{6}{*}{$\mathrm{D} / \mathrm{L}$} & 1 & 0.1 & 0.5 & 0.8 & 0.95 & 1.2 & 1.35 & 1.55 & 1.75 & 2.25 & 2.55 & 3 & 3.5 & 4 \\
\hline & 3 & 0.15 & 0.6 & 0.9 & $\begin{array}{l}1.2 \\
\end{array}$ & 1.35 & 1.5 & 1.8 & 2.15 & 2.75 & 4 & 10 & 10 & 10 \\
\hline & 6 & 0.2 & 0.7 & 0.95 & 1.35 & $\begin{array}{l}1.6 \\
\end{array}$ & 1.8 & 2.4 & 10 & 10 & 10 & 10 & 10 & 10 \\
\hline & 10 & 0.3 & 0.75 & 1.1 & 1.45 & 1.65 & 1.9 & 2.55 & 10 & 10 & 10 & 10 & 10 & 10 \\
\hline & 20 & 0.4 & 0.9 & 1.2 & 1.5 & 1.7 & 2.05 & 2.9 & 10 & 10 & 10 & 10 & 10 & 10 \\
\hline & 30 & 0.5 & 1 & 1.4 & 1.7 & 2 & 2.45 & 3.2 & 10 & 10 & 10 & 10 & 10 & 10 \\
\hline
\end{tabular}

Critical Velocities for HSLA-100 Type Steels

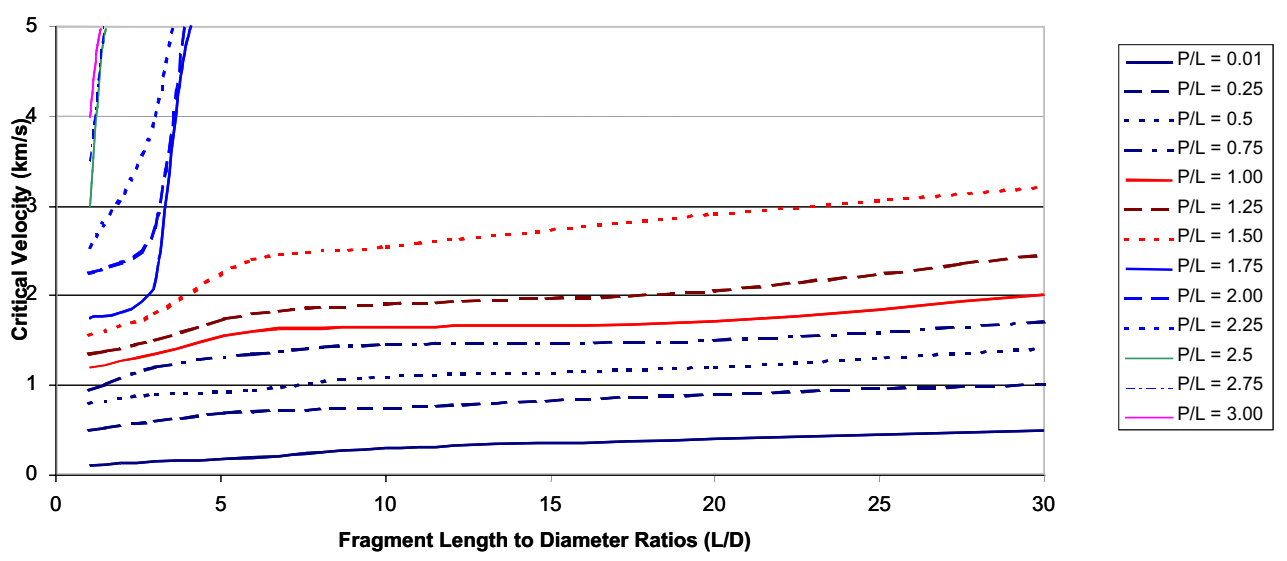

Figure 4.5. Critical velocity versus fragment $L / D$ ratios for various target thickness to fragment length ratios $(P / L)$.

Once a fragment's critical velocity is determined, the next step is computing the probability the fragment could achieve this speed. Figure 2.5 provided a cumulative distribution for fragment velocity. A cumulative distribution is used because if a fragment surpasses its critical velocity perforation occurs. This means all chances that a fragment travels at or above its critical velocity are of interest. 


\subsection{Performing a Simulation}

The approach used by the Stochastic Sampling model to measure the probability of failure is somewhat analogous to reaching into a large bin of randomly shaped fragments and throwing them one at a time at a steel plate with random velocity and counting how many fragments perforate the target. This approach depends on the number of samples taken, and like all such approaches, it is never clear how many critical fragments events are sampled. As the number of random events grows, the mean response of the sampled fragment events approaches the true mean response of a DynEx test. However, what happens in the tail regions of the simulated response distribution is more difficult to determine. It is the very tail region response that drives failure estimates.

If a simulation is performed with 100 samples, there is no way to predict how many more failures would have occurred had the sample size been 120 rather than 100. A premise upon which Monte Carlo or Latin-hypercube random sampling approaches are based is that when the number of stochastic samples is large all probable fragment events are investigated and the frequency of failure reaches steady state. The issue of determining a probability of failure from the simulation results depends on how the results are to be interpreted. If the probability of failure is measured as a reliability, then

$$
P(\text { failure })=\frac{\# \text { samples }-\# \text { failures }}{\# \text { samples }} .
$$

This counting approach provides a rate at which a failure occurs. It is somewhat like answering the question, "If I turn in the key in my car 100 times, how often will the car fail to start?" If starting the car is the test and if one time the car fails to start, then $P($ failure $)=0.01$. However, the DynEx problem is not analogous. If 100 fragments are thrown at the target and one fragment perforates the probability of failure is 1.00 , not 0.01 . This is because all 100 independent samples are occurring simultaneously during an experiment and failure is defined as one fragment perforation occurring.

Another drawback to adopting a reliability approach is that the probability of failure depends on where samples are taken as well as how many samples are taken. If the domain of possible fragment geometries is not properly sampled, the estimated probability of failure is skewed. Monte Carlo type techniques address this by requiring the number of samples to be large. Latinhypercube methods provide a way of adequately sampling the possible parameter domain with a much smaller number of samples.

It's logical to think about a random event, such as starting a car, as being repeated many times with small variations in the parameters. Each sample represents an event that could occur, and the and reliability is in fact a ratio of the number of times the simulation performed successfully to the number of times the simulation failed to perform successfully for all probable event scenarios. Again though, this logic does not apply to the DynEx problem. In a DynEx test, all events happen simultaneously and each fragment event is independent. Knowing the ratio of the number of failures per number of samples is not as interesting as understanding how each event's probability of perforation contributes to the overall probability of failure. It is the aggregate of events and how they relate to a probability of perforation that matters.

This suggests that perhaps the probability of failure should be based on the sum of all the probabilities of perforation for the fragment events. Since each fragment event has an associated probability of perforation, the sum of the probabilities could be used as a measure of the overall probability of failure. This was the approach used in the Likelihood of Occurrence model presented in Chapter 3. The difference between the Likelihood of Occurrence approach and the Stochastic Sampling approach is that in the Likelihood of Occurrence model, all likely fragment events were modeled simultaneously with an understanding of the number of fragments and the way they are configured. 
In the Stochastic Sampling model, fragment events are randomly selected. While the likelihood of occurrence for each fragment event can be determined, during a simulation no effort is made to control how sampling occurs. This means there is no assurance sampled fragment events distributed themselves in a manner equivalent to an actual DynEx test. This can be both a positive and negative aspect of the Stochastic Sampling simulation. It's a negative aspect because if we expect 41,500 fragments to form during a DynEx test and we perform 41,500 samples, there is no way to assure the "correct" 41,500 fragment events were evaluated. On the other hand, we aren't certain there are 41,500 fragment events in a DynEx test, and we are less certain about how the fragment events distribute themselves. Randomness allows us to consider sampling scenarios that our preconceptions might have caused us not to consider.

If the probability of failure is computed as the sum of each fragment event's probability of perforation, which is the approach used in the Likelihood of Occurrence simulation, the result depends on the number of random samples taken. In the limit,

$$
\lim _{\text {\# samples } \rightarrow \infty} P(\text { failure }) \rightarrow 1.00 \text {. }
$$

One way around this dilemma would be to normalize the probability of failure with respect to the number of samples. In general then,

$$
P(\text { failure })=\frac{\sum_{i=1, \text { \# samples }} P_{i} \text { (perforation) }}{\# \text { samples }} .
$$

This solution converges to the mean $P$ (failure) as the number of samples gets large. This can potentially dilute the impact of the rare events of interest. Suppose, for example, in 100 random samples the sum of the individual fragment event's probability of perforation is 0.0315 , where the maximum probability of perforation is 0.01 . A normalized approach yields

$$
P(\text { failure })=\frac{\sum_{i=1,100} P_{i} \text { (perforation) }}{100}=\frac{0.0315}{100}=3.15 \times 10^{-4} .
$$

Now, suppose after 120 samples the sum of the individual fragment event's probability of perforation is 0.035 . Then,

$$
P(\text { failure })=\frac{\sum_{i=1,120} P_{i}(\text { perforation })}{120}=\frac{0.035}{120}=2.9167 \times 10^{-4} .
$$

If after 250 samples the sum of the individual fragment event's probability of perforation is 0.0397 , then

$$
P(\text { failure })=\frac{\sum_{i=1,200} P_{i}(\text { perforation })}{200}=\frac{0.0397}{200}=1.985 \times 10^{-4} .
$$

Finally, suppose after 10,000 samples one fragment event results in a perforation and several other fragment events possess nonzero probabilities of perforation, such that

$$
P(\text { failure })=\frac{\sum_{i=1,10,000} P_{i}(\text { perforation })}{10,000}=\frac{1.943}{10,000}=1.943 \times 10^{-4} .
$$

In this scenario what is the best estimate of the probability of failure? If the sum of the probabilities of perforation is taken, as was done in the Likelihood of Occurrence model, then as the number of samples gets large, so will the probability of failure [i.e., the term in the numerator of Equations (4.7) to (4.12)]. If a normalized measure is used, the probability of failure depends on when you measure and on how many random fragment events resulted in perforation up to that instant. In the above scenario a steady state seems to exist near 10,000 samples. But is the 
estimated $P($ failure $)=1.942 \times 10^{-4}$ an accurate measure of performance, or should the $P($ failure $)=$ 1.0 represent the singular perforation event?

Imagine a domain $A$ representing all possible fragment events of a DynEx test. A subregion $B$ is defined to contain all fragment events assessed during a Stochastic Sampling simulation. Subregion $C$ is defined to represent the fragment events of a DynEx test having a nonzero probability of perforation. These three regions can be modeled as shown in Figure 4.6.

To explore the implications of this domain, let

$$
\begin{aligned}
& n=\text { the number of fragment events occurring during a physical DynEx test and } \\
& m=\text { the number of stochastic samples taken during a numerical simulation. }
\end{aligned}
$$

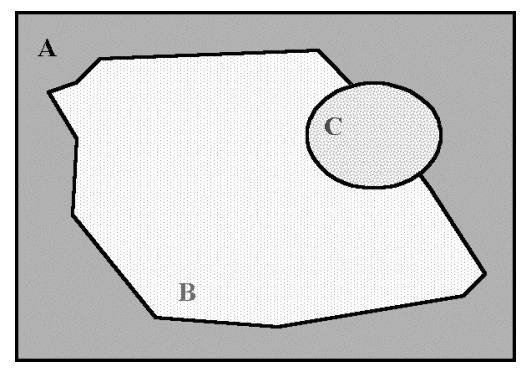

Figure 4.6. Domain of simulated fragment events relative to actual test events.

When

$$
m<n,
$$

$B$ is smaller than $A$.

When

$$
m=n,
$$

it is unlikely that $B$ has the same shape or size as $A$ because some fragment events are undersampled while other fragment events are oversampled in the numerical simulation.

As $m$ increases such that

$$
m>n,
$$

$B$ grows in area but some fragment events continue to be undersampled while an increasing number fragment events are oversampled.

As $m$ increases such that

$$
m \rightarrow \omega,
$$

where $\omega$ is a large number, $B$ continues to expand but remains smaller and of different shape than $A$. At the same time, more of subregion $C$ is sampled.

For some number of stochastic samples, $m^{\prime}$, all of subregion $C$ is sampled. The problem is that the value of $m^{\prime}$ is not known. Even if $m^{\prime}$ could be known, when the number of stochastic samples equals $m^{\prime}$, there are still some fragment events in $C$ that are oversampled and others that are undersampled. Also, for any $m^{\prime}$, the areas $C$ relative to $B$ and $B$ relative to $A$ are not known.

Finally, the rate that various fragment events are under- and oversampled in both regions $B$ and $C$ is not known. 
The dilemma is that a normalized approach to assessing the simulated probability of failure, in general, underestimates the true probability of failure because it spreads the impact of individual fragment events over all the samples taken. At the conclusion of a stochastic sampling simulation, there will be $m$ samples of which $m_{f}$ samples have a nonzero probability of perforation. How the simulation's net probability of failure is computed depends on how the results of the sampled fragment events are counted.

One measure of the probability of failure could be simply the maximum probability of penetration for all the individual fragment events. The obvious shortcoming of this measure is it does not take into account contributions from other less probable fragment events. In the above example, when the sample size was 100 , the maximum probability of penetration was 0.01 . But when the sample size was 10,000, the maximum probability of penetration was 1.00 . Somewhere in between lies the true probability of failure.

In the stochastic sampling simulation model used to assess the probability that a DynEx test results in a fragment perforation, the worst probable point (WPP) and the $95 \%$ confidence value are used as simulation metrics. Thirty thousand random and independent fragment events are generated using Latin-hypercube with a minimal standard randomizer method. The probability that each of these independent events results in perforation is determined on the basis of the criteria of the logical model's influence diagram.

It is known from experimental and antidotal evidence that approximately 41,500 fragments are generated during a DynEx test. Of those, $\sim 4,279$ have the potential to perforate the containment vessel. In a simulation involving 30,000 stochastic samples, most of the 4,279 potential fragments will be sampled. Some of the $\sim 4,279$ fragment events of interest are undersampled while others are oversampled. In general, though, the mean of the sampled events should approach the true mean of the DynEx test fragment events. A normalized measuring approach will likely underestimate the true probability of failure because there always exists the possibility that some worst-case fragment scenario was not sampled. A maximum value approach uses the same sample space where some events are undersampled while other events are oversampled. However, in 30,000 samples, a maximum value approach should find a reasonable worst-case fragment scenario.

Table 4.2 shows the results of the stochastic sampling simulations for the three vessel thickness scenarios. The $95 \%$ confidence $P$ (failure) is defined as the fragment event for which $95 \%$ of the stochastic samples have a smaller probability of perforation and $5 \%$ of the samples have a higher $P$ (perforation). The worst probable point is the probability of failure for the fragment event having the highest likelihood of occurring. The sample mean and standard deviation represent the distribution statistics for the 30,000 fragment events sampled.

TABLE 4.2. Results OF THE STOCHASTIC SAMPLING SiMULATION FOR THREE VeSSEL SCENARIOS

\begin{tabular}{|c|c|c|c|c|c|}
\cline { 3 - 6 } \multicolumn{2}{c|}{} & \multicolumn{4}{c|}{ Results of Stochastic Sampling Simulation } \\
\cline { 3 - 6 } \multicolumn{2}{c|}{} & $\begin{array}{c}\text { Worst Probable } \\
\text { Point (MPP) }\end{array}$ & $\begin{array}{c}\mu \text { of Sampled } \\
\text { Fragment Events }\end{array}$ & $\begin{array}{c}\sigma \text { of Sampled } \\
\text { Fragment Events }\end{array}$ & $\begin{array}{c}95 \% \text { Confidence } \\
\text { P(perforation) }\end{array}$ \\
\hline $\begin{array}{c}\text { Target } \\
\text { Thickness }\end{array}$ & $1^{\prime \prime}$ & $2.20 \mathrm{E}-03$ & $1.38 \mathrm{E}-05$ & $5.11 \mathrm{E}-05$ & $1.16 \mathrm{E}-04$ \\
\cline { 2 - 6 } & $2 "$ & $1.55 \mathrm{E}-04$ & $3.72 \mathrm{E}-07$ & $5.55 \mathrm{E}-06$ & $1.15 \mathrm{E}-05$ \\
\cline { 2 - 6 } & $5.25 "$ & $2.50 \mathrm{E}-09$ & $2.10 \mathrm{E}-13$ & $4.26 \mathrm{E}-11$ & $8.54 \mathrm{E}-11$ \\
\hline
\end{tabular}

\section{STOCHASTIC SAMPLING SIMULATION CONVERGENCE}

In general, with any random sampling technique, the more samples taken the more the possibility space is interrogated. However, like any process there is a point where the effort associated with taking additional samples is not warranted relative to the knowledge gained. To assess the quality of the stochastic sampling simulation convergence, four metrics are measured. They are (1) the worst probable point (WPP), (2) the mean of the sample results, (3) the standard 
deviation of the sampled results, and (4) the 95\% confidence value. The WPP represents the maximum probability of a perforation event computed during a simulation. The $95 \%$ confidence represents the probability of perforation for which $95 \%$ of the samples have an equal or lesser probability of perforation. Tables 5.1,5.2, and 5.3 show the convergence summaries for the $1 ", 2$, and $5.25^{\prime \prime}$ containment vessel thickness simulations.

These results show that each vessel thickness simulation converges toward a steady state solution as the sample size approaches 30,000. Random Latin-hypercube sampling is used with the minimal standard randomizer method. For all three vessel thickness models, the WPP value converges within a reasonable range. The mean and standard deviations also appear to converge. The $95 \%$ confidence $P$ (perforation) value, which is defined as the $2 \sigma$ event assuming a Gaussian distribution, appears to converge. Figures 5.1, 5.2, and 5.3 show converging lognormal probability density function plots for increasing sample sizes for the three respective vessel thickness models.

\section{TABLE 5.1. CONVERGENCE SUMMARY FOR 1" CONTAINMENT VeSSEL THICKNESS SiMUlationS}

\begin{tabular}{|c|c|c|c|c|c|}
\cline { 3 - 6 } \multicolumn{1}{c|}{} & \multicolumn{4}{c|}{ Results of Stochastic Sampling Simulation } \\
\hline \multirow{4}{*}{1 1" Vessel Thickness } & $\begin{array}{c}\text { Worst Probable } \\
\text { Point (WPP) }\end{array}$ & $\begin{array}{c}\mu \text { of Sampled } \\
\text { Fragment Events }\end{array}$ & $\begin{array}{c}\sigma \text { of Sampled } \\
\text { Fragment Events }\end{array}$ & $\begin{array}{c}\text { 95\% Confidence } \\
\text { P(perforation) }\end{array}$ \\
\hline \multirow{4}{*}{$\begin{array}{c}\text { Number } \\
\text { of }\end{array}$} & 100 & $1.54 \mathrm{E}-06$ & $2.74 \mathrm{E}-05$ & $1.57 \mathrm{E}-04$ & $3.41 \mathrm{E}-04$ \\
\cline { 2 - 6 } & 200 & $2.28 \mathrm{E}-04$ & $1.37 \mathrm{E}-05$ & $3.56 \mathrm{E}-05$ & $8.49 \mathrm{E}-05$ \\
\cline { 2 - 6 } & 500 & $1.57 \mathrm{E}-04$ & $1.14 \mathrm{E}-05$ & $3.23 \mathrm{E}-05$ & $7.61 \mathrm{E}-05$ \\
\cline { 2 - 6 } & 1.000 & $5.29 \mathrm{E}-04$ & $1.42 \mathrm{E}-05$ & $4.11 \mathrm{E}-05$ & $9.65 \mathrm{E}-05$ \\
\cline { 2 - 6 } & 2,000 & $1.72 \mathrm{E}-03$ & $1.62 \mathrm{E}-05$ & $6.85 \mathrm{E}-05$ & $1.53 \mathrm{E}-04$ \\
\cline { 2 - 6 } & 5,000 & $2.07 \mathrm{E}-03$ & $1.38 \mathrm{E}-05$ & $5.60 \mathrm{E}-05$ & $1.26 \mathrm{E}-04$ \\
\cline { 2 - 6 } & 10,000 & $2.08 \mathrm{E}-03$ & $1.46 \mathrm{E}-05$ & $5.56 \mathrm{E}-05$ & $1.26 \mathrm{E}-04$ \\
\cline { 2 - 6 } & 20.000 & $2.13 \mathrm{E}-03$ & $1.43 \mathrm{E}-05$ & $5.14 \mathrm{E}-05$ & $1.17 \mathrm{E}-04$ \\
\cline { 2 - 6 } & 30,000 & $2.20 \mathrm{E}-03$ & $1.38 \mathrm{E}-05$ & $5.11 \mathrm{E}-05$ & $1.16 \mathrm{E}-04$ \\
\hline
\end{tabular}

TABle 5.2. CONVERGENCE SUMMARY FOR 2" CONTAINMENT VeSSEL THICKNESS SiMUlATIONS

\begin{tabular}{|c|c|c|c|c|c|}
\hline & & \multicolumn{4}{|c|}{ Results of Stochastic Sampling Simulation } \\
\hline 2"Vessel & Thickness & $\begin{array}{c}\text { Worst Probable } \\
\text { Point (WPP) }\end{array}$ & $\begin{array}{c}\mu \text { of Sampled } \\
\text { Fragment Events }\end{array}$ & $\begin{array}{c}\sigma \text { of Sampled } \\
\text { Fragment Events }\end{array}$ & $\begin{array}{c}95 \% \\
\text { Confidence } \\
\mathrm{P} \text { (perforation) }\end{array}$ \\
\hline \multirow{9}{*}{$\begin{array}{c}\text { Number } \\
\text { of } \\
\text { Samples }\end{array}$} & 100 & $9.63 \mathrm{E}-06$ & $5.61 \mathrm{E}-08$ & 1.03E-06 & 2.11E-06 \\
\hline & 200 & $4.16 \mathrm{E}-07$ & $3.00 \mathrm{E}-09$ & 4.79E-08 & $9.88 \mathrm{E}-08$ \\
\hline & 500 & 1.43E-04 & 1.10E-06 & 1.06E-05 & 2.23E- 05 \\
\hline & 1,000 & $1.29 \mathrm{E}-04$ & 4.01E-07 & $6.00 \mathrm{E}-06$ & 1.24E-05 \\
\hline & 2,000 & $1.37 \mathrm{E}-04$ & $3.26 \mathrm{E}-07$ & 4.87E-06 & $1.01 \mathrm{E}-05$ \\
\hline & 5,000 & $1.53 \mathrm{E}-04$ & 3.79E-07 & 5.95E-06 & 1.23E-05 \\
\hline & 10,000 & $1.52 \mathrm{E}-04$ & 4.25E-07 & 6.29E-06 & 1.30E-05 \\
\hline & 20,000 & 1.53E-04 & 4.05E- 07 & 5.91E-06 & 1.22E-05 \\
\hline & 30,000 & $1.55 \mathrm{E}-04$ & $3.72 \mathrm{E}-07$ & 5.55E-06 & 1.15E-05 \\
\hline
\end{tabular}

TABLE 5.3. CONVERGENCE SUMMARY FOR 5.25" CONTAINMENT VeSSEL THICKNESS SimUlATIONS

\begin{tabular}{|c|c|c|c|c|c|}
\hline & & \multicolumn{4}{|c|}{ Results of Stochastic Sampling Simulation } \\
\hline \multicolumn{2}{|c|}{$\begin{array}{l}5.25 " \\
\text { Vessel Thickness }\end{array}$} & $\begin{array}{l}\text { Worst Probable } \\
\text { Point (WPP) }\end{array}$ & $\begin{array}{c}\mu \text { of Sampled } \\
\text { Fragment Events }\end{array}$ & $\begin{array}{c}\sigma \text { of Sampled } \\
\text { Fragment Events }\end{array}$ & $\begin{array}{c}95 \% \\
\text { Confidence } \\
\mathrm{P} \text { (perforation) }\end{array}$ \\
\hline \multirow{9}{*}{$\begin{array}{c}\text { Number } \\
\text { of } \\
\text { Samples }\end{array}$} & 100 & $1.00 \mathrm{E}-13$ & $0.00 \mathrm{E}+00$ & $0.00 \mathrm{E}+00$ & $0.00 \mathrm{E}+00$ \\
\hline & 200 & $2.72 \mathrm{E}-12$ & $0.00 \mathrm{E}+00$ & $4.81 \mathrm{E}-11$ & $9.63 \mathrm{E}-11$ \\
\hline & 500 & $9.32 \mathrm{E}-11$ & $0.00 \mathrm{E}+00$ & $5.83 E-12$ & 1.17E-11 \\
\hline & 1,000 & $1.91 \mathrm{E}-10$ & $1.36 \mathrm{E}-13$ & $6.19 \mathrm{E}-12$ & 1.25E-11 \\
\hline & 2,000 & $2.81 \mathrm{E}-10$ & $0.00 \mathrm{E}+00$ & $2.93 \mathrm{E}-11$ & $5.86 \mathrm{E}-11$ \\
\hline & 5,000 & $1.59 \mathrm{E}-09$ & $0.00 \mathrm{E}+00$ & $5.37 \mathrm{E}-11$ & 1.07E-10 \\
\hline & 10,000 & 1.75E-09 & $5.72 \mathrm{E}-13$ & $3.74 \mathrm{E}-11$ & 7.53E-11 \\
\hline & 20,000 & 1.70E-09 & $2.64 \mathrm{E}-13$ & $3.67 E-11$ & $7.37 \mathrm{E}-11$ \\
\hline & 30,000 & 2.50E-09 & 2.10E-13 & $4.26 \mathrm{E}-11$ & $8.54 \mathrm{E}-11$ \\
\hline
\end{tabular}




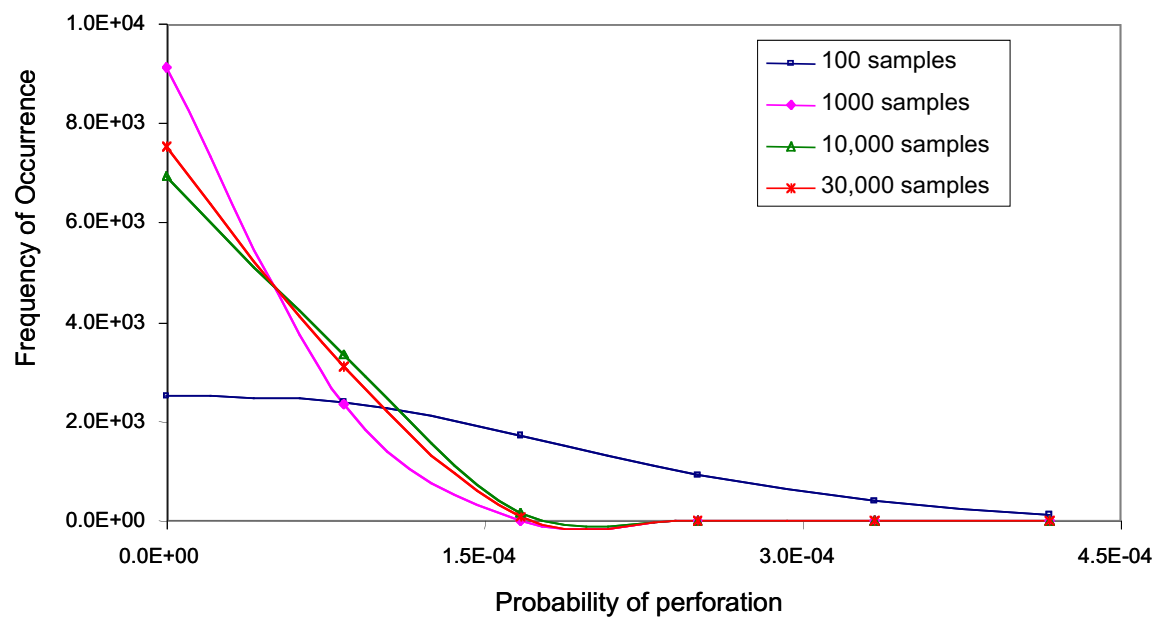

Figure 5.1. Converging pdf plots for increasing sample sizes for 1" vessel thickness simulation.

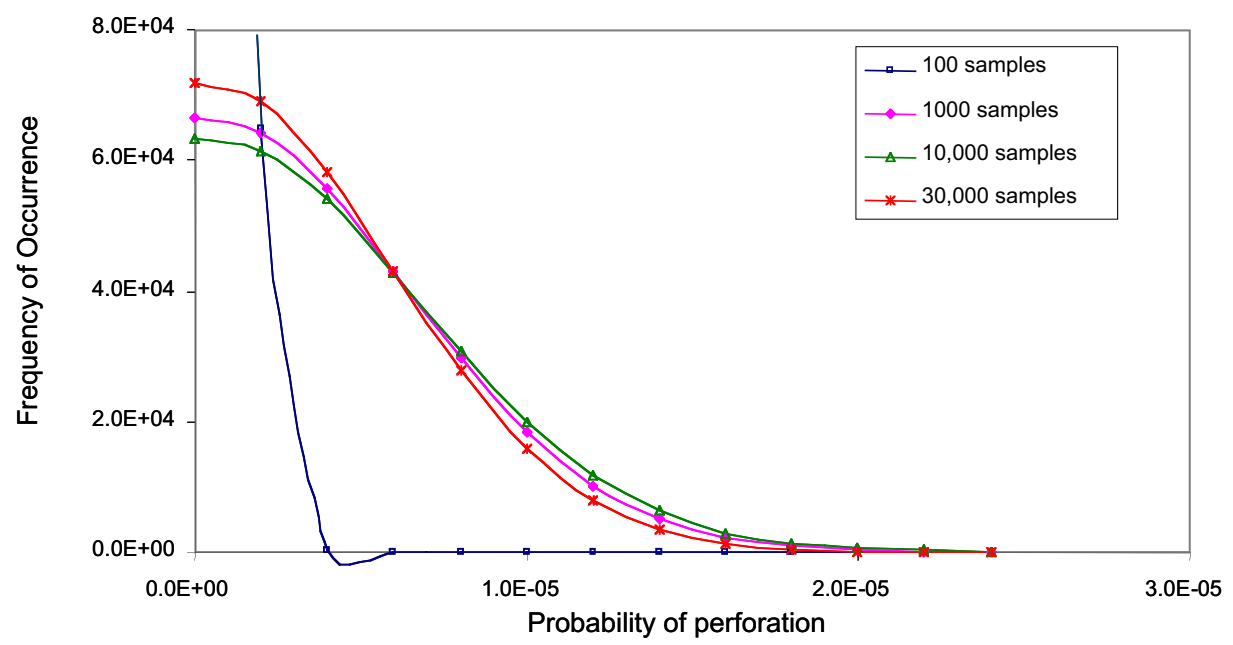

Figure 5.2. Converging pdf plots for increasing sample sizes for 2" vessel thickness simulation.

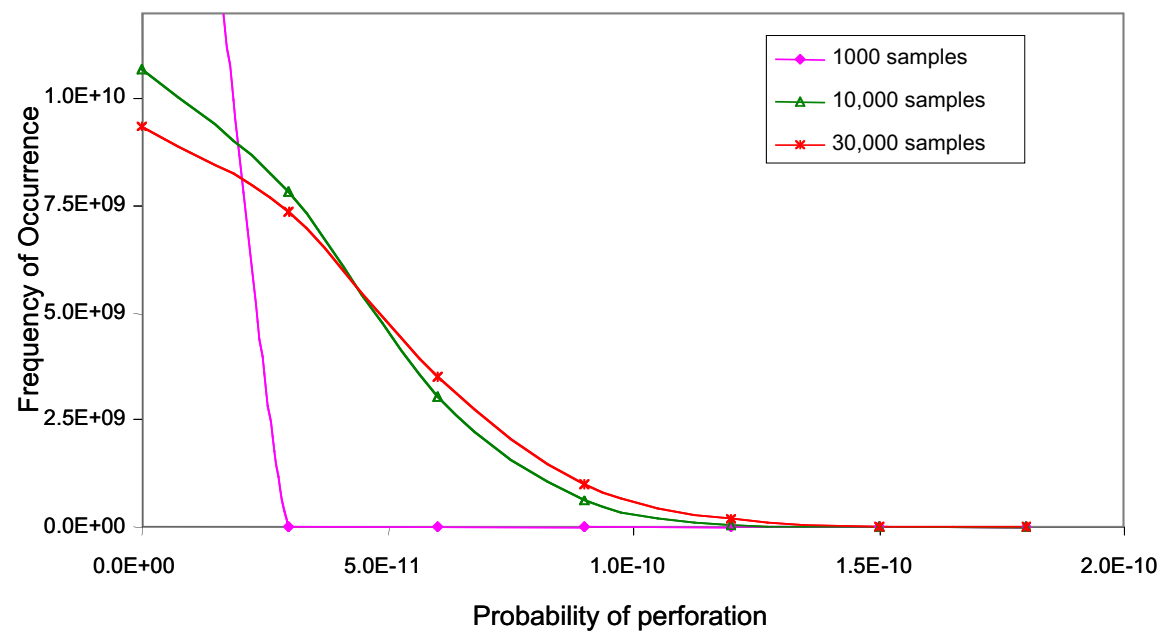

Figure 5.3. Converging pdf plots for increasing sample sizes for $5.25^{\prime \prime}$ vessel thickness simulation. 
While each vessel thickness simulation converges differently, they appear to converge to a steady solution near 30,000 samples. Figures 5.4 and 5.5 show the Gaussian pdf for 30,000 samples over the range from $\mu$ to $\mu+3 \sigma$ for the 1 " containment vessel's stochastic sampling simulation model. For these distributions, the $\mathrm{x}$-axis represents the results of the stochastic simulation. In other words, the $\mathrm{x}$-axis represents the probability of perforation. The normal pdf indicates the frequency for which various perforation probability events occur.

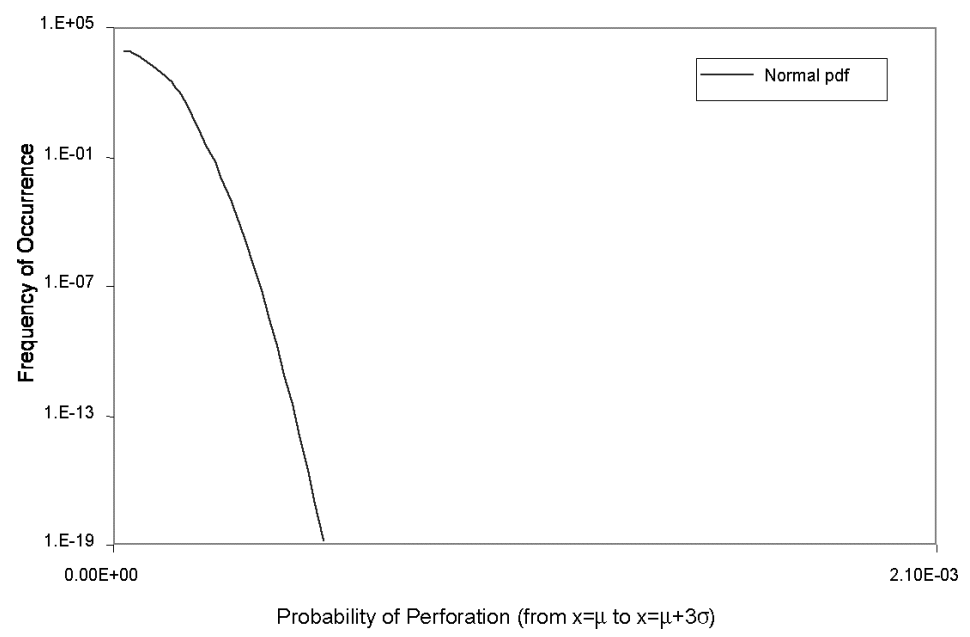

Figure 5.4. The probability density function for the 1 " vessel using 30,000 samples over the range from $\mu$ to $\mu+3 \sigma$.

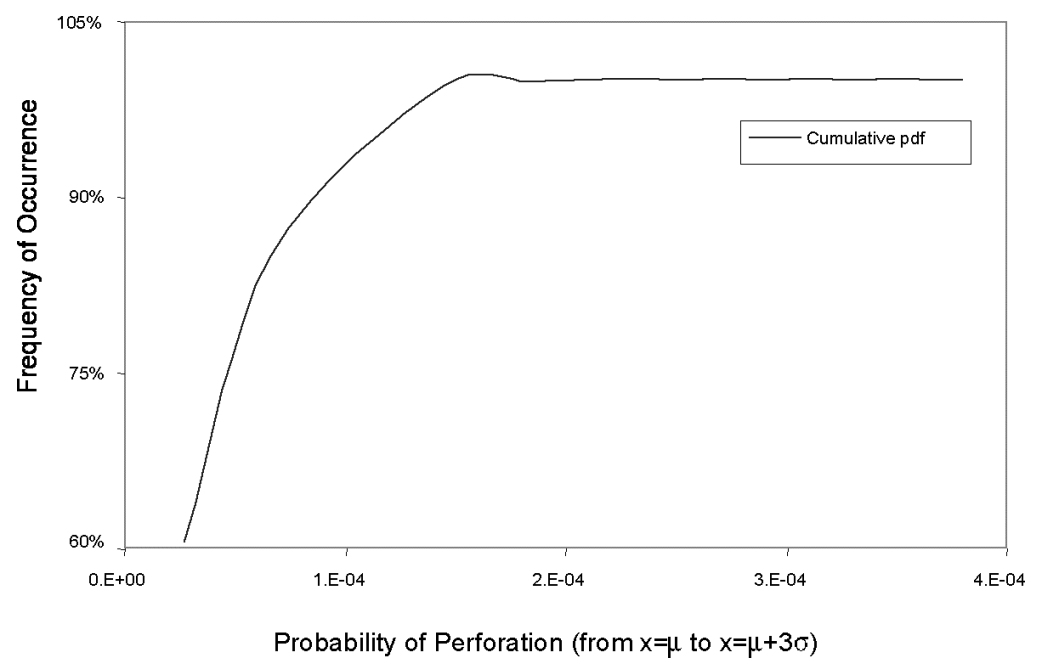

Figure 5.5. The cumulative probability density function for 30,000 samples over the range from $\mu$ to $\mu+3 \sigma$.

The six-sigma probability of perforation event has a frequency of occurrence of $2.77 \times 10^{-16}$. The probability of perforation associated with this event is

$$
P_{\text {WPP_ } 1}(\text { perforation })=4.98 \times 10^{-4} .
$$

While an event whose probability of perforation is $4.98 \times 10^{-4}$ with a frequency of occurrence equal to $2.77 \times 10^{-16}$ could be viewed as having little chance of happening, it may not be the ultimate metric for the probability of a DynEx failure occurring. Regardless, in the context of assessing simulation convergence, it is an informative metric. Another informative metric for convergence is a cumulative assessment of the likely fragment outcomes of a DynEx test. The 
cumulative distribution indicates that $99.99999999 \%$ of the fragment events have a probability of perforating the one inch thick vessel less than or equal to

$$
P_{99.9 \overline{9} \% \_1}(\text { perforation })=3.41 \times 10^{-4} .
$$

This value says that during a DynEx test all but $1.0 \times 10^{-9}$ events have a probability of perforation less than $3.41 \times 10^{-4}$. However, only the outliner events matter in the DynEx scenario because those are the ones that do damage. A DynEx failure is defined as one fragment penetrating the containment vessel. The cumulative effects do not capture the worst-case events.

The $95 \%$ confidence value is a standard metric in statistical analysis for measuring the stability and inherent confidence one has in a process. $P_{95 \%}$ provides a probability of perforation value for which $95 \%$ of the fragment events have an equal or lesser probability of occurring. The $95 \%$ confidence probability of perforation is

$$
P_{95 \%_{-} 1}(\text { perforation })=1.45 \times 10^{-4} .
$$

While this measure is a weak indicator of failure, it nonetheless provides a metric for assessing the convergence characteristics of the simulation analysis.

Figures 5.6 and 5.7 show the pdf and cumulative pdf for the 2" vessel thickness simulation using 30,000 samples. As before, the $x$-axis represents the results of the stochastic simulation, which is the probability a randomly selected fragment perforates the containment vessel wall. The range of the plots is taken from the mean of the distribution $\left(\mu=3.72 \times 10^{-7}\right)$ to $\mu$ plus six times the standard deviation $\left(\sigma=5.55 \times 10^{-6}\right)$. As indicated, the maximum probability of perforation at the worst probable point is

$$
P_{W P P_{-} 2}(\text { perforation })=3.36 \times 10^{-5} .
$$

The cumulative distribution indicates that $99.99999981 \%$ of the fragment events have a probability of perforation less than or equal to

$$
P_{99.9 \overline{9} \% \_2}(\text { perforation })=3.09 \times 10^{-5} \text {. }
$$

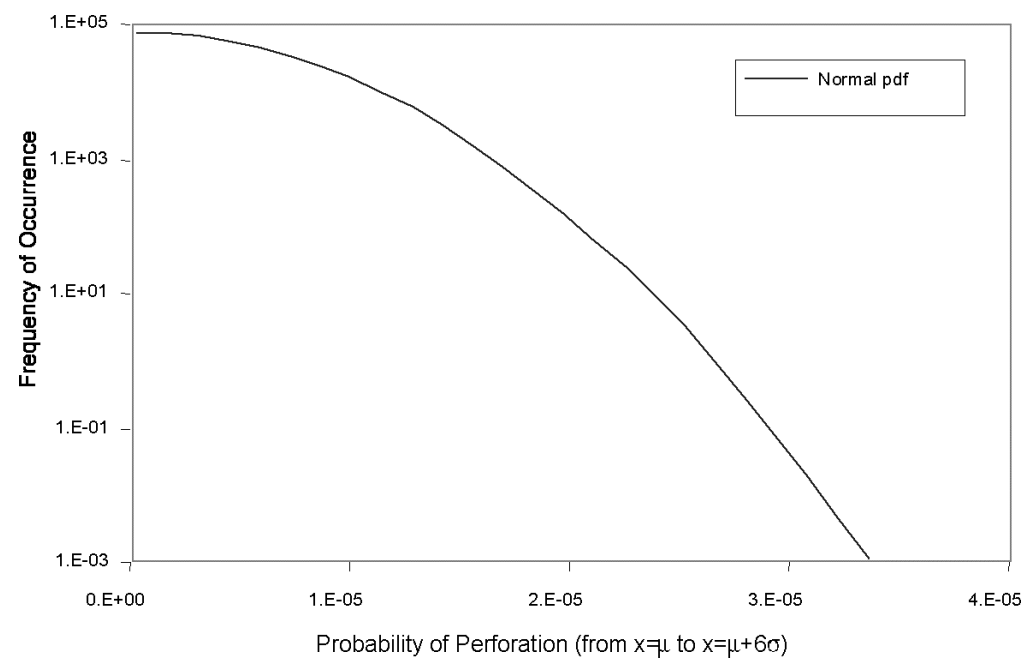

Figure 5.6. Probability density function for the 2 inch thick vessel using 30,000 samples over the range from $\mu$ to $\mu+6 \sigma$. 


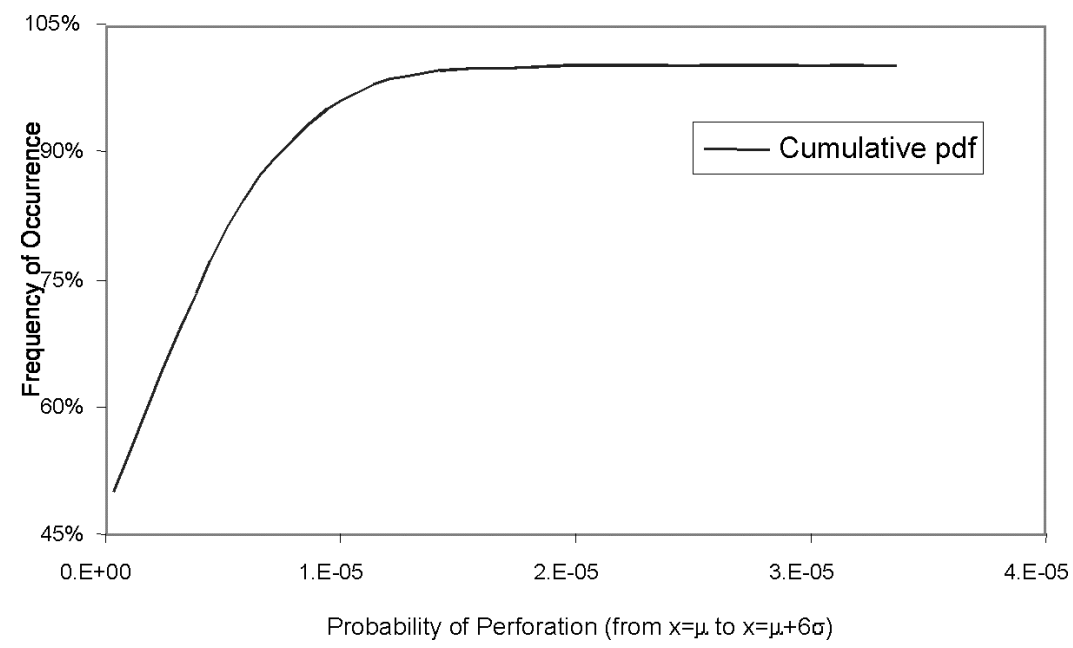

Figure 5.7. Cumulative probability density function for the 2 inch thick vessel using 30,000 samples over the range from $\mu$ to $\mu+6 \sigma$.

The $95 \%$ confidence value indicates that $95 \%$ of the fragment events have an equal or lesser probability of perforating a 2 -inch-thick vessel equal to

$$
P_{95 \% \_2}(\text { perforation })=1.15 \times 10^{-5} \text {. }
$$

Figures 5.8 and 5.9 show the pdf and cumulative pdf for the $5.25^{\prime \prime}$ vessel thickness simulation. The range of the plots is from the mean of the distribution $\left(\mu=2.10 \times 10^{-15}\right)$ to $\mu$ plus six times the standard deviation $\left(\sigma=4.26 \times 10^{-11}\right)$. As indicated, the probability of perforation at the worst probable point is

$$
P_{\mathrm{WPP}_{-} 3}(\text { perforation })=2.56 \times 10^{-10} .
$$

The cumulative distribution indicates that $99.99999981 \%$ of the fragment events have a probability of perforating the 5.25 inch thick vessel less than or equal to

$$
P_{99.9 \overline{9} \% \_3}(\text { perforation })=2.35 \times 10^{-10} \text {. }
$$

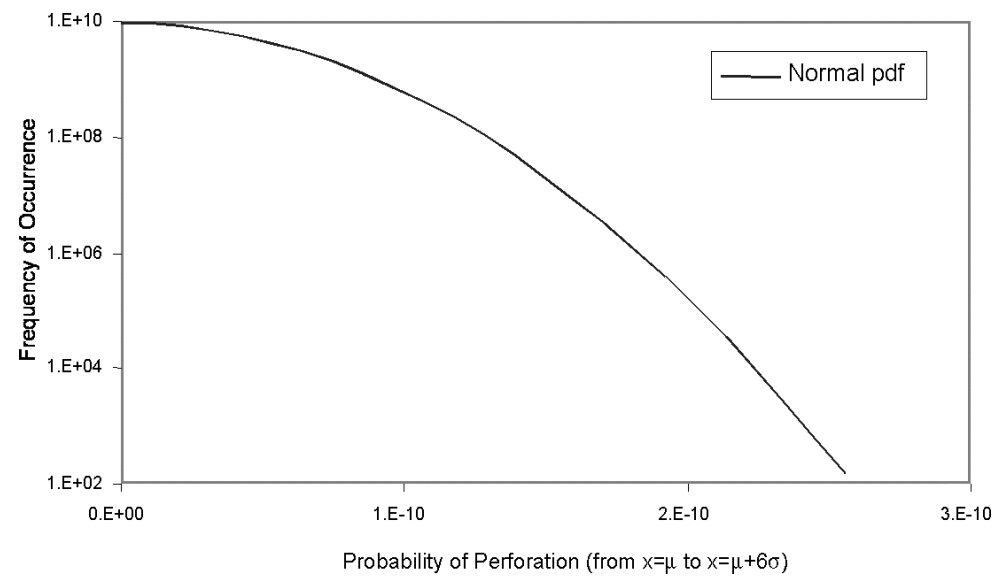

Figure 5.8. Probability density function for the 5.25 inch thick vessel using 30,000 samples over the range from $\mu$ to $\mu+6 \sigma$. 


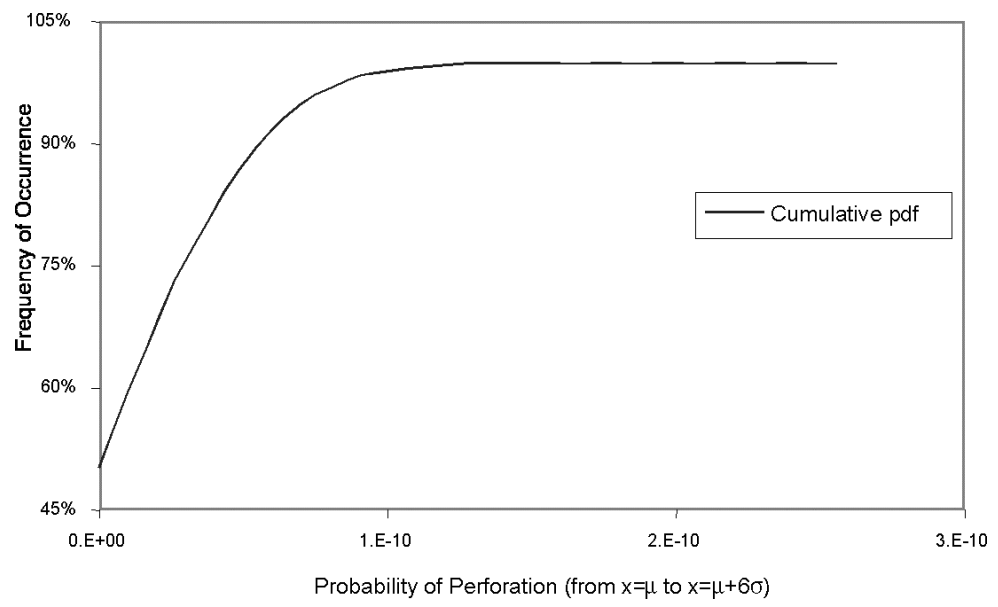

Figure 5.9. Probability density function for the 5.25 inch thick vessel using 30,000 samples over the range from $\mu$ to $\mu+6 \sigma$.

The $95 \%$ confidence value indicates $95 \%$ of the fragment events have an equal or lesser probability of perforating the 5.25-inch-thick vessel equal to

$$
P_{95 \% \_3}(\text { perforation })=8.54 \times 10^{-11} \text {. }
$$

For all three vessel thickness analyses, the worst probable point provides the most conservative estimate for the probability that a DynEx test results in failure. In all three analyses the spread between the $95 \%$ confidence value and the worst probable point is relatively small. This suggests that the outlier fragment events of most concern do not exist too far from the majority of the less probable events. This is an indicator of the stability the stochastic model.

The convergence study demonstrates that the stochastic model and sampling simulation have good convergence properties. One aspect of the stochastic model is that all fragment events sampled are possible. Since the output of a fragment event analysis is an estimate of the probability that the fragment would perforate the containment vessel, all resultant probability estimates are legitimate. The Latin hypercube method of stochastic sampling depends on the number of samples specified. The goal of a Latin hypercube simulation is to canvas as much of the possibility space as possible with the number of specified samples. This means that a 100 sample simulation and 30,000 sample simulation both attempt to canvas the possibility space, only they accomplish it by sampling different points.

With this in mind, the set of worst probable points for the different sampling scenarios in Table 5.1 all represent a result taken from the possibility space. Therefore the largest WWP in the set represents the most conservative estimate for the probability of a single fragment event resulting in perforation during a DynEx test. Table 5.4 contains the maximum WWP computed for each vessel thickness scenario, which in turn represents the most probable perforation event. In all cases the largest WWP is given by the 30,000 sample analysis, indicating that the more the possibility space is sampled, the more likely a worst case fragment event is sampled.

\section{TABle 5.4. MAXimum Worst Probable Point From All Simulations Performed}

\begin{tabular}{|c|c|c|}
\cline { 3 - 3 } \multicolumn{2}{c|}{} & $\begin{array}{c}\text { Maximum worst } \\
\text { probable point }\end{array}$ \\
\hline Vessel & $1 "$ & $2.20 \mathrm{E}-03$ \\
\cline { 2 - 3 } Thickness & $2 "$ & $1.55 \mathrm{E}-04$ \\
\cline { 2 - 3 } & $5.25 "$ & $2.50 \mathrm{E}-09$ \\
\hline
\end{tabular}


It is both tempting and appealing to think of the maximum worst probable point as being a conditional probability contingent on the event's frequency of occurrence. In this framework the multiplication rule for conditional probability would help to lower our estimate of a DynEx test's probability of failure in the following manner:

$$
P(\text { failure })=P(W P P) * F(\text { occurrence } \mid W P P),
$$

and

$$
\begin{aligned}
P_{1^{\prime \prime}}(\text { failure }) & =2.20 \times 10^{-3} * 3.22 \times 10^{-5}=7.33 \times 10^{-8}, \\
P_{2^{\prime \prime}}(\text { failure }) & =1.55 \times 10^{-4} * 3.22 \times 10^{-5}=5.16 \times 10^{-9}, \text { and } \\
P_{5.25^{\prime \prime}}(\text { failure }) & =2.50 \times 10^{-9} * 3.22 \times 10^{-5}=8.32 \times 10^{-14} .
\end{aligned}
$$

As argued at the conclusion of Chapter 4, this logic is artificial because the frequency at which the WPP occurs in the stochastic sampling simulation model for $N$ samples is not an accurate indicator of the frequency at which damaging fragment events occur during an actual DynEx test. Furthermore, if this logic were extended to embrace the replete Bayesian formulation, the conditional probability of failure for all $N$ samples would need to be summed. This again yields an artificial measure. The most conservative estimate of risk during a stochastic sampling simulation of a DynEx test seems to be the WPP, which is simply the maximum probability of failure found over the $\mathrm{N}$-sample events.

\subsection{Performing Multiple Simulations}

The results of a stochastic sampling simulation depend on both the number of random samples taken and the way parameter values are randomly selected. Simulations using different random selection criteria yield different results. Previously, a convergence analysis was performed using a fixed random sampling method. In other words, the seed of the random sampling tool remained the same as the number of samples increased. From the convergence analysis it was determined that thirty thousand samples were sufficient.

If the random sampling tool uses two different "seeds," then two different random variable sets are generated. In general, if $n$ different seeds are used, then $n$ unique random variable sets are generated. Each of these random variable sets could be thought of as a DynEx test simulation. Each time a physical DynEx test is performed, the response is different. The same is true each time a stochastic sampling simulation is performed using a different random sampling seed. Hence, performing $n$ simulations with uniquely different random sampling seeds is akin to modeling $n$ different DynEx tests.

Table 5.5 shows the results of performing 40 uniquely different stochastic sampling simulations for each of the three DynEx vessel thickness scenarios. The different random sampling seeds were the same for each of the three target thickness scenarios.

TABLE 5.5. Results OF FORTY UNIQUE StOCHASTIC SAMPLING SIMULATIONS MEASURED WITH RESPECT TO THEIR WORST PROBABLE POINTS

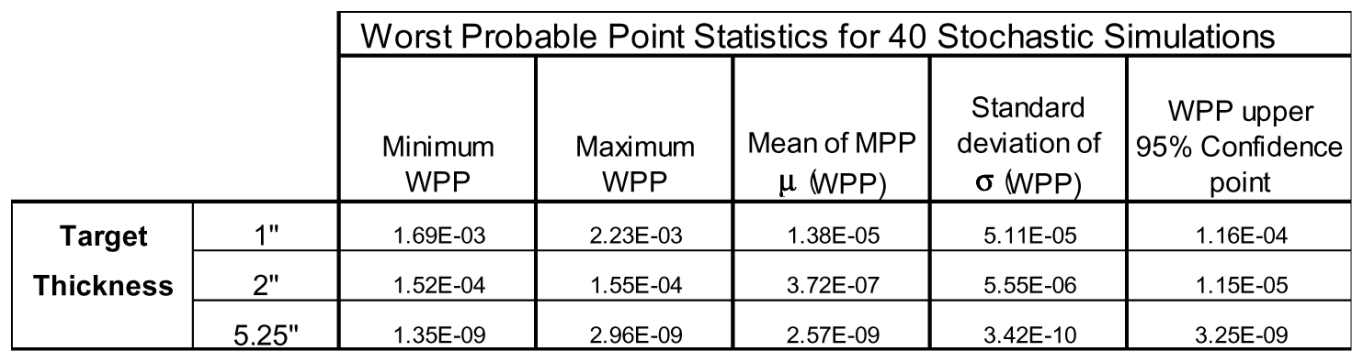


Comparing the results of Table 4.2 in Chapter 4, with the results of Table 5.5 shows there is not much variation between the forty different simulations. The worst probable points from the convergence study results of Table 4.2, don't change significantly from the results of forty different simulations. The 5.25" scenario changes to $4.6 \times 10^{-10}$, but the conclusions based on the difference remains unchanged. The $95 \%$ confidence point for the forty simulations indicates that $95 \%$ of the simulations have a maximum worst probable point less than or equal to $3.25 \times 10^{-9}$. The minimum worst probable point found in the forty simulations indicates that all forty simulations for each of the three target thickness scenarios fail to meet their performance criteria. Appendix $\mathrm{C}$ contains the results of the forty different sampling simulations used for each of the three target thickness scenarios.

\section{ASSESSING MARGIN AND SAFETY}

Seldom is it sufficient to define a product's performance using only a measure of failure. While knowing the probability of failure (i.e., the reliability) is paramount to DynEx decision-making, having a measure of the overall quality of the DynEx vessel relative to performance is also useful. Margin is an industry measure of the "goodness" of an engineered product relative to performance requirements. Generally based in statistical process control, margin is used to convey how near a product is to having a significant decrement in performance. Safety assessments invoke margin by measuring performance relative to acceptable risk. There are several product assessment measures. Three discussed here are

1. Capability ratio, or percent of specification

2. Safety index $(\beta)$, and

3. Engineering index.

The engineering index approaches product margin as a measure of quality and the time rate of change, specifically, the time until a products margin is full diminished. [Dolin 2002] Margin measures how close a product is to a "performance cliff." For example, it may be known that when a particular condition exists, the probability of failure is significant. Often a condition's existence can be estimated. While it's important to know when a product's probability of failure is significant, it is equally important to understand how the probability of failure is approached as the particular condition is approached. Margin measures how product performance behaves relative to defined metrics. For example, the probability of failure for a DynEx test is written as $P$ (failure), where $P$ (failure) is defined as the event

$$
\text { failure }=\text { a fragment perforation occurs. }
$$

If the probability of failure is small, it can be represented as

$$
P(\text { failure }) \rightarrow \varepsilon,
$$

where $\varepsilon$ is a small number, suggesting there is little risk of failure given the stated performance conditions. Understanding the DynEx design's probable response can be enhanced by computing margin to provide an indication of how close $\varepsilon$ is to changing significantly. [Dolin 2002] Given that fragment perforation is the DynEx vessel's performance condition of interest, failure is a function of many variables, including vessel thickness, fragment geometry, and fragment velocity. The optimum condition exists when the partial derivative of $P$ (failure) is zero, i.e.,

$$
\frac{\partial P(\text { failure })}{\partial(\text { vars })}=\frac{\partial \varepsilon}{\partial(\text { vars })}=0 .
$$

This condition exists when the parameters are not constant. The next best optimum condition occurs when

$$
\frac{\partial P(\text { failure })}{\partial(\text { vars })}=\frac{\partial \varepsilon}{\partial(\text { vars })}=\text { constant }
$$


This condition implies a linear correlation between the manner in which the $P$ (failure) is changing with respect to changes in the variables. When the rate of change in $\varepsilon$ is known to be a linear function of the variables of interest, margin can be estimated, and predictions can be made about when $\varepsilon$ will experience a significant change. The least optimal condition is when

$$
\frac{\partial P(\text { failure })}{\partial(\text { vars })}=\frac{\partial \varepsilon}{\partial(\text { vars })}=\mathrm{f}^{n}(\text { vars }) \text {, }
$$

where $\quad \mathrm{f}^{n}($ vars $) \equiv$ nonlinear function of the variables.

Finding the value for the partial derivative is nontrivial. Convenient closed form solutions of the kind given in Eq. (6.4) may not always be available. In those cases other techniques must be used to established the rate at which margin is diminishing.

Knowing $P($ failure) is acceptable provides no insight into whether it's rapidly approaching some rare event regime or if the response mean is nearing an important threshold. Margin can be used to indicate when a small change in a design parameter (i.e., the amount of high explosive) significantly impacts performance characteristics. However, this requires knowledge about the performance stability, which is an aspect of the performance capability ratio $C_{p}$, often referred to as simply the capability. [Kane 1986]

Margin is more than a measure of a sensitivity. It provides an estimated response distribution relative to specified performance requirements. At the core of all three product assessment metrics are the design or performance requirements. Design/manufacturing requirements include things like dimensional tolerance or material inhomogeneity. Performance requirements can also measure functional aspects of a design, including response limits in given environments or operational scenarios.

The DynEx design contains a performance requirement specifying that no fragments perforate the containment vessel. However, this requirement is absolute, deterministic, and unachievable in a strict mathematical sense because it can never be known with certainty when the requirement is met. Because of this, the fragment perforation requirement has been relaxed and restated probabilistically. The revised requirement states that the probability of a fragment perforating the containment vessel cannot exceed $1 \times 10^{-6}$.

Recognizing the possibility that a fragment event might result in perforation always exists led DynEx designers to encase the containment vessel with a secondary safety vessel. Ideally the safety vessel is designed so fragment events never result in perforation of both the containment vessel and the safety vessel. Again, such an absolute and deterministic requirement is unachievable in a strict mathematical sense. This reality led DynEx designers to restate the performance requirement probabilistically to say that the probability that a fragment perforates both the containment and safety vessels cannot exceed $1 \times 10^{-9}$. These performance requirements become the two performance limits for which margin is measured against.

\subsection{Likelihood of Occurrence Results Relative to Performance Requirements}

Figures 6.1, 6.2, and 6.3 provide graphical depictions for the relationship between the likelihood of occurrence simulation predictions and the performance specification limits. Figure 6.1 shows the cumulative probability of perforation relative to the cumulative probability that various geometries occur. Notice that only rare geometry events have a probability of perforation exceeding the performance requirement. Only $0.852 \%$ of the probable geometries result in a probability of perforation exceeding the performance limit. This translates to $0.882 \%$ cumulative probability of failure. When discrete fragment events are considered, the maximum probability that a single fragment perforates the 1 " thick containment vessel is 0.00374 . Another way to phrase these results is to say that the worst probable fragment event has a $0.374 \%$ probability of perforating the containment vessel, and overall there exists a $0.882 \%$ probability of perforation 
occurring. The conclusion given the performance requirement is that the $1^{\prime \prime}$ containment vessel has zero margin and will not contain a DynEx test.

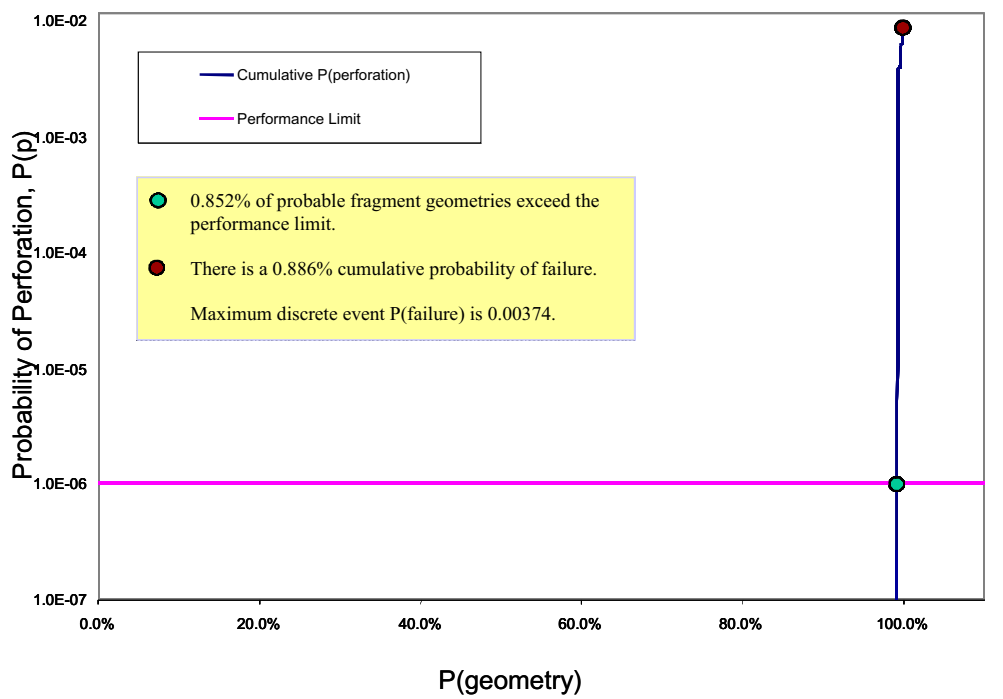

Figure 6.1. Likelihood of occurrence predictions for a 1"containment vessel relative to the probability of different geometries.

Figure 6.2 shows the probability of perforation when a 2" thick vessel is used to contain a DynEx test. Notice the performance requirement is the same as shown in Figure 6.1. Now though, the probability of perforation relative to the probable geometries is significantly less. When a 2" containment vessel is used, only $0.0069 \%$ of the probable geometries possess probabilities of perforation exceeding the performance requirement. There is a $0.00152 \%$ cumulative probability that a fragment perforates the containment vessel. The worst case discrete fragment event has $0.00067 \%$ probability of perforation. The conclusion of this likelihood of occurrence simulation is that the $1^{\prime \prime}$ containment vessel performs better and the 2 " thick containment vessel has zero margin and will not contain a DynEx test.

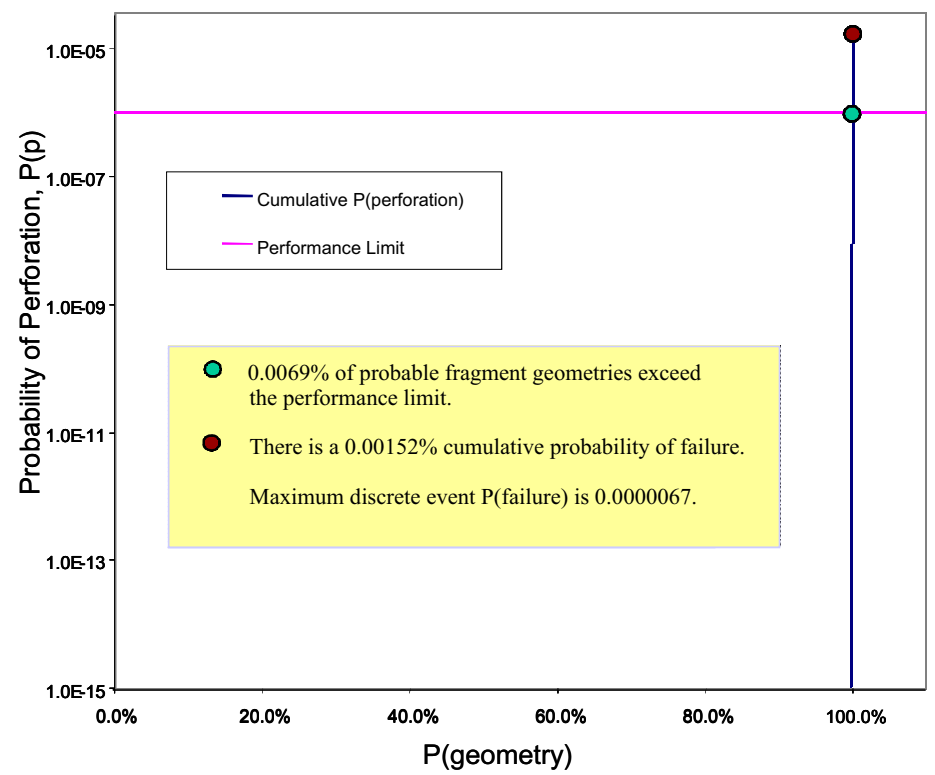

Figure 6.2. Likelihood of occurrence predictions for a 2"containment vessel relative to the probability of different geometries. 
Figure 6.3 shows the probability of perforation when a 5.25" thick vessel is used to contain a DynEx test. This thickness constitutes a 2" thick containment vessel encased by a 3.25 " thick safety vessel. We know from the previous assessment that the 2" thick vessel probably won't contain the DynEx test fragments. We are interested in understanding the probability that the containment vessel plus the safety vessel provide sufficient containment. The performance requirement is that the cumulative probability of perforation cannot exceed $1.0 \times 10^{-9}$. As shown, $0.0 \%$ of the probable geometries exceed this performance requirement. There is, however, still a $1.231 \times 10^{-11} \%$ cumulative probability of failure. The worst-case discrete fragment event has $1.054 \times 10^{-11} \%$ probability of perforation. The conclusion of this likelihood of occurrence simulation is that the 2 " thick containment vessel encased by a $3.25^{\prime \prime}$ thick safety vessel performs adequately, given the specified performance requirement.

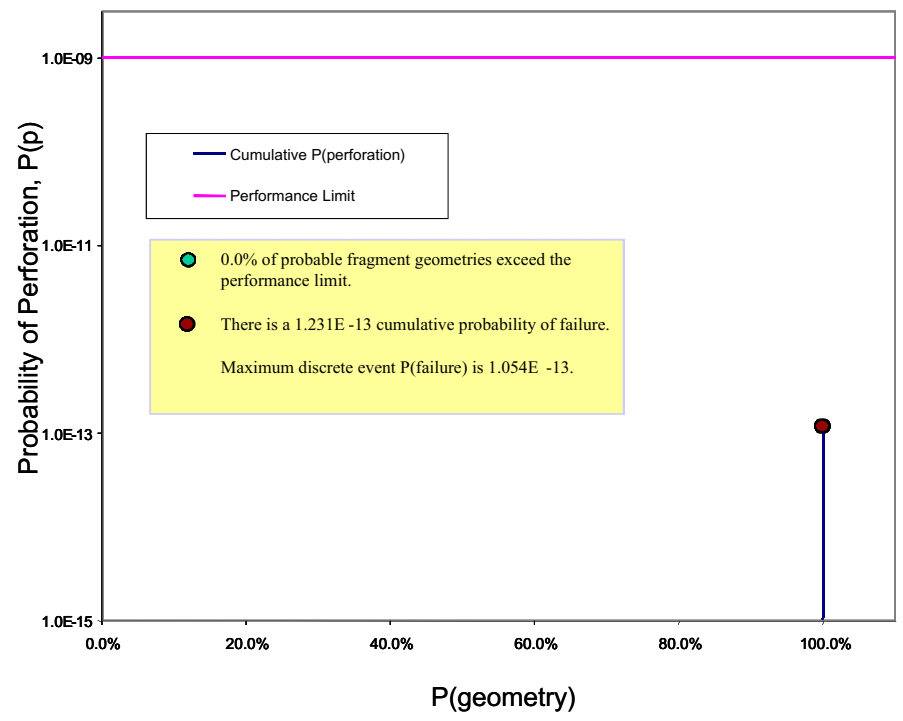

Figure 6.3. Likelihood of occurrence predictions for a 5.25" vessel thickness relative to the probability of different geometries occur.

\subsection{Stochastic Sampling Simulation Results Relative to Performance Requirements}

Figures 6.4, 6.5, and 6.6 provide graphical depictions of the relationship between the stochastic sampling simulation predictions and the performance specification limit. Figure 6.4 shows the lognormal probability of failure distribution resulting from the stochastic sampling simulation of a 1" thick containment vessel stochastic sampling simulation and its performance limit. A lognormal probability distribution function is used to describe the probability of failure relative to the fragment geometry's frequency of occurrence. The distribution is plotted through the sixsigma events. Notice the performance requirement, often referred to as an upper safety limit (USL), is left of the stochastic sampling probability distribution mean.

The worst probable point (WPP) is defined as the discrete fragment event having the highest probability of perforation. While the WPP event is possible, its occurrence is extremely rare. Because the USL is left of the stochastic sampling mean, there is no margin. Hence, the 1" thick containment vessel does not contain the DynEx test fragments.

Figure 6.5 shows the lognormal probability of failure distribution resulting from the stochastic sampling simulation of a 2" thick containment vessel and the USL curves. The lognormal probability distribution is plotted through the six-sigma fragment events. The worst probable point (WPP) is defined as the discrete fragment event having the highest probability of perforation. While the WPP event is possible, it is extremely rare. The USL is to the right of the 
stochastic sampling mean. This means that most of the sample events end in success. However, a significant number of events end in failure. Hence, there is no margin, and based on the Stochastic Sampling simulation results and the performance requirement (USL), the 2" thick containment vessel does not contain the DynEx test fragments.

Figure 6.6 shows the lognormal probability of failure distribution resulting from the stochastic sampling simulation of a 5.25" thick vessel and the USL. This simulation depicts a 2 " thick containment vessel encased by a $3.25^{\prime \prime}$ safety vessel. The lognormal probability distribution is plotted through the six-sigma events. While the WPP event is possible, it is extremely rare. For this stochastic simulation the USL is to the right of the six-sigma event. In a typical process control analysis, this means margin exists. However, in the strict definition of failure stated for the DynEx design, the Stochastic Sampling simulation predicts failure. Hence, the 2" thick containment vessel encased by a $3.25^{\prime \prime}$ safety vessel probably does not contain the DynEx test fragments.

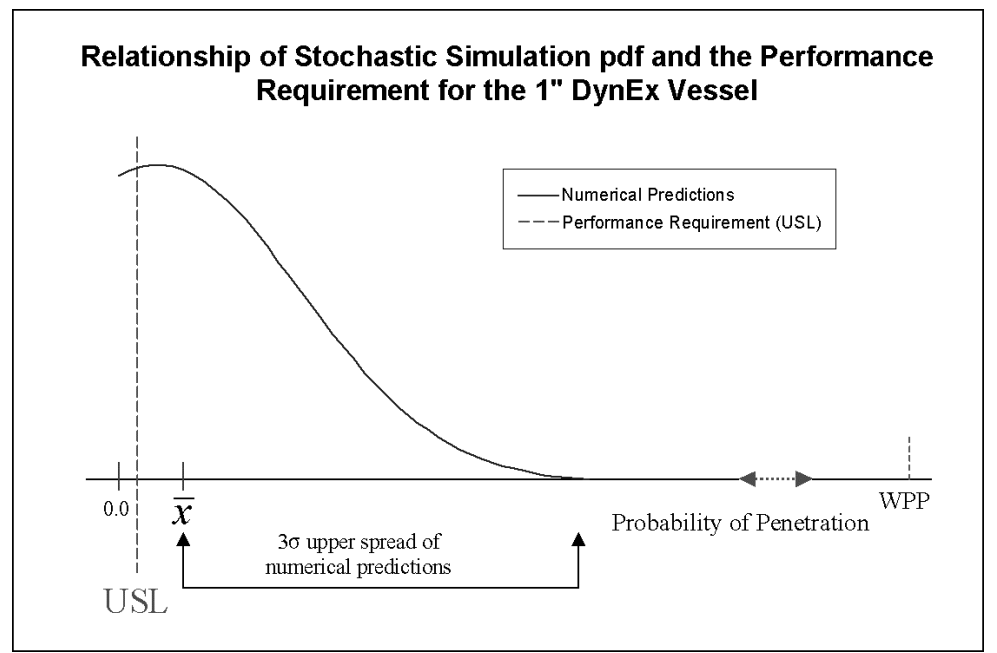

Figure 6.4. Stochastic sampling simulation predictions using a 1" thick vessel relative to the probability of different geometries occur.

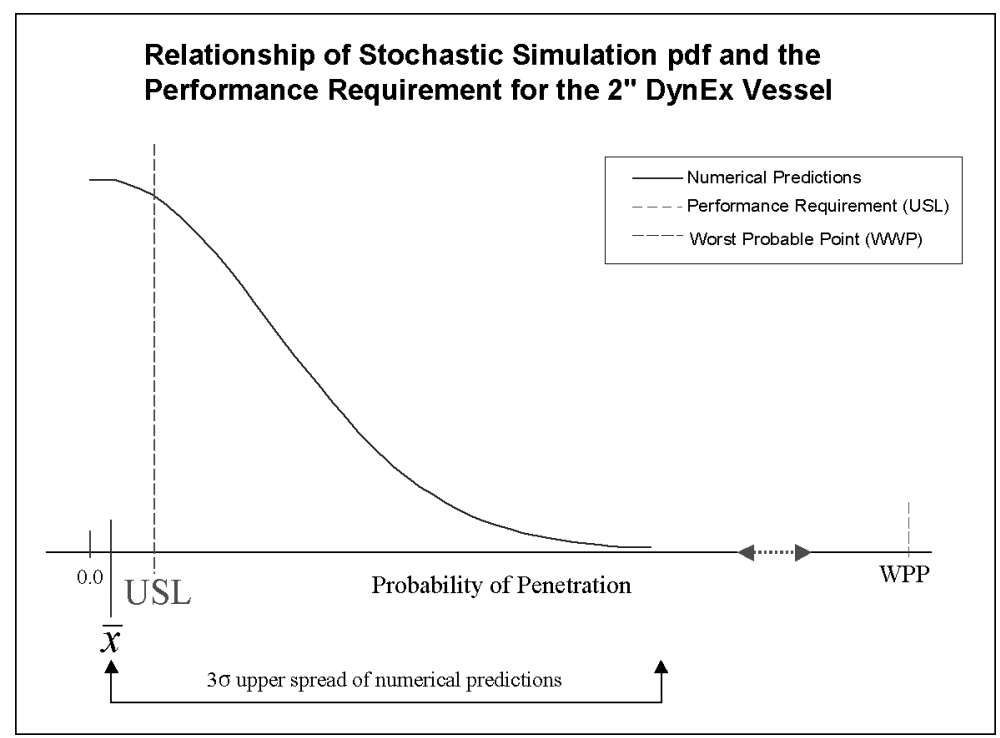

Figure 6.5. Stochastic sampling simulation predictions using a 2" thick vessel relative to the probability of different geometries occur. 


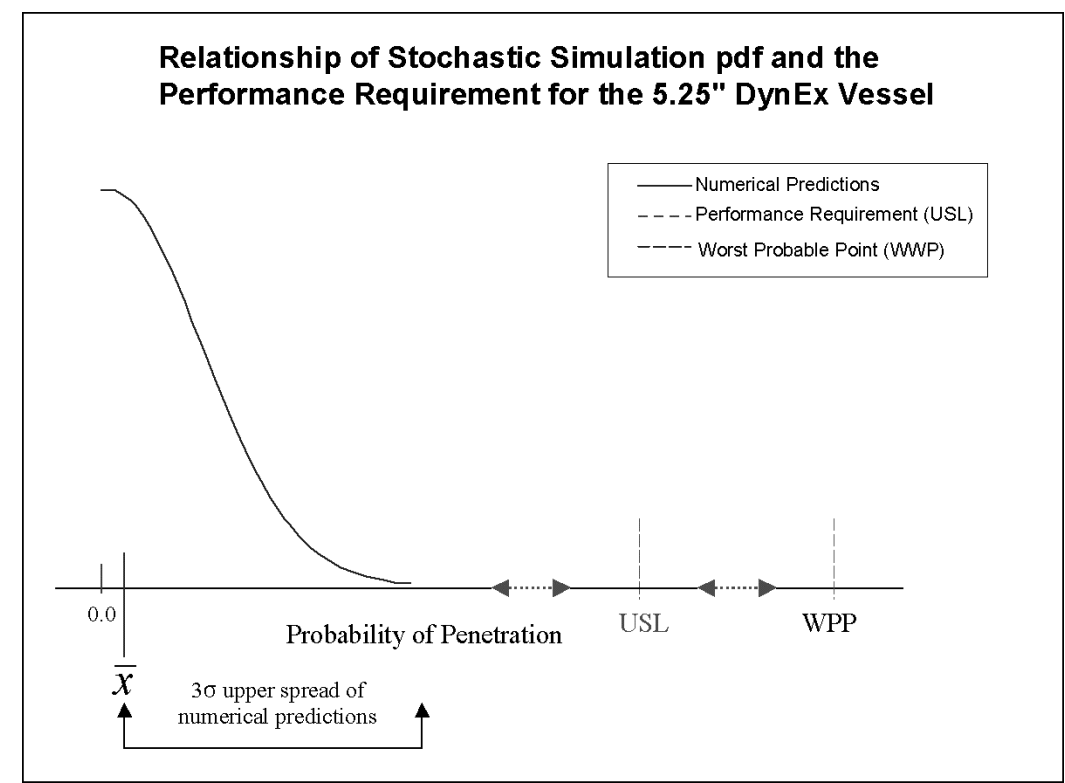

Figure 6.6. Stochastic sampling simulation predictions using a 5.25" vessel thickness relative to the probability of different geometries occur.

Notice that the plots used to depict the Likelihood of Occurrence simulation results are different than those used to depict the Stochastic Sampling simulation results. This is because these two simulation techniques model different probability problems. The Likelihood of Occurrence simulation models the entire DynEx test as an event, while the Stochastic Sampling simulation models each fragment configuration as an event. Because of this distinction, the probability formulations are different, and making comparisons between the two modeling methods is not direct.

\subsection{Capability Ratio-Percent of Specification}

The term "capability ratio," was coined by Charbonneau and Webster in 1978. The capability ratio is also referred to as the percent of specification, where

$$
C_{p}=\frac{\text { allowable process spread }}{\text { actual process spread }}
$$

and

$$
\% \text { of specification }=100 \frac{1}{C_{p}} .
$$

In the DynEx simulations,

$$
C_{p}=\frac{U S L-\mu}{3 \sigma}=\frac{U S L-\bar{x}}{3 \sigma} .
$$

The capability ratio and percent of specification are measures of a product's goodness when an acceptable level of failure can be tolerated. The capability ratio and percent of specification were initially developed for use in process control to improve manufacturing processes. [Kane 1986] They are co-opted here to measure performance based on numerical simulation relative to specified performance requirements. These measures traditionally assume events beyond the sixsigma regime are outside the scope of control. 
However, in the DynEx situation it is precisely these rare events we seek to quantify. The capability ratio and percent of specification can be used for this quantification. Based on values for $C_{p}$ and percent of specification, conclusions can be made. For instance, when

1. $C_{p}<0, \quad$ the performance limit is less than the mean of the sample data and zero margin exists,

2. $0 \leq C_{p} \leq 1$, the predicted performance out to the six-sigma event is less than the performance requirement and no margin exists, and

3. $C_{p}>1, \quad$ its value is called the margin.

In the limit, as the probability of failure approaches zero with respect to USL, $C_{p}$ approaches infinity. The opposite holds for the percent of specification. When the absolute value of the percent of specification is greater than one, no margin exists. In the limit as the probability of failure approaches zero with respect to USL, the percent of specification approaches zero.

Table 6.1 shows the capability ratio and percent of specification values for the three Likelihood of Occurrence simulations. The capability ratio for both the 1 " and 2" thick vessel simulations are less than one, so no margin exists. The capability ratio for the $5.25^{\prime \prime}$ thick vessel simulation is very large, implying a large margin. The capability ratio and percent of specification calculations indicate that the 1" and 2" containment vessels do not contain the DynEx test fragments but that the 2 " containment vessel encased by the $3.25^{\prime \prime}$ safety vessel does.

TABLE 6.1. CAPABILITy RATIOS AND PERCENT OF SPECIFICATION VALUES FOR LIKELIHOOD OF OCCURRENCE SIMULATIONS

\begin{tabular}{|c|c|c|c|c|c|}
\cline { 2 - 6 } \multicolumn{1}{c|}{} & \multicolumn{5}{c|}{ Results of Likelihood of Occurrence Simulation } \\
\hline $\begin{array}{c}\text { Target } \\
\text { Thickness }\end{array}$ & $\begin{array}{c}\text { Upper } \\
\text { Specification } \\
\text { Limit (USL) }\end{array}$ & $\begin{array}{c}\mu \text { of Sampled } \\
\text { Fragment } \\
\text { Events }\end{array}$ & $\begin{array}{c}\sigma \text { of Sampled } \\
\text { Fragment } \\
\text { Events }\end{array}$ & $\begin{array}{c}\text { Capability } \\
\text { Ratio } \\
\text { (Cp) }\end{array}$ & $\begin{array}{c}\% \text { of } \\
\text { Specification }\end{array}$ \\
\hline $1^{\prime \prime}$ & $1.00 \mathrm{E}-06$ & $2.22 \mathrm{E}-04$ & $7.12 \mathrm{E}-04$ & -0.10 & -968.202 \\
\hline $2^{\prime \prime}$ & $1.00 \mathrm{E}-06$ & $3.81 \mathrm{E}-07$ & $1.49 \mathrm{E}-06$ & 0.14 & 724.040 \\
\hline $5.25^{\prime \prime}$ & $1.00 \mathrm{E}-09$ & $3.08 \mathrm{E}-15$ & $1.67 \mathrm{E}-14$ & 19963.74 & 0.005 \\
\hline
\end{tabular}

Table 6.2 shows the capability ratio and percent of specification values for the three Stochastic Sampling simulations. For the 1 " thick vessel simulation the performance requirement is less than the mean of the sample data, which results in a negative capability ratio. Hence, no margin exists. The capability ratio for the $2^{\prime \prime}$ thick containment vessel simulation is between zero and one, so no margin exists. The capability ratio for the 2 " thick containment vessel plus the $3.25^{\prime \prime}$ thick safety vessel simulation is small, implying little margin exists. The results of the capability ratio and percent of specification calculations indicate that the 1" and 2" containment vessels do not contain the DynEx test fragments. The results suggest that the 2" containment vessel encased by the 3.25" safety vessel could contain the DynEx test fragments but probable won't.

TABle 6.2. CAPABILITY RATIOS AND PERCENT OF SPECIFICATION VALUES FOR THE STOCHASTIC SAMPLING SIMULATIONS

\begin{tabular}{|c|c|c|c|c|c|}
\hline \multirow[b]{2}{*}{$\begin{array}{c}\text { Target } \\
\text { Thickness }\end{array}$} & \multicolumn{5}{|c|}{ Results of Stochastic Sampling Simulation } \\
\hline & $\begin{array}{c}\text { Upper } \\
\text { Specification } \\
\text { Limit (USL) }\end{array}$ & $\begin{array}{c}\mu \text { of Sampled } \\
\text { Fragment } \\
\text { Events }\end{array}$ & $\begin{array}{c}\sigma \text { of Sampled } \\
\text { Fragment } \\
\text { Events }\end{array}$ & $\begin{array}{l}\text { Capability } \\
\text { Ratio } \\
\text { (Cp) }\end{array}$ & $\begin{array}{c}\% \text { of } \\
\text { Specification }\end{array}$ \\
\hline $1^{\prime \prime}$ & $1.00 \mathrm{E}-06$ & $1.38 \mathrm{E}-05$ & $5.11 \mathrm{E}-06$ & -0.083 & -1197.89 \\
\hline $2 "$ & $1.00 \mathrm{E}-06$ & 3.72E-07 & $5.55 \mathrm{E}-06$ & 0.038 & 2648.89 \\
\hline $5.25^{\prime \prime}$ & $1.00 \mathrm{E}-09$ & $2.10 \mathrm{E}-13$ & $4.26 \mathrm{E}-11$ & 7.823 & 12.78 \\
\hline
\end{tabular}




\subsection{Safety Index $(\beta)$}

A product's performance can be measured as a function of risk rather than performance. One way to think about risk is as a probability of failure. [Wirsching 1992] If

$$
\begin{aligned}
& p_{0}=\text { target risk or probability of failure, and } \\
& p_{f}=\text { the probability of failure estimated from analysis or simulation, }
\end{aligned}
$$

then for a safe design,

$$
p_{f} \leq p_{0}
$$

If a safety index is defined such that

$$
\begin{aligned}
\beta_{0} & =\text { the target safety index } \\
\beta & =\text { the safety index estimated from analysis or simulation, } \\
\beta_{0} & =\Phi^{-1}\left(p_{0}\right), \text { and } \\
\beta & =\Phi^{-1}\left(p_{f}\right)
\end{aligned}
$$

where $\Phi$ is the standard normal cumulative density function (CDF), for a safe design,

$$
\beta \geq \beta_{0}
$$

Determining appropriate values for $p_{0}$ and $\beta_{0}$ is a matter of subjective interpretation often referred to as establishing risk criteria. There is no objective formula for assigning a maximum allowable probability of failure, or minimum allowable safety index. There are however, important factors to consider in developing risk criteria. For example,

1. Is there a public safety issue?

2. Would failure impact the environment?

3. Would there be a loss of credibility (reputation) resulting from public reaction to a failure?

Choosing an allowable risk value is difficult. To assess the extent of a risk factor for the DynEx design, we can consider values other industries have adopted. For general structural design a recommended target safety index is $\beta_{0}=3.0$. This corresponds to a desired $p_{0}=1.0 \times 10^{-3}$ probability of failure. This value is also commonly used in mechanical system design. The International Civil Aviation Organization (ICAO) recommends a maximum probability of catastrophic failure in an aircraft's service life to have a maximum value of $p_{0}=1.0 \times 10^{-5}$. Motorola's famous $6 \sigma$ quality in manufactured units, which is more a qualitative metric than quantitative, translates into 3.4 defects in a million for processes dominated by normal distributions.

All the branches of the military use the following levels of acceptable risk in testing weapons systems: [Keese 1989]

- $\quad p_{0}$ (nonparticipant fatality)

- $p_{0}$ (participant fatality)

- $\quad p_{0}$ (serious damage to a government installation)

$$
\begin{aligned}
& =1.0 \times 10^{-6}, \\
& =1.0 \times 10^{-5}, \text { and } \\
& =1.0 \times 10^{-3} .
\end{aligned}
$$

The value assigned to target risk expresses a level to strive for in either design or within broader decision making. This is different than assessing the risks that actually exist. For example, the chances of getting killed in an automobile accident in the United States are $1.0 \times 10^{-6}$ per hour of 
exposure. The same probability of dying exists in commercial airline travel. However, the United States Air Force reports that the accident rate in their C-130 aircraft is $1.0 \times 10^{-5}$ per hour of exposure. These values represent actual risk.

This means traveling by car is just as safe as commercial airline travel when risk is measured relative to hours of exposure. Both are an order of magnitude more safe than flying in an Air Force C-130. However, public perception is that commercial airline travel is significantly safer than automobile travel. This perception is valid for long distance travel. If the distance between New York and Los Angles is 3000 miles and a car averages $60 \mathrm{mph}$, then there are 50 hours of exposure in a one-way automobile trip. If an airplane averages $400 \mathrm{mph}$, there are 7.5 hours of exposure in a commercial airline trip. This means the risk of injury is greater for the automobile trip based on the fact that it takes longer to travel by car.

In general the target risks used in design or decision-making are lower than either the actual risk or the perception of what the actual risk is. Risk is often a matter of perception. For example, in 1991 there were three fatalities in an estimated one million bungee jumps. This means the chances of dying during a C-130 aircraft ride are significantly greater than they are in bungee jumping. Ironically, most people when offered the proposition of either riding in an Air Force C-130 or bungee jumping would likely choose the C-130 ride, feeling it is safer. Society generally perceives risk in the following way:

- $10^{-6}$ No great concern. Aware accidents can occur but believe it would never happen to them.

- $10^{-5}$ People recognize the hazards and are willing to accept some inconvenience to avoid them. For example, childproof safety bottles. People warn children of possible danger (e.g., drowning or poisoning) but do not avoid the hazardous situations.

- $10^{-4}$ Willing to spend public money to control hazards. Safety slogans are used to show an element of fear (e.g., "only you can prevent forest fires").

- $10^{-3}$ Unacceptable to everyone. Immediate action should be taken to reduce the hazard.

Consequence is another aspect of safety, which is often highly coupled with risk. The Norwegian agency responsible for certifying large-scale structures defines three failure consequences:

1. Very Serious: large possibility of personal injuries/fatalities, significant environmental impact, or dramatic economic ramifications.

2. Serious: possibility of personal injuries/fatalities, environmental impact, or economic ramifications.

3. Not Serious: small possibility of personal injuries/fatalities, negligible environmental impact, or minor economic ramifications.

Table 6.3 shows the risk assessment specified in the Federal Aviation Administration's requirement for the service life of an aircraft. [FAA] Notice that an aircraft service life is defined by the most probable events occurring most frequently and having minor consequence. Conversely, events with catastrophic consequence are extremely improbable and their rate of occurrence is virtually nonexistent. These high risk/high consequence events have the same probability of failure as that specified for the combined DynEx containment plus safety vessels. In the DynEx design, the target probability of failure for the containment vessel is $p_{0}=1.0 \times 10^{-6}$. For the combined $2^{\prime \prime}$ thick containment vessel encased by the 3.25 " thick safety vessel, the target probability of failure is $p_{0}=1.0 \times 10^{-9}$. 
TABLE 6.3. JAR-25 RELATIONSHIP BETWEEN PROBABILITY AND SEVERITY OF EFFECTS

\begin{tabular}{|c|c|c|c|}
\hline Probability & $\begin{array}{l}\text { Category of } \\
\text { Effect }\end{array}$ & Occurrence & $P$ (failure) \\
\hline $\begin{array}{l}\text { Probable } \\
\text { Improbable } \\
\text { Extremely } \\
\text { Improbable }\end{array}$ & $\begin{array}{c}\text { Minor } \\
\text { Major } \\
\text { Hazardous } \\
\text { Catastrophe }\end{array}$ & $\begin{array}{l}\text { Frequent } \\
\text { Reasonably } \\
\text { Probable } \\
\text { Remote } \\
\text { Extremely } \\
\text { Remote }\end{array}$ & $\begin{array}{r}1.00 \mathrm{E}+00 \\
1.00 \mathrm{E}-01 \\
1.00 \mathrm{E}-02 \\
>1.00 \mathrm{E}-03 \\
<1.00 \mathrm{E}-03 \\
1.00 \mathrm{E}-04 \\
>1.00 \mathrm{E}-05 \\
<1.00 \mathrm{E}-05 \\
1.00 \mathrm{E}-06 \\
>1.00 \mathrm{E}-07 \\
<1.00 \mathrm{E}-07 \\
1.00 \mathrm{E}-08 \\
>1.00 \mathrm{E}-09 \\
<1.00 \mathrm{E}-09\end{array}$ \\
\hline
\end{tabular}

Since failure of a DynEx test is defined as one fragment perforating the given vessel, the target probability of failure is the same for a single fragment event as it is for the entire system. Thus,

$$
\begin{aligned}
p_{0(\mathrm{CV})} & =p_{0(\mathrm{CV}) \mathrm{LoO}}=p_{0(\mathrm{CV}) \mathrm{SSS}}=1.0 \times 10^{-6}, \text { and } \\
p_{0(\mathrm{CV}+\mathrm{SV})} & =p_{0(\mathrm{CV}+\mathrm{SV}) \mathrm{LoO}}=p_{0(\mathrm{CV}+\mathrm{SV}) \mathrm{SSS}}=1.0 \times 10^{-9} .
\end{aligned}
$$

where

$$
\begin{aligned}
\mathrm{CV} & =\text { containment vessel } \\
\mathrm{SV} & =\text { safety vessel } \\
\mathrm{LoO} & =\text { Likelihood of Occurrence model }, \text { and } \\
\mathrm{SSS} & =\text { Stochastic Sampling Simulation model } .
\end{aligned}
$$

This results in a target safety index of

$$
\begin{aligned}
& \beta_{0(\mathrm{CV})}=\Phi^{-1}\left(p_{0(\mathrm{CV})}\right)=4.750, \text { and } \\
& \phi_{0(\mathrm{CV}+\mathrm{SV})}=\Phi^{-1}\left(p_{0(\mathrm{CV}+\mathrm{SV})}\right)=5.998
\end{aligned}
$$

Table 6.4 shows the results of the Likelihood of Occurrence and Stochastic Sampling simulations relative to their respective safety indices. Even though the two simulation methods are modeling different probability problems, their safety indices can be compared. Results from the Likelihood of Occurrence simulations suggest that the 1" and 2" containment vessels are unsafe. This means that the probability of fragment perforation exceeds the stated allowable level of risk. For the 2" thick containment vessel simulation, $\beta_{2^{\prime \prime}}$, almost equals the value of $\beta_{0}$. This means that a small increase in the containment vessel thickness, or a slight relaxation of the failure criteria, would result in a safe design. The DynEx design containing both the 2" containment vessel and the 3.25" safety vessel is, however, safe.

TABLE 6.4. SAFETY INDICES FOR THE SIX NUMERICAL SIMULATIONS

\begin{tabular}{|c|c|c|c|c|}
\hline $\begin{array}{c}\text { Simulation } \\
\text { Type }\end{array}$ & Model & $\begin{array}{c}\text { Target Safety } \\
\text { Index }\end{array}$ & $\begin{array}{c}\text { Computed } \\
\text { Safety Index }\end{array}$ & \\
\hline Likelihood & $1 "$ & 4.75 & 2.37 & CV by itself is Unsafe \\
of & $2^{\prime \prime}$ & 4.75 & 4.69 & CV by itself is slightly Unsafe \\
Occurrence & $5.25^{\prime \prime}$ & 5.998 & 7.32 & 2" CV + SF is SAFE \\
\hline & $1^{\prime \prime}$ & 4.75 & 2.85 & CV by itself is Unsafe \\
Stochastic & $2^{\prime \prime}$ & 4.75 & 3.61 & CV by itself is Unsafe \\
Sampling & $5.25^{\prime \prime}$ & 5.998 & 5.85 & 2" CV + SF is slightly Unsafe \\
\hline
\end{tabular}


The Stochastic Sampling simulation predictions are not as encouraging. The predictions indicate that the 1 " and 2 " thick containment vessels are unsafe relative to the target safety index. Adding the $3.25^{\prime \prime}$ thick safety vessel to the 2 " thick containment vessel does not change the end result. However, $\beta_{5.25^{\prime \prime}(\mathrm{SSs})}$ is close to $\beta_{0}$ suggesting that a small increase in the thickness of either the containment vessel or the safety vessel, or a slight relaxation of the failure criteria, would result in a safe design.

\section{5. $\quad$ Engineering Index}

Reliability analysis has two limitations. First, reliability is often presented as a continuous metric when the criteria for success is binomial. In other words, reliability is an all-or-nothing assessment where partial failures are difficult to model. A system either does or does not perform as required. A second limitation of reliability analysis is its basis in probability theory. An axiom of probability theory states that the probability of an event occurring cannot exceed one. In the context of reliability, this is analogous to saying that a product is assessed at its upper performance limit even when the product surpasses this limit. Probability theory, when used in reliability analysis, does not provide a mechanism for representing overdesigned engineered products.

Suppose an engineer designs a product to perform a task within some environment. The product design eventually emerging will overperform the task (based on the performance requirements) in environments more severe than stated. In other words, the product is overdesigned. With respect to the product's reliability $(R)$, three conditions exist:

1. $R<1.0$, when product performance does not meet the performance requirements,

2. $R=1.0$, when product performance equals the performance requirements, and

3. $R=1.0$, when product performance surpasses performance requirements.

The engineering index attempts to quantify the goodness or quality of an engineered system, subsystem, or component when condition three exists. [Dolin 2002] It is analogous to the capability ratio, except that its intended use is in reliability assessment rather than process control. The goal of the engineering index is to assess the state of an engineered product in a domain that the mathematics of probability-based reliability theory cannot accommodate.

Suppose life were an engineered system, where breathing and brain function were parameters used to determine whether or not a person is alive. In this context, humans can be thought of as "overdesigned" systems because most humans exceed minimum performance requirements. In general, humans enjoy a quality of life that, while difficult to quantify, is nonetheless profound. For example, young adults at the peak of their strength, endurance, and learning potential might claim to posses the highest quality of life. Older adults who have slowed down physically might claim a higher quality of life because they possess greater knowledge, maturity, and wisdom.

Knowledge is replete concerning probable life expectancy and can be used to assess a person's reliability (with respect to our stated metrics). However, reliability theory cannot assess the quality of life a human might possess. Intuitively we believe that young people are more robust and better able to survive physical hardship and unexpected situations than their older counterparts. This suggests that as people age, they have less margin even though they are fully satisfying life's performance requirements. There are many other considerations determining a person's quality of life. A person kept alive on a respirator and an AIDS patient who can barely function taking 30 pills a day are examples of degradation mechanisms other than aging. Up to the moment of death, a person is alive, even though we would never consider asking a person near death, or someone with a severely diminished quality of life, to run a marathon.

This biological analogy holds for engineered systems. When new, engineered systems are both overdesigned and robust. As systems age or otherwise degrade, margin diminishes even though the system continues meeting all performance requirements. However, we intuitively expect the 
system's "quality of life" to diminish with time. While probability-based reliability methods cannot model this "quality of life" phenomena, the engineering index can.

Developed at the Los Alamos National Laboratory, the engineering index is used to inform decision makers how they are approaching changes in their reliability of estimates. Unlike process control or safety metrics, the engineering index is intended to infer into the future. Hence a powerful aspect of the engineering index is its ability to provide information about when in the future reliability changes are most likely to occur. [Dolin 2002]

The probability of a fragment penetrating the containment and safety vessels has thus far been presented as a reliability problem. However, the issue is not how many times out of $n$ tests the vessel fails, but rather, whether the vessel fails in one test. Therefore, what we really want to know when we ask about the probability of failure is how much margin the vessel has relative to a stated performance requirement.

The performance metric the EI assessment quantifies is the probability of perforation, $P(\mathrm{f})$. The stated performance requirement on this metric is $1 \times 10^{-9}$, which represents the highest allowable probability of perforation the containment and safety vessels can have. This is a crisp, discrete Type-III requirement. [Dolin 2002] A Type-III requirement is one that is bounded from above. Using the probability of failure as an EI metric is different from other engineering indices computed up till now.

The two different analysis models yield different EIs. The Likelihood of Occurrence model treats an entire DynEx test as a single event. The Stochastic Sampling model simulates 30,000 random fragments taken one at a time. For the Likelihood of Occurrence model, the discrete fragment event most likely to perforate the vessel has a likelihood of occurrence of $1.054 \times 10^{-13}$. The resulting uncertainty distribution is discrete, yielding a probability mass function. For the Stochastic Sampling model, the random fragment event having the highest probability of perforation has a value of $2.598 \times 10^{-9}$. The resulting uncertainty distribution for the random fragment events yields a probability density function with $\mu=3.09 \times 10^{-13}$ and $\sigma=4.052 \times 10^{-11}$.

Figure 6.7 shows the EI formulation for the Likelihood of Occurrence model. Notice that each formulation uses an initial assessed condition (IAC) of $1 \times 10^{-16}$. The IAC is an estimate of how well we believe the DynEx device performs before use. The IAC value used in this assessment represents the best engineering judgment of the vessel's performance. This is a qualitative judgment, and different engineers would have different values. In the end, the value of the EI varies with different IACs, but the conclusions we infer do not.

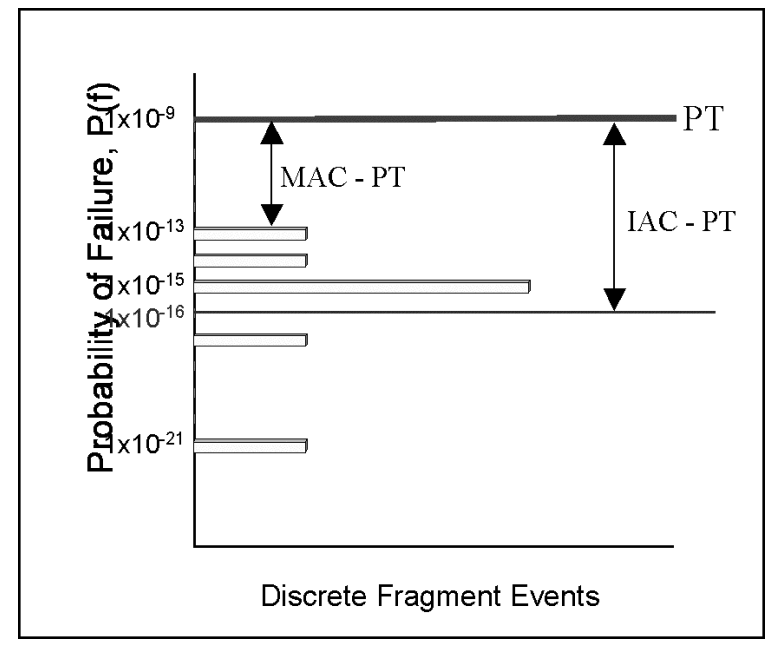

Figure 6.7. Engineering index for the containment and safety vessels as computed using the Likelihood of Occurrence model. 
Using IAC $=1 \times 10^{-16}$, we see that orders of magnitude separate the performance requirement (PT), the IAC, and the simulated probabilities of failure. Hence, the EI is computed on a lognormal scale. The EI for the Likelihood of Occurrence model then becomes

$$
\mathrm{EI}=\frac{\mathrm{MAC}-\mathrm{PT}}{\mathrm{IAC}-\mathrm{PT}}=\frac{-13+9}{-16+9}=\frac{4}{7}=0.5714 \text {. }
$$

Figure 6.8 highlights the EI formulation for the Stochastic Sampling model. Again, the EI for the Stochastic Sampling model is computed on a lognormal scale using the same PT and IAC. The EI for the Stochastic Sample model is

$$
\mathrm{EI}=\frac{\mathrm{MAC}-\mathrm{PT}}{\mathrm{IAC}-\mathrm{PT}}=\frac{8.58536-9}{16-9}=-0.05919 .
$$

Notice that $\mathrm{EI}(\mathrm{LoO})$ is positive. This indicates that margin exists based on the Likelihood of Occurrence simulation. This is consistent with what Figure 6.7 indicates. The EI(SS) is negative, indicating no margin exists in the Stochastic Sampling simulation. Again, this is consistent with what Figure 6.8 suggests.

Since the performance requirement was specified as a reliability, the computed EI engenders the following kind of conclusion:

1. On the basis of the LoO simulation, we are $\mathbf{X} \%$ confident that the DynEx vessel is $\left(1.0-1.0 \times 10^{-7}\right) \%$ reliable with a performance margin of $\mathrm{EI}=0.5714$.

With respect to the SS simulation we conclude the following:

2. On the basis of the SS simulation, we are $\mathbf{Y} \%$ confident that the DynEx vessel is not $\left(1.0-1.0 \times 10^{-7}\right) \%$ reliable because we have a negative margin of $\mathrm{EI}=-0.05919$.

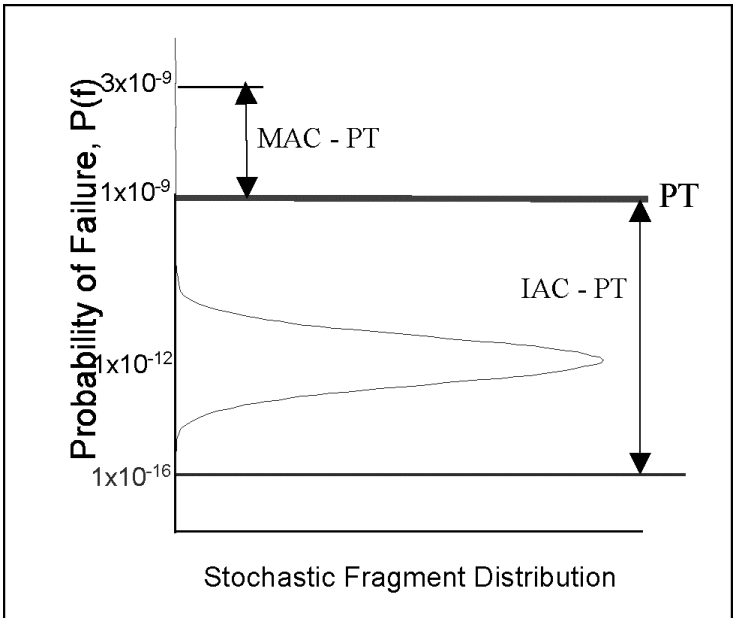

Figure 6.8. Engineering index for the containment and safety vessels as computed using the Stochastic Sampling model.

The confidence metrics $\mathbf{X}$ and $\mathbf{Y}$ would need to be determined on the basis of, among other things, the uncertainties of the EI calculation.

It is tempting to use the EI calculation to reassess the reliability statements. Given where the zero margin points exist for each simulation method, we could use the EI to restate the above conclusions as the following:

1. On the basis of the $\mathrm{LoO}$ simulation, we are $\mathbf{X} \%$ confident that the DynEx vessel is $\left(1.0-1.0 \times 10^{-11}\right) \%$ reliable. 
2. On the basis of the SS simulation, we are $\mathbf{Y} \%$ confident that the DynEx vessel is $\left(1.0-3.0 \times 10^{-7}\right) \%$ reliable.

\section{USING PROBABILISTIC ASSESSMENTS TO VALIDATE NUMERICAL SIMULATION}

The initial goal of the DynEx design's probabilistic assessment was to validate the numerical tools used to predict the vessel's quality and safety. While the probabilistic assessment models can be used to predict the safety and quality of the DynEx design on their own, there are domains that the probabilistic models don't include. These domains represent possible DynEx scenarios for which no pre-existing knowledge is available. Even though the probabilistic models can be used to infer beyond the domains of existing experimental and theoretical knowledge by making assumptions about the parameter distributions, that has thus far not been a desired application. Rather, the goal remains to rely on validated numerical tool predictions.

The hope is for the probabilistic models to (a) predict performance within the domain of existing knowledge and (b) validate numerical prediction tools within that domain. Once validated, the numerical prediction tools can be used to assess the performance of the DynEx vessel outside the domain of existing data. With this strategy in mind, several issues immerge. For instance, how are the results of a numerical prediction to be compared with probabilistic predictions? Another issue involves inferring beyond existing data. How accurate are the predictions made by a numerical tool outside the domain for which it was validated? While many other issues remain, only these two are considered here.

\subsection{Comparing Numerical Tool Predictions with Probabilistic Predictions}

A powerful feature of numerical analysis is its ability to allow insight in domains where no physical test information exists. Conversely, a common shortcoming of numerical analysis is its repeatable and deterministic nature. A numerical analysis using the same model and conditions yields the same results each time its exercised. This phenomena lies in contrast to the physical world, where repeatability is seldom achieved in an experiment because physical samples and conditions are dynamic. The results of a numerical analysis are often binomially deterministic in that failure either does or does not occur. This is again in contrast to the physical world, where partial failures are possible. Another aspect of numerical analysis is that any set of input conditions can be assessed. This is both good and bad because a set of input conditions can almost always be found for which failure occurs. The unresolved issue is not so much, "Can I fail the system I'm assessing?" but "How likely are the failure conditions to exist?" In other words, are those failure conditions probable, and if so, what is their likelihood of occurrence?

Trying to address those questions led to the development of the Likelihood of Occurrence simulation model presented in Chapter 3. The Likelihood of Occurrence simulation model considers probable fragment events within the domain of previous experiments. Because the results of the Likelihood of Occurrence simulations are based on physical test information, they can be used to validate the accuracy of the numerical tool for discrete parameter scenarios. Tables A1 and A2 in Appendix A contain a discrete set of Likelihood of Occurrence simulation results for the $1^{\prime \prime}$ and $2^{\prime \prime}$ vessel thicknesses, respectively.

Table D1 in Appendix D, contains a discrete set of finite element analysis results for the 2" vessel thickness scenario generated by the BREAKOUT code from Southwest Research Institute. This numerical analysis was performed by E. Rodriguez at the Los Alamos National Laboratory. [Rodriguez 2001] The discrete set of input parameters consists of a constant fragment diameter $D=0.5 \mathrm{~cm}$, a varying fragment length in the range of $0.5 \mathrm{~cm} \leq L \leq 8.0 \mathrm{~cm}$, and three different fragment velocities $(2,1.75$, and $1.5 \mathrm{~km} / \mathrm{s})$. Table 7.1 shows the results of the numerical analysis predictions compared with the probabilistic assessment. Notice the good agreement between the numerical analysis and probabilistic assessment response predictions. 
TABLE 7.1. VALIDATION ASSESSMENT FOR THE 0.5 CM DiAMETER FRAGMENT IMPACTING A 2" TARGET

\begin{tabular}{|c|c|c|c|c|c|c|}
\hline \multicolumn{7}{|c|}{ Validation Assessment } \\
\hline $\begin{array}{c}\text { Fragment } \\
\text { Diameter } \\
(\mathrm{cm})\end{array}$ & $\begin{array}{l}\text { Fragment } \\
\text { Length } \\
(\mathrm{cm})\end{array}$ & $\begin{array}{c}\text { Fragment } \\
\text { Velocity } \\
(\mathrm{km} / \mathrm{s})\end{array}$ & $\begin{array}{c}\text { Critical } \\
\text { Velocity } \\
(\mathrm{km} / \mathrm{s})\end{array}$ & $\begin{array}{c}\text { Analysis } \\
\text { Prediction } \\
\end{array}$ & $\begin{array}{l}\text { Probabilistic } \\
\text { Assessment }\end{array}$ & $\begin{array}{l}\text { Likelihood This } \\
\text { Fragment } \\
\text { Ever } \\
\text { Perforates } \\
(\%) \\
\end{array}$ \\
\hline 0.50 & 0.50 & 2.00 & 5.00 & No Perforation & No Perforation & 0.00 \\
\hline 0.50 & 1.50 & 2.00 & 5.00 & No Perforation & No Perforation & 0.00 \\
\hline 0.50 & 2.00 & 2.00 & 4.00 & No Perforation & No Perforation & 0.00 \\
\hline 0.50 & 3.00 & 2.00 & 3.00 & No Perforation & No Perforation & 0.00 \\
\hline 0.50 & 3.50 & 2.00 & 2.35 & Perforation & No Perforation & $9.20 \mathrm{E}-16$ \\
\hline 0.50 & 4.00 & 2.00 & 1.65 & Perforation & Perforation & $6.70 \mathrm{E}-04$ \\
\hline 0.50 & 5.00 & 2.00 & 1.55 & Perforation & Perforation & $6.86 \mathrm{E}-04$ \\
\hline 0.50 & 6.00 & 2.00 & 1.40 & Perforation & Perforation & 3.37E-05 \\
\hline 0.50 & 7.00 & 2.00 & 1.35 & Perforation & Perforation & 7.04E-06 \\
\hline 0.50 & 8.00 & 2.00 & 1.28 & Perforation & Perforation & $2.58 \mathrm{E}-07$ \\
\hline 0.50 & 0.50 & 1.75 & 5.00 & No Perforation & No Perforation & 0.00 \\
\hline 0.50 & 1.50 & 1.75 & 5.00 & No Perforation & No Perforation & 0.00 \\
\hline 0.50 & 2.00 & 1.75 & 4.00 & No Perforation & No Perforation & 0.00 \\
\hline 0.50 & 3.00 & 1.75 & 3.00 & No Perforation & No Perforation & 0.00 \\
\hline 0.50 & 3.50 & 1.75 & 2.35 & No Perforation & No Perforation & $9.20 \mathrm{E}-16$ \\
\hline 0.50 & 4.00 & 1.75 & 1.65 & Perforation & Perforation & $6.70 \mathrm{E}-04$ \\
\hline 0.50 & 5.00 & 1.75 & 1.55 & Perforation & Perforation & $6.86 \mathrm{E}-04$ \\
\hline 0.50 & 6.00 & 1.75 & 1.40 & Perforation & Perforation & 3.37E-05 \\
\hline 0.50 & 7.00 & 1.75 & 1.35 & Perforation & Perforation & 7.04E-06 \\
\hline 0.50 & 8.00 & 1.75 & 1.28 & Perforation & Perforation & $2.58 \mathrm{E}-07$ \\
\hline 0.50 & 0.50 & 1.50 & 5.00 & No Perforation & No Perforation & 0.00 \\
\hline 0.50 & 1.50 & 1.50 & 5.00 & No Perforation & No Perforation & 0.00 \\
\hline 0.50 & 2.00 & 1.50 & 4.00 & No Perforation & No Perforation & 0.00 \\
\hline 0.50 & 3.00 & 1.50 & 3.00 & No Perforation & No Perforation & 0.00 \\
\hline 0.50 & 3.50 & 1.50 & 2.35 & No Perforation & No Perforation & $9.20 \mathrm{E}-16$ \\
\hline 0.50 & 4.00 & 1.50 & 1.65 & No Perforation & No Perforation & $6.70 \mathrm{E}-04$ \\
\hline 0.50 & 5.00 & 1.50 & 1.55 & Perforation & No Perforation & $6.86 \mathrm{E}-04$ \\
\hline 0.50 & 6.00 & 1.50 & 1.40 & Perforation & Perforation & 3.37E-05 \\
\hline 0.50 & 7.00 & 1.50 & 1.35 & Perforation & Perforation & 7.04E-06 \\
\hline 0.50 & 8.00 & 1.50 & 1.28 & Perforation & Perforation & $2.58 \mathrm{E}-07$ \\
\hline
\end{tabular}

The rightmost column contains the likelihood that a fragment with the specified geometry would ever perforate the target. This assessment is based on all the event uncertainties, including, the likelihood a discrete fragment geometry exists, and given it exists, the likelihood it travels at or above its critical velocity. This column is included to highlight the fact that even though a perforation may be predicted, it is really only one piece of information necessary to make a performance assessment. For example, the fragment having a length of $L=8 \mathrm{~cm}$ is predicted to perforate in all three velocity scenarios. However, this perforation event has only a $2.58 \times 10^{-7} \%$ chance of occurring. To conclude from the numerical analysis that the DynEx vessel fails for $L=8 \mathrm{~cm}, D=0.5 \mathrm{~cm}$ fragment geometries would imply a weakness in the DynEx design, which would be an overstatement.

Table 7.2 provides a comparison between the numerical analysis predictions and the probabilistic assessments for the $0.75 \mathrm{~cm}$ and $1.00 \mathrm{~cm}$ diameter fragments of various lengths and impact velocities. Again, the numerical analysis agrees well with the probabilistic assessments. However, it again needs to be pointed out that all the geometry/velocity events considered by the numerical analysis have a low likelihood of both occurring and leading to a perforation. This again highlights the need to think beyond simply a numerical result.

While the results of this benchmark study suggest good agreement between the analysis predictions and the probabilistic assessments, it is only a beginning. To declare the numerical predictions validated, more analyses need to be performed, in particular, more analyses using a broader range of velocities. 
TABLE 7.2. VALIDATION ASSESSMENT FOR 0.75 AND 1.0 CM DiAMETER FRAGMENTS IMPACTING A 2" TARGET

\begin{tabular}{|c|c|c|c|c|c|c|}
\hline \multicolumn{7}{|c|}{ Validation Assessment } \\
\hline $\begin{array}{c}\text { Fragment } \\
\text { Diameter } \\
(\mathrm{cm})\end{array}$ & $\begin{array}{l}\text { Fragment } \\
\text { Length } \\
(\mathrm{cm})\end{array}$ & $\begin{array}{c}\text { Fragment } \\
\text { Velocity } \\
(\mathrm{km} / \mathrm{s})\end{array}$ & $\begin{array}{l}\text { Critical } \\
\text { Velocity } \\
(\mathrm{km} / \mathrm{s})\end{array}$ & $\begin{array}{c}\text { Analysis } \\
\text { Prediction }\end{array}$ & $\begin{array}{l}\text { Probabilistic } \\
\text { Assessment }\end{array}$ & $\begin{array}{c}\text { Likelihood } \\
\text { This } \\
\text { Fragment } \\
\text { Ever } \\
\text { Perforates } \\
(\%) \\
\end{array}$ \\
\hline 0.75 & 0.75 & 2.00 & 5.00 & No Perforation & No Perforation & 0.00 \\
\hline 0.75 & 2.25 & 2.00 & 5.00 & No Perforation & No Perforation & 0.00 \\
\hline 0.75 & 3.00 & 2.00 & 2.20 & Perforation & No Perforation & 4.40E-12 \\
\hline 0.75 & 4.50 & 2.00 & 1.70 & Perforation & Perforation & 3.92E-05 \\
\hline 0.75 & 5.25 & 2.00 & 1.50 & Perforation & Perforation & 7.84E-05 \\
\hline 0.75 & 6.00 & 2.00 & 1.35 & Perforation & Perforation & $6.45 \mathrm{E}-06$ \\
\hline 0.75 & 0.75 & 1.75 & 5.00 & No Perforation & No Perforation & 0.00 \\
\hline 0.75 & 2.25 & 1.75 & 5.00 & No Perforation & No Perforation & 0.00 \\
\hline 0.75 & 3.00 & 1.75 & 2.20 & No Perforation & No Perforation & $4.40 \mathrm{E}-12$ \\
\hline 0.75 & 4.50 & 1.75 & 1.70 & Perforation & Perforation & $3.92 \mathrm{E}-05$ \\
\hline 0.75 & 5.25 & 1.75 & 1.50 & Perforation & Perforation & 7.84E-05 \\
\hline 0.75 & 6.00 & 1.75 & 1.35 & Perforation & Perforation & $6.45 \mathrm{E}-06$ \\
\hline 0.75 & 0.75 & 1.50 & 5.00 & No Perforation & No Perforation & 0.00 \\
\hline 0.75 & 2.25 & 1.50 & 5.00 & No Perforation & No Perforation & 0.00 \\
\hline 0.75 & 3.00 & 1.50 & 2.20 & No Perforation & No Perforation & 4. $40 \mathrm{E}-12$ \\
\hline 0.75 & 4.50 & 1.50 & 1.70 & Perforation & No Perforation & $3.92 \mathrm{E}-05$ \\
\hline 0.75 & 5.25 & 1.50 & 1.50 & Perforation & Perforation & $7.84 \mathrm{E}-05$ \\
\hline 0.75 & 6.00 & 1.50 & 1.35 & Perforation & Perforation & $6.45 \mathrm{E}-06$ \\
\hline 1.00 & 1.00 & 2.00 & 5.00 & No Perforation & No Perforation & 0.00 \\
\hline 1.00 & 3.00 & 2.00 & 2.25 & Perforation & No Perforation & $2.37 \mathrm{E}-15$ \\
\hline 1.00 & 4.00 & 2.00 & 1.65 & Perforation & Perforation & $7.77 \mathrm{E}-07$ \\
\hline 1.00 & 6.00 & 2.00 & 1.35 & Perforation & Perforation & 8.34E-08 \\
\hline 1.00 & 7.00 & 2.00 & 1.30 & Perforation & Perforation & $3.16 \mathrm{E}-08$ \\
\hline 1.00 & 8.00 & 2.00 & 1.16 & Perforation & Perforation & 2.20E-09 \\
\hline 1.00 & 1.00 & 1.75 & 5.00 & No Perforation & No Perforation & 0.00 \\
\hline 1.00 & 3.00 & 1.75 & 2.25 & Perforation & No Perforation & $2.37 \mathrm{E}-15$ \\
\hline 1.00 & 4.00 & 1.75 & 1.65 & Perforation & Perforation & 7.77E-07 \\
\hline 1.00 & 6.00 & 1.75 & 1.35 & Perforation & Perforation & 8.34E-08 \\
\hline 1.00 & 7.00 & 1.75 & 1.30 & Perforation & Perforation & 3.16E-08 \\
\hline 1.00 & 8.00 & 1.75 & 1.16 & Perforation & Perforation & $2.20 \mathrm{E}-09$ \\
\hline 1.00 & 1.00 & 1.50 & 5.00 & No Perforation & No Perforation & 0.00 \\
\hline 1.00 & 3.00 & 1.50 & 2.25 & Perforation & No Perforation & $2.37 \mathrm{E}-15$ \\
\hline 1.00 & 4.00 & 1.50 & 1.65 & Perforation & No Perforation & 7.77E-07 \\
\hline 1.00 & 6.00 & 1.50 & 1.35 & Perforation & Perforation & 8.34E-08 \\
\hline 1.00 & 7.00 & 1.50 & 1.30 & Perforation & Perforation & 3.16E-08 \\
\hline 1.00 & 8.00 & 1.50 & 1.16 & Perforation & Perforation & 2.20E-09 \\
\hline
\end{tabular}

\subsection{Assessing a Numerical Tool's Ability to Infer beyond the Domain for Which It Was Validated}

The primary purpose of developing a numerical prediction capability is to assess the performance of the DynEx vessels in domains where knowledge is lacking. The first step in assessing a numerical tool's ability to infer beyond the domain for which it was validated is to define what outer domains are of interest and to understand the relationship between the validated domain and these outer domains.

Model validation is highly application dependent. In other words, it matters what questions you propose to a validated model. At this point the numerical analysis tool cannot be declared validated. Additionally, the outer domains of interest have yet to be defined. Finally, a relationship between the domain to be validated and whatever outer domains will be defined has not been established. For these reasons, the numerical tool cannot be used to infer beyond the validation domain. 


\section{SUMMARY OF RESULTS}

The performance requirement for the DynEx vessel states if one of the 41,000 probable fragments perforates the containment vessel, failure occurs. The margin of uncertainty on this deterministic requirement is there can be no greater than a $1 \times 10^{-6}$ chance that a fragment perforates half the containment vessel thickness, which is one inch. This represents the thickness of the existing DynEx vessel and is considered a design requirement for the new design. There can be no greater than a $1 \times 10^{-6}$ chance that a fragment perforates the full two inch thickness of the containment vessel. This is a performance requirement for the new vessel design. Finally, there can be no greater than a $1 \times 10^{-9}$ chance that a fragment perforates the new containment vessel and the safety vessel encasing it. This combined 5.25" perforation constraint is a safety requirement.

Two different simulation methods were used to assess the probability that a DynEx experiment will result in failure. For each of the simulation methods, three separate scenarios were investigated. Probability assessments were made using a synthesis of information available from historical evidence (i.e., past explosive experiments) and theory. The assessments do not involve structural or hydrodynamic code predictions.

The first simulation approach was referred to as the Likelihood of Occurrence Simulation. In this approach the probability space of likely fragment geometries was discretized, and all likely fragment events were considered simultaneously. The probability of failure was computed in a two-step process. First, the likelihood that fragments of discrete size and shape occur during a DynEx experiment was predicted. Then the probability that each of those fragments causes perforation was determined. On the basis of experimental evidence and explosive handbook theory, it was estimated that approximately 41,000 fragments of various sizes and geometries form during a DynEx experiment. The 41,000 fragments were distributed among discrete fragment configurations based on Mott's distribution.

For each fragment configuration the probability of perforation was computed along with its likelihood of occurrence. Modeling all 41,000 fragments as a single event, the probability that at least one fragment will perforate a one-inch thick vessel was determined to be $8.9 \times 10^{-3}$. The probability that at least one fragment will perforate a two-inch thick vessel is $1.52 \times 10^{-5}$. Finally, the probability that at least one fragment will perforate a $5.25^{\prime \prime}$ thick vessel is $1.23 \times 10^{-13}$. This last estimate is equivalent to the conditional probability that at least one fragment will perforate a 3.25 " thick safety vessel, given that it has perforated a two inch thick HSLA-100 containment vessel. On the basis of these assessments, it can be concluded the DynEx vessel does not meet either the design or performance requirements. However, it does adequately meet the safety requirement. Performing a Maximum Likelihood Point Estimate assessment did not change these results.

The second simulation approach follows a more traditional probabilistic assessment methodology. Thirty-thousand random single fragment events were evaluated using Latinhypercube stochastic simulation. The probability that each of these independent events will result in a perforation was determined on the basis of the criteria of the logical model's influence diagram. The overall probability that a DynEx experiment will result in failure was taken as the maximum probability of perforation found for all the fragment events. The logical model predicts a probability of failure for a one-inch thick vessel at $2.20 \times 10^{-3}$. The probability of failure for a two-inch thick vessel is $1.55 \times 10^{-4}$. The probability of failure for a five and one-quarter inch thick vessel is $2.50 \times 10^{-9}$. On the basis of these assessments, it can be concluded the DynEx vessel does not meet any of the performance requirements.

To refine the results of the Stochastic Sampling Simulation, each of the three vessel scenarios was repeated forty times. Each stochastic simulation used a different random seed and thus rendered a slightly different result. There is little variation between the forty simulations. The worst probable point from the convergence study doesn't significantly change the conclusions made on the DynEx vessel performance. 
The probability of failure $P$ (failure) alone does not tell the complete story. Hence, margin and safety assessments were made. The Likelihood of Occurrence and Stochastic Sampling simulations solve different probability problems. The margin and safety metrics provided a mechanism for comparing results. Given the performance requirements, both the one and two inch containment vessels by themselves are inadequate for containing a DynEx test. The two inch thick containment vessel plus the 3.25 inch safety vessel however was determined to be safe in the Likelihood of Occurrence simulation and nearly adequate in the Stochastic Sampling simulation.

Numerical analysis codes were used to model a DynEx experiment. As with any numerical prediction, there was uncertainty in the accuracy of both the mathematical engine as well the model used to predict response for a given problem scenario. Using results from the probabilistic simulations, the numerically predicted responses were validated. The knowledge base built up from the probabilistic assessments was used to provide input distributions for the analysis models. The results of analyses using the BREAKOUT code were compared against the equivalent results from the Likelihood of Occurrence Simulation model. While their responses were consistent, it was felt that more comparisons were necessary before the BREAKOUT code could be declared validated.

\subsection{Uncertainty}

There were several sources of uncertainty in the probabilistic assessment simulation models. The completeness upon which the discrete assessments capture the continuum of fragment geometries is uncertain. The distributions used to assess the likelihood that various fragment geometries occur is not as well understood as one would like. So too is the velocity distribution. There is uncertainty in assessing probable fragment velocities, just as there is in determining the critical velocity. There is uncertainty in knowing how well the Stochastic Sampling Simulation models an actual DynEx experiment even though good convergence characteristics were demonstrated.

There are other uncertainties as well. For example, both the effect of and distribution in the orientation of the fragments cannot be known. For this reason a uniform distribution seemed reasonable. Both fragment and target material property variation were not accounted for. Variation in how the high explosive imparts its energy into the case, how fragments form, and if there is jetting were not considered. As much as possible, the first order uncertainties were managed by making conservative estimates.

\subsection{Reasons for Conservatism}

Where possible, conservatism was used to compensate for variable uncertainty. For example, all angles of attack within the $\pm \alpha$ cone were considered perpendicular to the containment vessel wall. This assumption is conservative for two reasons. First, a perpendicular impact has a minimal effective containment vessel thickness equal to the actual vessel thickness. Fragments that impact at an angle to the containment vessel have a larger effective thickness. Second, by assuming a perpendicular impact, the velocity vector and the fragment's orientation are aligned. This means that there is no orthogonal velocity component and all the energy is directed toward perforation. The assumption that all angles of attack within the $\pm \alpha$ cone are perpendicular means that the most damaging case is always considered whenever an angle of attack is within $\pm \alpha$.

The velocity probability density function assumes fragment velocity is not related to fragment geometry. While the relationship between velocity and geometry is not fully known, it is believed larger fragments travel at lower velocities than smaller fragments. However, it is the larger fragments that do the greatest damage. By treating fragment velocity as an independent parameter, larger fragments are allowed to possess velocities higher than they would ever achieve in an actual DynEx test. This means we are simulating conditions worse than reasonably possible. 
Mott's distribution predicts 41,500 fragments are generated during a DynEx test. Of those, 4,279 are considered large enough to be candidates for perforation. The other 37,221 fragments are too small to generate the energy necessary for perforation. The mass of these smaller fragments is not neglected though. Rather, their mass is made available to be distributed among the 40 discrete fragment events. This results in an overestimation of the number of larger candidate fragments likely to occur during a DynEx test. The simulation model therefore considers more potentially damaging fragment events than are likely to occur.

Where possible, conservatism is used. The net result should be that the conclusions reached are themselves conservative. For this reason it can be confidently concluded the DynEx vessel combined with the safety vessel can be used to contain a DynEx test.

\section{CONCLUSIONS}

Two different simulation methods were used to assess the probability a DynEx experiment results in failure. Failure occurs if at least one fragment perforates the specified wall thickness. For each of the simulation methods, three separate scenarios are investigated. Probability assessments are made using a combination of information available from historical evidence (i.e., past explosive experiments) and theory. The assessments do not involve structural or hydrodynamic code predictions.

The first simulation approach is referred to as the Likelihood of Occurrence. In this approach the probability space of likely fragment geometries is discretized, and all likely fragment events are considered simultaneously. The probability of failure is computed in a two-step process. First the likelihood that fragments of discrete size and shape occur during a DynEx experiment is predicted. Then the probability that each of those fragments causes perforation is determined. On the basis of experimental evidence and explosives handbook theory, it is estimated that 41,000 fragments of various size and geometry form during a DynEx experiment. The 41,000 fragments are distributed among discrete fragment configurations.

For each fragment configuration the probability of perforation is computed along with the likelihood of occurrence. Modeling all 41,000 fragments as a single event, the probability that at least one fragment perforates a one-inch thick vessel is $8.9 \times 10^{-3}$. The probability that at least one fragment perforates a two-inch thick vessel is $1.52 \times 10^{-5}$. Finally, the probability that at least one fragment perforates a five and one-quarter inch thick vessel is $1.23 \times 10^{-13}$. This last estimate is equivalent to the conditional probability at least one fragment perforates a three-and-a-quarter inch thick safety vessel, given it has perforated a two inch thick HSLA-100 containment vessel.

The second simulation approach follows a more traditional probabilistic assessment method. Thirty thousand random single fragment events are evaluated using Latin-hypercube stochastic simulation. The probability that each of these independent events results in a perforation is based on the criteria of a logical model's influence diagram. The overall probability a that DynEx experiment results in failure is taken as the maximum probability of perforation found for all the fragment events. The logical model predicts a probability of failure for a one-inch thick vessel as $2.20 \times 10^{-3}$. The probability of failure for a two-inch thick vessel is $1.55 \times 10^{-4}$. The probability of failure for a five and one-quarter inch thick vessel is $2.50 \times 10^{-9}$

Because the probability of failure $[P($ failure $)]$, alone does not tell the complete story, margin and safety assessments are made. Since the Likelihood of Occurrence and Stochastic Sampling simulations model different probability problems, the margin and safety metrics allow a mechanism for comparing results. Assessments are made relative to the stated performance requirement that the probability of failure for the containment vessel be

$$
P_{\mathrm{CV}} \text { (failure) } \leq 1.0 \times 10^{-6} \text {. }
$$

and the probability of failure for the containment vessel plus the safety vessel be

$$
P_{\mathrm{CV}+\mathrm{SF}}(\text { failure }) \leq 10 \times 10^{-9} \text {. }
$$


Given these performance requirements, both the one and two inch containment vessels by themselves are inadequate for containing a DynEx test. The two inch thick containment vessel plus the 3.25 inch safety vessel however was determined to be safe in the Likelihood of Occurrence simulation and nearly adequate in the Stochastic Sampling simulation.

Numerical analysis codes were used to model a DynEx experiment. As with any numerical prediction, there is uncertainty in the accuracy of both the mathematical engine as well the model used to predict response for a given problem scenario. Using results from the probabilistic simulations, the numerically predicted responses are validated. The knowledge base was also used to provide input distributions for the analysis models. To date the Dyna large-strain, largedeformation Lagrangian tool and the (Predict) penetration tool have been investigated for validation.

\section{REFERENCES}

Anderson, C. E., B. L. Morrison, and D. L. Littlefield, “A Penetration Mechanics Database," Southwest Research Institute Report SwRI-3593/001, San Antonio, Texas (1992).

Carbonneau, H. C., and G. L. Webster, Industrial Quality Control (Prentice Hall, Englewood Cliffs, New Jersey, 1978).

Dolin, R. M., J. M. Booker, C. L. Faust, M. S. Hamada, B. Reardon, and J. Newmyer, "Principles of an Engineering Index: A Metric for Quantifying Margin Relative to Performance (U)," Los Alamos National Laboratory Report LA-13934 (2002).

Federal Aviation Administration JAR-25, Change 13, Chapter 9, Section 2, Figure 1.

Higgins, J. J., and S. Keller-McNulty, Concepts in Probability and Stochastic Modeling (Duxbury Press, New York, 1995).

Kane, V. E., "Process Capability Indices," Journal of Quality Technology 18 (1), 41-52 (1986).

Keese, D. L., and W. R. Barton, "Risk Assessment and Its Application to Flight Safety Analysis," Sandia National Laboratories Report SAND89-1982 (1989).

Rodriguez, E. A., and R. L. Martineau, Fragmentation and Fragment Penetration Design Criteria for HSLA-100 Steel Confinement Vessels (U)," Los Alamos National Laboratory document DX-DO:00-01(S) (October 2000).

Rodriguez, E., "Fragmentation and Fragment Penetration Design Criteria for HSLA-100 Steel Confinement Vessels (U)," Los Alamos National Laboratory document. DynEx:00-089(S) (September 2001).

Walpole, R. E., and R. H. Myers, Probability and Statistics for Engineers and Scientists, 4th ed. (MacMillian Publishing Company, New York, 1989).

Wirsching, P. H., "Advanced Reliability Methods," University of Arizona, unpublished data (lecture at Southwest Research Institute, San Antonio, Texas, 1992).

United States Department of Energy, "A Manual for the Prediction of Blast and Fragment Loadings on Structures," DOE/TIC-11268, DOE Albuquerque Operations Office, Amarillo Area Office, Pantex Plant (November 1980). 
APPENDIX A

DISCRETE PROBABILISTIC ASSESSMENT MATRICES 
TAble A1. Discrete Probability Assessment FOR 1 InCH Thick CONTAINMENT Vessel

\begin{tabular}{|c|c|c|c|c|c|c|c|c|c|c|c|c|}
\hline & & \multicolumn{10}{|c|}{$L / D$} \\
\hline \multicolumn{2}{|c|}{$\begin{array}{c}P=\text { Pdesign (1in) } \\
2.54 \mathrm{~cm}\end{array}$} & & $\begin{array}{c}1 \\
L O=H i g h\end{array}$ & $\begin{array}{c}3 \\
\text { Medium }\end{array}$ & $\begin{array}{c}4 \\
\text { Low }\end{array}$ & $\begin{array}{c}6 \\
\text { low }\end{array}$ & $\begin{array}{c}7 \\
\text { low }\end{array}$ & $\begin{array}{c}8 \\
\text { VeryLow }\end{array}$ & $\begin{array}{c}10 \\
\text { VeryLow }\end{array}$ & $\begin{array}{c}12 \\
\text { Extremely Low }\end{array}$ & $\begin{array}{c}14 \\
\text { Extremely Low }\end{array}$ & $\begin{array}{c}16 \\
\text { Exremely Low }\end{array}$ \\
\hline \multirow{36}{*}{ D } & \multirow{5}{*}{0.25} & L & 0.25 & 0.750 & 1.000 & 1.500 & 1.750 & 2.000 & 2.500 & 3.000 & 3.500 & 4.000 \\
\hline & & $\mathrm{P} / \mathrm{L}$ & 10.16 & 3.387 & 2.540 & 1.693 & 1.451 & 1.270 & 1.016 & 0.847 & 0.726 & 0.635 \\
\hline & & mass(rag) & 0.54 & 1.631 & 2.175 & 3.263 & 3.806 & 4.350 & 5.438 & 6.525 & 7.613 & 8.700 \\
\hline & & P(mass) & 0.885 & 0.065 & 0.020 & 0.01000 & 0.01000 & 0.00600 & 0.00100 & 0.00120 & 0.00080 & 0.00070 \\
\hline & & $\begin{array}{l}\text { P(LIDD) } \\
\text { \# Fragments }\end{array}$ & $\begin{array}{l}0.70 \\
4240\end{array}$ & $\begin{array}{c}0.070 \\
10\end{array}$ & $\begin{array}{c}0.040 \\
1\end{array}$ & $\begin{array}{c}0.020 \\
2.281 \mathrm{E}-01\end{array}$ & 0.011 & 0.007 & 0.0030 & 0.0010 & 0.0003 & 0.0001 \\
\hline & \multirow{3}{*}{$\begin{array}{c}P(D=.25) \\
0.2436\end{array}$} & \# Candidates & 942 & 2 & 0 & $5.069 \mathrm{E}-02$ & $\begin{array}{l}1.075 \mathrm{E}-01 \\
2.390 \mathrm{E}-02\end{array}$ & $\begin{array}{l}3.593 \mathrm{E}-02 \\
7.984 \mathrm{E}-03\end{array}$ & $\begin{array}{l}2.053 E-03 \\
4.562 E-04\end{array}$ & $\begin{array}{l}6.844 \mathrm{E}-04 \\
1.521 \mathrm{E}-04\end{array}$ & $\begin{array}{l}1.173 \mathrm{E}-04 \\
2.607 \mathrm{E}-05\end{array}$ & $\begin{array}{l}2.994 \mathrm{E}-05 \\
6.654 \mathrm{E}-06\end{array}$ \\
\hline & & $\operatorname{Vcr}(\mathrm{km} / \mathrm{s})$ & $\begin{array}{r}5.00 \\
0.0000\end{array}$ & $\begin{array}{r}5.000 \\
0.0000\end{array}$ & $\begin{array}{l}3.800 \\
0.0000\end{array}$ & np & 2.500 & 2.000 & 1.650 & 1.500 & 1.300 & 0.900 \\
\hline & & $\begin{array}{l}\mathrm{P}(\mathrm{P} \text { V(r) } \\
\mathrm{P} \text { (penetration) }\end{array}$ & $\begin{array}{c}0.0000 \\
0.000 E+00\end{array}$ & $\begin{array}{c}0.0000 \\
0.000 \mathrm{E}+00\end{array}$ & $\begin{array}{c}0.0000 \\
0.000 E+00\end{array}$ & $\begin{array}{c}0.0000 \\
0.000 E+00\end{array}$ & $\begin{array}{c}0.000 \mathrm{E}+00 \\
0.000 \mathrm{E}+00\end{array}$ & $\begin{array}{c}0.000032 \\
2.530 \mathrm{E}-07\end{array}$ & $\begin{array}{c}0.3085 \\
1.408 \mathrm{E}-04\end{array}$ & $\begin{array}{c}0.8413 \\
1.280 \mathrm{E}-04\end{array}$ & $\begin{array}{c}0.9987 \\
2.604 \mathrm{E}-05\end{array}$ & $\begin{array}{c}1.0000 \\
6.654 \mathrm{E}-06\end{array}$ \\
\hline & \multirow{7}{*}{0.5} & $\mathrm{~L}$ & 0.500 & 1.500 & 2.000 & 3.000 & 3.500 & 4.000 & 5.000 & 6.000 & 7.000 & 8.000 \\
\hline & & & 5.080 & 1.693 & 1.270 & 0.847 & 0.726 & 0.635 & 0.508 & 0.423 & 0.363 & 0.318 \\
\hline & & mass(frag) & 2.175 & 6.525 & 8.700 & 13.050 & 15.225 & 17.400 & 21.750 & 26.100 & 30.450 & 34.800 \\
\hline & & $\mathrm{P}$ (mass) & 0.010 & 0.001 & 0.001 & 0.001 & 2.20E-04 & $3.00 \mathrm{E}-05$ & 4.00E-05 & $5.00 \mathrm{E}-06$ & 4.00E-06 & $5.00 \mathrm{E}-07$ \\
\hline & & P(L/D|D) & 0.70 & 0.070 & 0.040 & 0.020 & 0.011 & 0.007 & 0.0030 & 0.0010 & 0.0003 & 0.0001 \\
\hline & & \# Fragments & 27 & 0.106 & 0.030 & $8.846 \mathrm{E}-03$ & $1.311 \mathrm{E}-03$ & $9.952 \mathrm{E}-05$ & 4.550E-05 & $1.580 \mathrm{E}-06$ & 3.250E-07 & 1.185E-08 \\
\hline & & \# Candidates & 6 & 0.024 & 0.007 & $1.966 \mathrm{E}-03$ & 2.913E-04 & $2.212 \mathrm{E}-05$ & $1.011 E-05$ & $3.510 \mathrm{E}-07$ & 7.221E-08 & $2.633 \mathrm{E}-09$ \\
\hline & \multirow{3}{*}{$\begin{array}{c}P(D=.5) \\
0.5398\end{array}$} & $\operatorname{Ver}(\mathrm{km} / \mathrm{s})$ & 5.000 & 1.700 & 1.650 & 1.500 & 1.480 & 1.250 & 1.150 & 1.060 & 1.000 & 0.900 \\
\hline & & $\mathrm{P}(>\mathrm{V} \mathrm{Cr})$ & 0.000 & 0.1587 & 0.3085 & 0.8413 & 0.8849 & 0.9998 & 1.0000 & 1.0000 & 1.0000 & 1.0000 \\
\hline & & $\mathrm{P}$ (penetration) & $0.000 E+00$ & $3.743 \mathrm{E}-03$ & $2.080 \mathrm{E}-03$ & $1.654 \mathrm{E}-03$ & $2.577 \mathrm{E}-04$ & $2.211 \mathrm{E}-05$ & $1.011 \mathrm{E}-05$ & $3.510 \mathrm{E}-07$ & $7.221 \mathrm{E}-08$ & 2.633E-09 \\
\hline & \multirow{6}{*}{0.75} & $\mathrm{~L}$ & 0.750 & 2.250 & 3.000 & 4.500 & 5.250 & 6.000 & 7.500 & 9.000 & 10.500 & 12.000 \\
\hline & & P/L & 3.387 & 1.129 & 0.847 & 0.564 & 0.484 & 0.423 & 0.339 & 0.282 & 0.242 & 0.212 \\
\hline & & mass(frag) & 4.894 & 14.681 & 19.575 & 29.363 & 34.256 & 39.150 & 48.938 & 58.725 & 68.513 & 78.300 \\
\hline & & $\mathrm{P}$ (mass) & $1.00 \mathrm{E}-03$ & 2.20E-04 & 3.00E-05 & $5.00 \mathrm{E}-06$ & $4.00 E-06$ & $5.00 \mathrm{E}-07$ & 4.00E-07 & $5.00 \mathrm{E}-08$ & $4.00 \mathrm{E}-08$ & $5.00 \mathrm{E}-09$ \\
\hline & & $P(L / D \mid D)$ & 0.70 & 0.070 & 0.040 & 0.020 & 0.011 & 0.007 & 0.0030 & 0.0010 & 0.0003 & 0.0001 \\
\hline & & \# Fragments & 0.467 & 0.003 & 0.000 & $1.112 \mathrm{E}-05$ & 4. $193 \mathrm{E}-06$ & $2.918 \mathrm{E}-07$ & $8.005 E-08$ & $2.779 \mathrm{E}-09$ & $5.718 \mathrm{E}-10$ & $2.085 \mathrm{E}-11$ \\
\hline & \multirow{3}{*}{$\begin{array}{c}P(D=.75) \\
0.2137\end{array}$} & \# Candidates & 0.104 & 0.001 & 0.000 & $2.471 \mathrm{E}-06$ & $9.318 \mathrm{E}-07$ & $6.485 \mathrm{E}-08$ & $1.779 \mathrm{E}-08$ & $6.177 \mathrm{E}-10$ & $1.271 \mathrm{E}-10$ & $4.632 \mathrm{E}-12$ \\
\hline & & $\begin{array}{l}\operatorname{Vcr}(\mathrm{km} / \mathrm{s}) \\
\mathrm{P}(>\mathrm{Vcr})\end{array}$ & $\begin{array}{l}4.000 \\
0.000\end{array}$ & $\begin{array}{c}1.390 \\
0.9821356\end{array}$ & $\begin{array}{c}1.340 \\
0.9953388\end{array}$ & $\begin{array}{l}1.150 \\
1.000\end{array}$ & $\begin{array}{l}1.050 \\
1.000\end{array}$ & $\begin{array}{l}1.000 \\
1.000\end{array}$ & $\begin{array}{l}0.980 \\
1.000\end{array}$ & $\begin{array}{l}0.950 \\
1.000\end{array}$ & $\begin{array}{l}0.850 \\
1.000\end{array}$ & $\begin{array}{l}0.800 \\
1.000\end{array}$ \\
\hline & & $\mathrm{P}$ (penetration) & $0.000 \mathrm{E}+00$ & $7.474 \mathrm{E}-04$ & 4.426E-05 & $2.471 \mathrm{E}-06$ & $9.318 \mathrm{E}-07$ & $6.485 \mathrm{E}-08$ & $1.779 \mathrm{E}-08$ & $6.177 \mathrm{E}-10$ & $1.271 \mathrm{E}-10$ & 4.632E-12 \\
\hline & \multirow[b]{7}{*}{$P(D=1)$} & & 1.000 & 3.000 & 4.000 & 6.000 & 7.000 & 8.000 & 10.000 & 12.000 & 14.000 & 16.000 \\
\hline & & & 2.540 & 0.847 & 0.635 & 0.423 & 0.363 & 0.318 & 0.254 & 0.212 & 0.181 & 0.159 \\
\hline & & mass(frag) & 8.700 & 26.100 & 34.800 & 52.200 & 60.900 & 69.600 & 87.000 & 104.400 & 121.800 & 139.200 \\
\hline & & $\mathrm{P}$ (mass) & 0.001 & $5.00 \mathrm{E}-06$ & $5.00 \mathrm{E}-07$ & $5.00 \mathrm{E}-08$ & $4.00 E-08$ & $5.00 \mathrm{E}-09$ & 4.00E-09 & 4. $00 \mathrm{E}-10$ & 4.00E-11 & $5.00 \mathrm{E}-12$ \\
\hline & & $P(L / D \mid D)$ & 0.70 & 0.070 & 0.040 & 0.020 & 0.011 & 0.007 & 0.0030 & 0.0010 & 0.0003 & 0.0001 \\
\hline & & \# Fragme & 0.011 & 0.000 & 0.000000 & $3.775 E-09$ & 1.424E-09 & $9.910 \mathrm{E}-11$ & $2.718 E-11$ & $7.550 \mathrm{E}-13$ & $1.941 \mathrm{E}-14$ & $7.078 E-16$ \\
\hline & & \# Candidates & 0.002 & 0.0000 & 0.000000 & 8.389E-10 & 3.164E-10 & 2.202E-11 & $6.040 \mathrm{E}-12$ & $1.678 \mathrm{E}-13$ & 4.314E-15 & $1.573 \mathrm{E}-16$ \\
\hline & \multirow[t]{2}{*}{0.0129} & $\operatorname{Vcr}(\mathrm{km} / \mathrm{s})$ & 3.400 & 1.300 & 1.200 & 0.950 & 0.900 & 0.800 & 0.750 & $\begin{array}{l}0.700 \\
1.000\end{array}$ & 0.650 & 0.550 \\
\hline & & 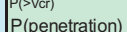 & $0.000 E+00$ & $5.864 \mathrm{E}-07$ & $\begin{array}{c}1.000 \\
2.517 E-08\end{array}$ & $\begin{array}{c}1.000 \\
8.389 \mathrm{E}-10\end{array}$ & $\begin{array}{c}1.000 \\
3.164 \mathrm{E}-10\end{array}$ & $2.202 \mathrm{E}-11$ & $\begin{array}{c}1.000 \\
6.040 \mathrm{E}-12\end{array}$ & $\begin{array}{c}1.000 \\
1.678 \mathrm{E}-13\end{array}$ & 4.314E-15 & $1.573 \mathrm{E}-16$ \\
\hline
\end{tabular}

TABLE A2. DisCRETE PROBABILITY ASSESSMENT FOR 2 INCH THICK HSLA-100 CONTAINMENT VeSSEL

\begin{tabular}{|c|c|c|c|c|c|c|c|c|c|c|c|c|}
\hline \multirow{2}{*}{\multicolumn{2}{|c|}{$\begin{array}{l}P=\text { Pactual (2in) } \\
5.08 \mathrm{~cm}\end{array}$}} & & \multicolumn{10}{|c|}{$L / D$} \\
\hline & & & \multirow{3}{*}{$\begin{array}{c}1 \\
\text { LO = High } \\
0.25 \\
20.32\end{array}$} & \multirow{3}{*}{$\begin{array}{c}3 \\
\text { Medium } \\
0.750 \\
6.773\end{array}$} & \multirow{3}{*}{$\begin{array}{c}4 \\
\text { Low } \\
1.000 \\
5.080\end{array}$} & \multirow{3}{*}{$\begin{array}{c}6 \\
\text { low } \\
1.500 \\
3.387\end{array}$} & \multirow{2}{*}{$\begin{array}{c}7 \\
\text { low } \\
1.750\end{array}$} & \multirow{2}{*}{$\begin{array}{c} \\
\begin{array}{c}8 \\
\text { VeryLow }\end{array} \\
2.000\end{array}$} & \multirow{2}{*}{$\begin{array}{c}10 \\
\text { VeryLow }\end{array}$} & \multirow{2}{*}{$\begin{array}{c}12 \\
\text { Extremely Low } \\
3.000\end{array}$} & \multirow{2}{*}{$\begin{array}{c}\begin{array}{c}14 \\
\text { Extremely Low }\end{array} \\
3.500\end{array}$} & \multirow{2}{*}{$\begin{array}{c}16 \\
\text { Extremely Low } \\
4.000\end{array}$} \\
\hline \multirow{35}{*}{ D } & & L & & & & & & & & & & \\
\hline & \multirow{6}{*}{0.25} & P/L & & & & & 2.903 & 2.540 & 2.032 & 1.693 & 1.451 & 1.270 \\
\hline & & mass(frag) & 0.54 & 1.631 & 2.175 & 3.263 & 3.806 & 4.350 & 5.438 & 6.525 & 7.613 & 8.700 \\
\hline & & $P$ (mass) & 0.885 & 0.065 & 0.020 & 0.01000 & 0.01000 & 0.00600 & 0.00100 & 0.00120 & 0.00080 & 0.00070 \\
\hline & & $P(L / D \mid D)$ & 0.70 & 0.070 & 0.040 & 0.020 & 0.011 & 0.007 & 0.0030 & 0.0010 & 0.0003 & 0.0001 \\
\hline & & \# Fragments & $\begin{array}{c}4240 \\
942\end{array}$ & $\begin{array}{c}10 \\
2\end{array}$ & $\begin{array}{l}1 \\
0\end{array}$ & $2.281 \mathrm{E}-01$ & $1.075 \mathrm{E}-01$ & $3.593 \mathrm{E}-02$ & $2.053 E-03$ & $6.844 \mathrm{E}-04$ & 1.173E-04 & $2.994 \mathrm{E}-05$ \\
\hline & & $\operatorname{Vcr}(\mathrm{km} / \mathrm{s})$ & 5.00 & & & $\begin{array}{l}5.07 E-02 \\
5000\end{array}$ & 2.39E-02 & 7.98E-03 & 4.56E-04 & $1.52 \mathrm{E}-04$ & $2.61 \mathrm{E}-05$ & 6.65E-06 \\
\hline & \multirow[t]{2}{*}{$\begin{array}{l}P(D=.25) \\
0.2436\end{array}$} & $P(>V c r)$ & $\begin{array}{l}5.0000 \\
0.0000\end{array}$ & $\begin{array}{l}0.000 \\
0.0000\end{array}$ & 0.0000 & $\begin{array}{l}5.000 \\
0.0000\end{array}$ & $\begin{array}{c}5.000 \\
0.0000\end{array}$ & $\begin{array}{c}n p \\
0.0000\end{array}$ & $\begin{array}{c}n p \\
0.0000\end{array}$ & $\begin{array}{c}3.500 \\
0.000 E+00\end{array}$ & $\begin{array}{c}2.250 \\
4.036 \mathrm{E}-11\end{array}$ & $\begin{array}{c}1.900 \\
1.3500 \mathrm{E}-03\end{array}$ \\
\hline & & $\mathrm{P}$ (perforation) & $0.00 E+00$ & $0.00 \mathrm{E}+00$ & $0.00 \mathrm{E}+00$ & $0.00 \mathrm{E}+00$ & $0.00 \mathrm{E}+00$ & $0.00 \mathrm{E}+00$ & $0.000 \mathrm{E}+00$ & $0.000 \mathrm{E}+00$ & $1.052 \mathrm{E}-15$ & $8.982 \mathrm{E}-09$ \\
\hline & \multirow{6}{*}{0.5} & $L$ & 0.500 & 1.500 & 2.000 & 3.000 & 3.500 & 4.000 & 5.000 & 6.000 & 7.000 & 8.000 \\
\hline & & $\begin{array}{l}\text { P/L } \\
\text { mass(frag) }\end{array}$ & $\begin{array}{l}10.160 \\
2.175\end{array}$ & $\begin{array}{l}3.387 \\
6.525\end{array}$ & $\begin{array}{l}2.540 \\
8.700\end{array}$ & $\begin{array}{c}1.693 \\
13.050\end{array}$ & $\begin{array}{c}1.451 \\
15.225\end{array}$ & $\begin{array}{c}1.270 \\
17.400\end{array}$ & $\begin{array}{c}1.016 \\
21.750\end{array}$ & $\begin{array}{c}0.847 \\
26.100\end{array}$ & $\begin{array}{c}0.726 \\
30.450\end{array}$ & $\begin{array}{c}0.635 \\
34.800\end{array}$ \\
\hline & & $\mathrm{P}$ (mass) & 0.010 & 0.001 & 0.001 & 0.001 & $2.20 \mathrm{E}-04$ & 3.00E-05 & 4.00E-05 & $5.00 \mathrm{E}-06$ & $4.00 \mathrm{E}-06$ & $5.00 \mathrm{E}-07$ \\
\hline & & $P(L / D \mid D)$ & 0.70 & 0.070 & 0.040 & 0.020 & 0.011 & 0.007 & 0.0030 & 0.0010 & 0.0003 & 0.0001 \\
\hline & & \# Fragments & 26 & 0.104 & 0.030 & $8.682 \mathrm{E}-03$ & $1.286 \mathrm{E}-03$ & $9.768 \mathrm{E}-05$ & 4.465E-05 & $1.550 \mathrm{E}-06$ & 3. $189 \mathrm{E}-07$ & 1.163E-08 \\
\hline & & \# Candidates & 6 & $2.32 \mathrm{E}-02$ & $6.62 \mathrm{E}-03$ & $1.93 \mathrm{E}-03$ & $2.86 \mathrm{E}-04$ & $2.17 \mathrm{E}-05$ & $9.92 \mathrm{E}-06$ & 3.45E-07 & $7.09 \mathrm{E}-08$ & $2.58 \mathrm{E}-09$ \\
\hline & \multirow{2}{*}{$\begin{array}{c}P(D=.5) \\
0.5298\end{array}$} & $\begin{array}{l}\operatorname{Vcr}(\mathrm{km} / \mathrm{s}) \\
\mathrm{P}(>\mathrm{Vcr})\end{array}$ & $\begin{array}{l}5.000 \\
0.0000\end{array}$ & $\begin{array}{l}5.000 \\
0.0000\end{array}$ & $\begin{array}{l}4.000 \\
0.0000\end{array}$ & $\begin{array}{c}3.000 \\
0.000 E+00\end{array}$ & $\begin{array}{c}2.350 \\
3.220 \mathrm{E}-14\end{array}$ & $\begin{array}{l}1.650 \\
0.3085\end{array}$ & $\begin{array}{l}1.550 \\
0.6915\end{array}$ & $\begin{array}{l}1.400 \\
0.9772\end{array}$ & $\begin{array}{l}1.350 \\
0.9938\end{array}$ & $\begin{array}{l}1.280 \\
0.9993\end{array}$ \\
\hline & & $\mathrm{P}$ (perforation) & $0.000 \mathrm{E}+00$ & $0.000 E+00$ & $0.000 \mathrm{E}+00$ & $0.000 E+00$ & 9.204E-18 & 6.697E-06 & $6.861 \mathrm{E}-06$ & $3.367 \mathrm{E}-07$ & 7.044E-08 & 2.582E-09 \\
\hline & \multirow{5}{*}{0.75} & r & 0.750 & 2.250 & 3.000 & 4.500 & 5.250 & 6.000 & 7.500 & 9.000 & 10.500 & 12.000 \\
\hline & & P/L & 6.773 & 2.258 & 1.693 & 1.129 & 0.968 & 0.847 & 0.677 & 0.564 & 0.484 & 0.423 \\
\hline & & mass(frag) & 4.894 & 14.681 & 19.575 & 29.363 & 34.256 & 39.150 & 48.938 & 58.725 & 68.513 & 78.300 \\
\hline & & $\mathrm{P}$ (mass) & $1.00 \mathrm{E}-03$ & 2.20E-04 & 3.00E-05 & $5.00 E-06$ & $4.00 E-06$ & $5.00 \mathrm{E}-07$ & 4.00E- 07 & 5.00E-08 & $4.00 \mathrm{E}-08$ & $5.00 \mathrm{E}-09$ \\
\hline & & $\mid \begin{array}{l}P(L / D \mid D) \\
\# \text { Fragments }\end{array}$ & $\begin{array}{c}0.70 \\
0\end{array}$ & $\begin{array}{l}0.070 \\
0.003\end{array}$ & $\begin{array}{l}0.040 \\
0.000\end{array}$ & $\begin{array}{l}0.020 \\
1.112 E-05\end{array}$ & $\begin{array}{l}0.011 \\
4.193 E-06\end{array}$ & $\begin{array}{l}0.007 \\
2918-07\end{array}$ & $\begin{array}{l}0.0030 \\
8005 E-08\end{array}$ & & $\begin{array}{c}0.0003 \\
5718 \mathrm{E}-10\end{array}$ & $\begin{array}{l}0.0001 \\
2.085-11\end{array}$ \\
\hline & \multirow{3}{*}{$\begin{array}{c}P(D=.75) \\
0.2137\end{array}$} & \# Candidates & 0.104 & 0.001 & 0.000 & 0.000 & 0.000 & 0.000 & 0.000 & $\begin{array}{l}2.779 \mathrm{E}-09 \\
0.000\end{array}$ & $\begin{array}{l}5.718 \mathrm{E}-10 \\
0.000\end{array}$ & $\begin{array}{l}2.085 E-11 \\
0.000\end{array}$ \\
\hline & & $\begin{array}{l}\text { Vor }(\mathrm{km} / \mathrm{s}) \\
\mathrm{P}(\mathrm{V} \mathrm{Vrr})\end{array}$ & $\begin{array}{l}5.000 \\
0.0000\end{array}$ & $\begin{array}{l}5.000 \\
0.0000\end{array}$ & $\begin{array}{l}2.200 \\
0.0000\end{array}$ & $\begin{array}{l}1.700 \\
0.1587\end{array}$ & $\begin{array}{l}1.500 \\
0.8413\end{array}$ & $\begin{array}{l}1.350 \\
0.9938\end{array}$ & $\begin{array}{l}1.250 \\
0.9998\end{array}$ & $\begin{array}{l}1.200 \\
1.0000\end{array}$ & $\begin{array}{l}1.100 \\
1.0000\end{array}$ & $\begin{array}{c}0.800 \\
1.0000\end{array}$ \\
\hline & & $\mathrm{P}$ (perforation) & $0.000 E+00$ & $0.000 E+00$ & 4.403E-14 & $3.920 \mathrm{E}-07$ & $7.839 \mathrm{E}-07$ & $6.445 \mathrm{E}-08$ & $1.778 \mathrm{E}-08$ & $6.176 \mathrm{E}-10$ & $1.271 \mathrm{E}-10$ & $4.632 \mathrm{E}-12$ \\
\hline & \multirow{7}{*}{1} & L & 1.000 & 3.000 & 4.000 & 6.000 & 7.000 & 8.000 & 10.000 & 12.000 & 14.000 & 16.000 \\
\hline & & & 5.080 & 1.693 & 1.270 & 0.847 & 0.726 & 0.635 & 0.508 & 0.423 & 0.363 & 0.318 \\
\hline & & mass(frag) & 8.700 & 26.100 & 34.800 & 52.200 & 60.900 & 69.600 & 87.000 & 104.400 & 121.800 & 139.200 \\
\hline & & $P($ mass $)$ & 0.001 & $5.00 \mathrm{E}-06$ & $5.00 \mathrm{E}-07$ & $5.00 \mathrm{E}-08$ & $4.00 E-08$ & $5.00 \mathrm{E}-09$ & 4.00E- 09 & $4.00 \mathrm{E}-10$ & 4.00E-11 & $5.00 \mathrm{E}-12$ \\
\hline & & $P(L / D \mid D)$ & 0.70 & 0.070 & 0.040 & 0.020 & 0.011 & 0.007 & 0.0030 & 0.0010 & 0.0003 & 0.0001 \\
\hline & & \# Fragments & 0 & 0.000 & 0.000000 & $3.775 \mathrm{E}-09$ & 1.424E-09 & $9.910 \mathrm{E}-11$ & $2.718 \mathrm{E}-11$ & $7.550 \mathrm{E}-13$ & $1.941 \mathrm{E}-14$ & $7.078 \mathrm{E}-16$ \\
\hline & & \# Candidates & 0.002 & 0.000 & 0.000 & 0.000 & 0.000 & 0.000 & 0.000 & 0.000 & 0.000 & 0.000 \\
\hline & \multirow[t]{3}{*}{0.0129} & $\operatorname{Ver}(\mathrm{km} / \mathrm{s})$ & 5.000 & 2.250 & 1.650 & 1.350 & 1.300 & 1.160 & 1.100 & 1.000 & 0.950 & 0.900 \\
\hline & & $P(>V(r)$ & 0.0000 & 0.0000 & 0.3085 & 0.9938 & 0.9987 & 1.0000 & 1.0000 & 1.0000 & 1.0000 & 1.0000 \\
\hline & & P(perforation) & $0.000 \mathrm{E}+00$ & $2.370 \mathrm{E}-17$ & 7.765E-09 & 8.337E-10 & $3.160 \mathrm{E}-10$ & $2.202 \mathrm{E}-11$ & $6.040 \mathrm{E}-12$ & $1.678 \mathrm{E}-13$ & 4.314E-15 & $1.573 \mathrm{E}-16$ \\
\hline
\end{tabular}


TABLE A3. Discrete ProbABILITY ASSESSMENT FOR 2 INCH THICK HSLA-100 CONTAINMENT VESSEL ENCASED IN A 3.25 INCH STEEL SAFETY VESSEL

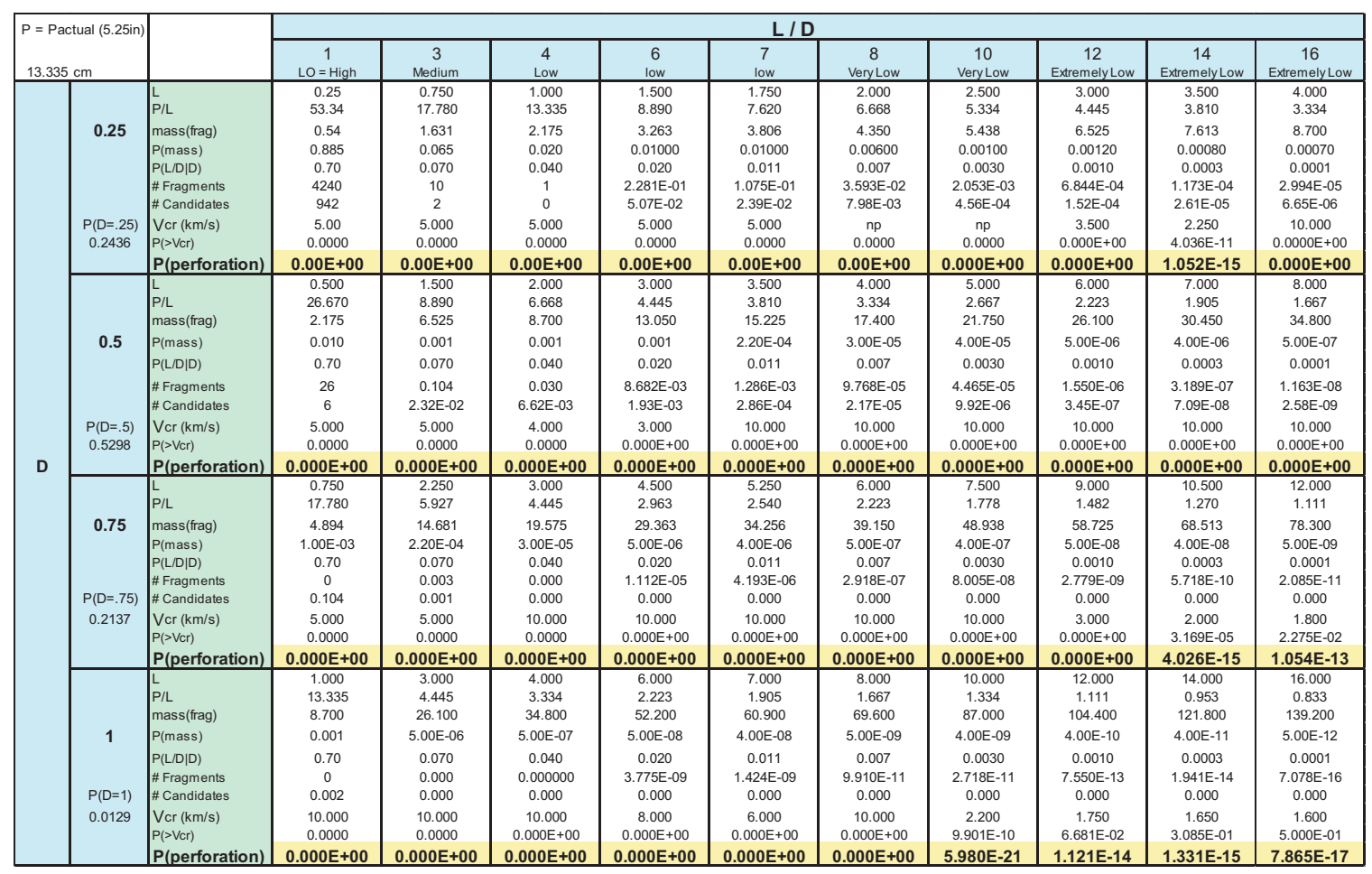





\section{APPENDIX B}

STOCHASTIC SAMPLING LOGICAL INFLUENCE DIAGRAM MODEL 
Stochastic sampling assessment of the probability a fragment perforates a containment vessel thickness during a DynEx explosive experiment

\section{INPUT Parameters}

\begin{tabular}{|llr|}
\hline Fragment Density & $(\mathrm{g} / \mathrm{cm} 3)$ & 17.69 \\
Fragment Thickness & $(\mathrm{cm})$ & 0.5 \\
Fragment Cone Angle & $(\mathrm{deg})$ & 20.00 \\
Target Thickness & $(\mathrm{cm})$ & 5.08 \\
& & \\
Mass Distribution & & Edit Table \\
Velocity Distribution & & Edit Table \\
& & \\
& & \\
\end{tabular}

\section{Uncertain Parameters}

Diameter Distribution

(L/D) Ratio Distribution

\begin{tabular}{|l|}
\hline Beta \\
\hline Beta \\
\hline
\end{tabular}

\section{OUTPUT Parameters}
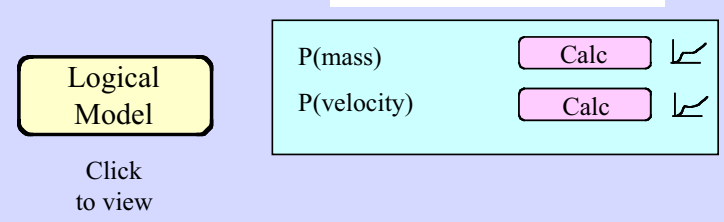

Click
to view

\section{Analysis Results}

$\mathrm{P}($ penetration)

Calc

Figure B1. Input/output and problem specification graphical user interface for the DynEx influence diagram.

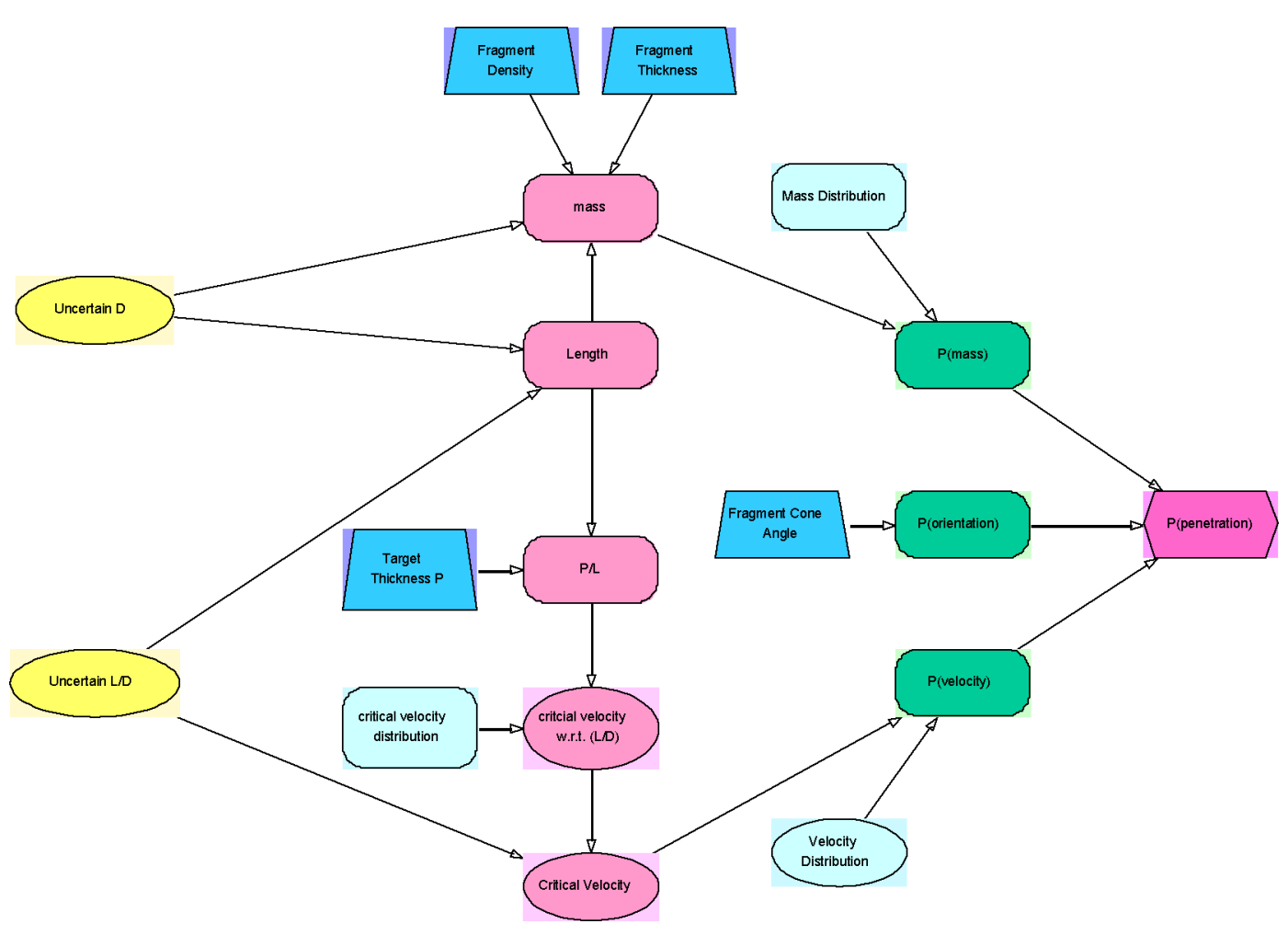

Figure B2. Main logical model for the DynEx influence diagram. 


\section{APPENDIX C}

\section{RESULTS OF FORTY STOCHASTIC SIMULATIONS USING}

DIFFERENT RANDOM SAMPLING SEEDS 
TABLE C1. RESUltS OF ForTy SimUlations Using DifFERENT SAMPLING SETS FOR THE 1 INCH TARGET THICKNESS SCENARIO

\begin{tabular}{|c|c|c|c|c|}
\hline \multirow[b]{2}{*}{ Run } & \multirow[b]{2}{*}{$\begin{array}{l}\text { Random } \\
\text { Number } \\
\text { seed }\end{array}$} & \multicolumn{2}{|c|}{1 Inch Vessel } & \multirow[b]{2}{*}{$\begin{array}{c}\text { Maximum } \\
\text { (failure) } \\
(\times 10-6)\end{array}$} \\
\hline & & $\begin{array}{c}\text { Simulation Mean } \\
(\times 10-9)\end{array}$ & $\begin{array}{c}\text { Simulation } \\
\text { Standard } \\
\text { Deviation } \\
(\times 10-6)\end{array}$ & \\
\hline 1 & 10 & 14.45 & 55.09 & 2.231 \\
\hline 2 & 20 & 14.49 & 54.86 & 2.065 \\
\hline 3 & 30 & 13.49 & 47.40 & 2.178 \\
\hline 4 & 40 & 14.63 & 54.77 & 2.112 \\
\hline 5 & 50 & 13.94 & 46.76 & 2.040 \\
\hline 6 & 60 & 14.47 & 56.98 & 2.218 \\
\hline 7 & 70 & 13.99 & 50.56 & 2.167 \\
\hline 8 & 80 & 14.24 & 52.58 & 2.192 \\
\hline 9 & 99 & 14.48 & 53.76 & 2.219 \\
\hline 10 & 100 & 14.04 & 52.32 & 2.175 \\
\hline 11 & 110 & 14.30 & 53.64 & 2.228 \\
\hline 12 & 120 & 13.61 & 46.49 & 2.224 \\
\hline 13 & 130 & 13.93 & 48.36 & 2.069 \\
\hline 14 & 140 & 13.96 & 48.71 & 1.964 \\
\hline 15 & 150 & 14.14 & 54.96 & 2.219 \\
\hline 16 & 160 & 14.23 & 55.19 & 2.222 \\
\hline 17 & 170 & 14.20 & 50.53 & 2.163 \\
\hline 18 & 180 & 14.07 & 48.80 & 2.196 \\
\hline 19 & 190 & 13.93 & 47.29 & 1.963 \\
\hline 20 & 2000 & 13.97 & 50.70 & 2.222 \\
\hline 21 & 2100 & 14.09 & 50.31 & 2.197 \\
\hline 22 & 2200 & 13.94 & 49.71 & 2.222 \\
\hline 23 & 2300 & 14.30 & 55.65 & 2.182 \\
\hline 24 & 2400 & 14.55 & 52.18 & 2.104 \\
\hline 25 & 2500 & 14.74 & 56.34 & 2.214 \\
\hline 26 & 2600 & 13.79 & 48.00 & 2.005 \\
\hline 27 & 2700 & 14.04 & 49.79 & 2.218 \\
\hline 28 & 2800 & 14.03 & 47.38 & 2.173 \\
\hline 29 & 2900 & 13.95 & 50.59 & 2.168 \\
\hline 30 & 30000 & 13.25 & 45.48 & 1.978 \\
\hline 31 & 31000 & 14.18 & 52.08 & 2.199 \\
\hline 32 & 32000 & 14.10 & 51.24 & 2.145 \\
\hline 33 & 33000 & 14.40 & 54.42 & 2.229 \\
\hline 34 & 34000 & 13.64 & 44.74 & 1.691 \\
\hline 35 & 35432 & 13.78 & 50.65 & 2.230 \\
\hline 36 & 36432 & 14.11 & 51.29 & 2.231 \\
\hline 37 & 37432 & 14.10 & 52.45 & 1.999 \\
\hline 38 & 38432 & 14.04 & 56.31 & 2.228 \\
\hline 39 & 39432 & 13.68 & 42.64 & 2.159 \\
\hline 40 & 400432 & 13.95 & 48.04 & 2.210 \\
\hline \multicolumn{2}{|c|}{ Mean values: } & 14.08 & 50.98 & 2.146 \\
\hline \multicolumn{2}{|c|}{ Std Deviations: } & 0.312 & 3.528 & 0.111 \\
\hline & & & WPP(fail & 2.231 \\
\hline & & & WPP(failu & 1.691 \\
\hline
\end{tabular}


TABLE C2. RESUltS OF ForTy SimUlations Using DifFERENT SAMPLING SETS FOR THE 2 INCH TARGET THICKNESS SCENARIO

\begin{tabular}{|c|c|c|c|c|}
\hline \multirow[b]{2}{*}{ Run } & & \multicolumn{3}{|c|}{2 Inch Vessel } \\
\hline & $\begin{array}{c}\text { Random } \\
\text { Number } \\
\text { seed }\end{array}$ & $\begin{array}{c}\text { Simulation Mean } \\
(\times 10-9)\end{array}$ & $\begin{array}{c}\text { Simulation } \\
\text { Standard } \\
\text { Deviation } \\
(\times 10-6)\end{array}$ & $\begin{array}{c}\text { Maximum } \\
\text { P(failure) } \\
(\times 10-6)\end{array}$ \\
\hline 1 & 10 & 441.8 & 6.629 & 153.2 \\
\hline 2 & 20 & 403.8 & 5.944 & 153.4 \\
\hline 3 & 30 & 422.2 & 6.337 & 153.8 \\
\hline 4 & 40 & 452.6 & 6.554 & 154.6 \\
\hline 5 & 50 & 404.5 & 6.233 & 151.6 \\
\hline 6 & 60 & 378.2 & 5.797 & 153.8 \\
\hline 7 & 70 & 467.7 & 6.658 & 153.1 \\
\hline 8 & 80 & 353.8 & 5.658 & 153.7 \\
\hline 9 & 99 & 376.9 & 5.766 & 154.6 \\
\hline 10 & 100 & 412.3 & 6.168 & 154.5 \\
\hline 11 & 110 & 454.1 & 6.472 & 154.0 \\
\hline 12 & 120 & 413.5 & 6.271 & 154.0 \\
\hline 13 & 130 & 460.2 & 6.439 & 154.1 \\
\hline 14 & 140 & 377.0 & 5.913 & 151.9 \\
\hline 15 & 150 & 379.2 & 5.914 & 154.2 \\
\hline 16 & 160 & 411.7 & 6.050 & 154.3 \\
\hline 17 & 170 & 378.1 & 5.855 & 154.6 \\
\hline 18 & 180 & 409.0 & 6.119 & 152.8 \\
\hline 19 & 190 & 377.0 & 5.781 & 154.1 \\
\hline 20 & 2000 & 416.5 & 5.992 & 153.9 \\
\hline 21 & 2100 & 485.9 & 6.824 & 154.3 \\
\hline 22 & 2200 & 362.5 & 5.586 & 154.3 \\
\hline 23 & 2300 & 349.1 & 5.573 & 154.6 \\
\hline 24 & 2400 & 436.6 & 6.275 & 153.8 \\
\hline 25 & 2500 & 406.1 & 5.974 & 154.6 \\
\hline 26 & 2600 & 409.4 & 5.986 & 154.7 \\
\hline 27 & 2700 & 451.1 & 6.535 & 153.5 \\
\hline 28 & 2800 & 366.0 & 5.634 & 154.5 \\
\hline 29 & 2900 & 415.5 & 6.176 & 154.1 \\
\hline 30 & 30000 & 429.3 & 6.341 & 154.2 \\
\hline 31 & 31000 & 384.1 & 6.032 & 153.9 \\
\hline 32 & 32000 & 372.2 & 5.777 & 154.2 \\
\hline 33 & 33000 & 409.9 & 6.002 & 154.5 \\
\hline 34 & 34000 & 433.1 & 6.397 & 154.5 \\
\hline 35 & 35432 & 438.2 & 6.484 & 154.5 \\
\hline 36 & 36432 & 396.6 & 6.182 & 154.5 \\
\hline 37 & 37432 & 438.2 & 6.350 & 154.2 \\
\hline 38 & 38432 & 418.2 & 6.332 & 154.4 \\
\hline 39 & 39432 & 375.5 & 5.726 & 153.4 \\
\hline 40 & 400432 & 389.6 & 5.965 & 154.0 \\
\hline \multicolumn{2}{|c|}{ Mean values: } & 408.9 & 6.118 & 153.97 \\
\hline \multicolumn{2}{|c|}{ Std Deviations: } & 33.135 & 0.322 & 0.691 \\
\hline & & & WPP(fail & 154.70 \\
\hline & & & WPP(failur & 151.60 \\
\hline
\end{tabular}


TABle C3. Results of ForTy SimUlations Using DifFERENT SAMPLING SETS FOR THE 5.25 INCH TARGET THICKNESS SCENARIO

\begin{tabular}{|c|c|c|c|c|}
\hline \multirow[b]{2}{*}{ Run } & & \multicolumn{3}{|c|}{5.25 Inch Vessel } \\
\hline & $\begin{array}{c}\text { Random } \\
\text { Number } \\
\text { seed }\end{array}$ & $\begin{array}{c}\text { Simulation Mean } \\
(\times 10-15)\end{array}$ & $\begin{array}{c}\text { Simulation } \\
\text { Standard } \\
\text { Deviation } \\
(\times 10-12)\end{array}$ & $\begin{array}{c}\text { Maximum } \\
\mathrm{P} \text { (failure) } \\
(\times 10-9)\end{array}$ \\
\hline 1 & 10 & 144.8 & 37.100 & 2.239 \\
\hline 2 & 20 & 223.9 & 33.690 & 2.169 \\
\hline 3 & 30 & 41.7 & 46.180 & 2.741 \\
\hline 4 & 40 & 627.0 & 51.410 & 2.441 \\
\hline 5 & 50 & 411.0 & 39.290 & 2.772 \\
\hline 6 & 60 & 251.1 & 40.010 & 2.792 \\
\hline 7 & 70 & 271.9 & 41.920 & 2.932 \\
\hline 8 & 80 & 345.4 & 39.750 & 2.582 \\
\hline 9 & 99 & 79.1 & 53.050 & 2.773 \\
\hline 10 & 100 & 34.8 & 34.880 & 2.589 \\
\hline 11 & 110 & 91.1 & 28.730 & 1.352 \\
\hline 12 & 120 & 143.2 & 41.720 & 2.332 \\
\hline 13 & 130 & 163.9 & 41.810 & 2.958 \\
\hline 14 & 140 & 563.8 & 37.670 & 2.512 \\
\hline 15 & 150 & 782.1 & 40.900 & 2.525 \\
\hline 16 & 160 & 467.7 & 47.070 & 2.936 \\
\hline 17 & 170 & 618.8 & 54.410 & 2.879 \\
\hline 18 & 180 & 500.5 & 36.860 & 2.695 \\
\hline 19 & 190 & 317.0 & 42.550 & 2.715 \\
\hline 20 & 2000 & 380.3 & 40.620 & 2.952 \\
\hline 21 & 2100 & 467.1 & 37.290 & 2.814 \\
\hline 22 & 2200 & 394.0 & 40.640 & 2.537 \\
\hline 23 & 2300 & 748.4 & 45.660 & 2.747 \\
\hline 24 & 2400 & 344.7 & 37.840 & 2.583 \\
\hline 25 & 2500 & 315.4 & 39.590 & 2.734 \\
\hline 26 & 2600 & 477.9 & 39.570 & 2.536 \\
\hline 27 & 2700 & -119.7 & 40.310 & 2.105 \\
\hline 28 & 2800 & 65.6 & 37.540 & 2.694 \\
\hline 29 & 2900 & 465.5 & 39.680 & 2.528 \\
\hline 30 & 30000 & 413.8 & 31.370 & 1.739 \\
\hline 31 & 31000 & 262.2 & 34.930 & 2.082 \\
\hline 32 & 32000 & -65.9 & 38.860 & 2.230 \\
\hline 33 & 33000 & 441.6 & 46.790 & 2.386 \\
\hline 34 & 34000 & 304.0 & 41.380 & 2.787 \\
\hline 35 & 35432 & 54.8 & 39.740 & 2.675 \\
\hline 36 & 36432 & 288.3 & 37.390 & 2.361 \\
\hline 37 & 37432 & 155.8 & 36.700 & 2.905 \\
\hline 38 & 38432 & 65.9 & 43.770 & 2.752 \\
\hline 39 & 39432 & 320.9 & 48.310 & 2.840 \\
\hline 40 & 400432 & 504.4 & 33.760 & 2.909 \\
\hline \multicolumn{2}{|c|}{ Mean values: } & 309.1 & 40.519 & 2.57 \\
\hline \multicolumn{2}{|c|}{ Std Deviations: } & 213.6 & 5.456 & 0.342 \\
\hline \multicolumn{4}{|c|}{ Max WPP(failure } & 2.958 \\
\hline & & & WPP(failu & 1.352 \\
\hline
\end{tabular}




\section{APPENDIX D}

RESULTS OF FINITE ELEMENT ANALYSES USING THE NUMERICAL ANALYSIS TOOL BREAKOUT 
TABle D1. Various Penetration PARAmeters for Fragments IMPACting a 2-INCH THICK HSLA-100 STEEL PLATE WITH A CONSTANT FRAGMENT $D=0.50 \mathrm{CM}$

\begin{tabular}{|c|c|c|c|c|c|c|c|c|c|c|}
\hline $\begin{array}{l}\text { Radius } \\
(\mathrm{cm})\end{array}$ & $\begin{array}{c}\text { Diameter } \\
(\mathrm{cm})\end{array}$ & $\begin{array}{l}\text { Length } \\
(\mathrm{cm})\end{array}$ & $\begin{array}{c}\text { Mass } \\
(g)\end{array}$ & $\begin{array}{c}\text { L/D } \\
\text { Ratio }\end{array}$ & $\begin{array}{l}\text { Velocity } \\
(\mathrm{km} / \mathrm{s})\end{array}$ & $\begin{array}{c}\text { Depth of } \\
\text { Penetratidn } \\
(\mathrm{cm})\end{array}$ & $\begin{array}{c}P / L \\
\text { Ratio }\end{array}$ & $\begin{array}{c}\text { Residual } \\
\text { Velocity } \\
(\mathrm{km} / \mathrm{s})\end{array}$ & $\begin{array}{c}\text { Residual } \\
\text { Length } \\
(\mathrm{cm})\end{array}$ & REMARKS \\
\hline 0.25 & 0.5 & 0.5 & 1.71 & 1 & 2 & 0.827 & 1.653 & 0.000 & 0.070 & \\
\hline 0.25 & 0.5 & 1 & 3.42 & 2 & 2 & 1.459 & 1.459 & 0.000 & 0.072 & \\
\hline 0.25 & 0.5 & 1.5 & 5.12 & 3 & 2 & 2.114 & 1.409 & 0.000 & 0.075 & \\
\hline 0.25 & 0.5 & 2 & 6.83 & 4 & 2 & 2.798 & 1.399 & 0.000 & 0.077 & \\
\hline 0.25 & 0.5 & 2.5 & 8.54 & 5 & 2 & 3.564 & 1.426 & 0.000 & 0.079 & \\
\hline 0.25 & 0.5 & 3 & 10.25 & 6 & 2 & 4.609 & 1.536 & 0.000 & 0.080 & \\
\hline 0.25 & 0.5 & 3.5 & 11.96 & 7 & 2 & & & 0.752 & 0.098 & Perforated \\
\hline 0.25 & 0.5 & 4 & 13.67 & 8 & 2 & & & 1.526 & 0.303 & Perforated \\
\hline 0.25 & 0.5 & 4.5 & 15.37 & 9 & 2 & & & 1.727 & 0.756 & Perforated \\
\hline 0.25 & 0.5 & 5 & 17.08 & 10 & 2 & & & 1.800 & 1.242 & Perforated \\
\hline 0.25 & 0.5 & 5.5 & 18.79 & 11 & 2 & & & 1.841 & 1.735 & Perforated \\
\hline 0.25 & 0.5 & 6 & 20.50 & 12 & 2 & & & 1.867 & 2.231 & Perforated \\
\hline 0.25 & 0.5 & 6.5 & 22.21 & 13 & 2 & & & 1.885 & 2.729 & Perforated \\
\hline 0.25 & 0.5 & 7 & 23.92 & 14 & 2 & & & 1.899 & 3.227 & Perforated \\
\hline 0.25 & 0.5 & 7.5 & 25.62 & 15 & 2 & & & 1.909 & 3.726 & Perforated \\
\hline 0.25 & 0.5 & 8 & 27.33 & 16 & 2 & & & 1.918 & 4.225 & Perforated \\
\hline 0.25 & 0.5 & 0.5 & 171 & & & & & & & \\
\hline & 05 & 1. & 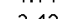 & 1 & 1.15 & 0.110 & 1.419 & 0.000 & 0.071 & \\
\hline 0.25 & 0.5 & 1 & 3.42 & 2 & 1.15 & 1.285 & 1.285 & 0.000 & 0.081 & \\
\hline 0.25 & 0.5 & 1.5 & 5.12 & 3 & 1.75 & 1.872 & 1.248 & 0.000 & 0.086 & \\
\hline 0.25 & 0.5 & 2 & 6.83 & 4 & 1.75 & 2.476 & 1.238 & 0.000 & 0.090 & \\
\hline 0.25 & 0.5 & 2.5 & 8.54 & 5 & 1.75 & 3.121 & 1.248 & 0.000 & 0.092 & \\
\hline 0.25 & 0.5 & 3 & 10.25 & 6 & 1.75 & 3.870 & 1.290 & 0.000 & 0.094 & \\
\hline 0.25 & 0.5 & 3.5 & 11.96 & 7 & 1.75 & 5.006 & 1.430 & 0.000 & 0.102 & \\
\hline 0.25 & 0.5 & 4 & 13.67 & 8 & 1.75 & & & 0.914 & 0.178 & Perforated \\
\hline 0.25 & 0.5 & 4.5 & 15.37 & 9 & 1.75 & & & 1.353 & 0.513 & Perforated \\
\hline 0.25 & 0.5 & 5 & 17.08 & 10 & 1.75 & & & 1.486 & 0.983 & Perforated \\
\hline 0.25 & 0.5 & 5.5 & 18.79 & 11 & 1.75 & & & 1.548 & 1.473 & Perforated \\
\hline 0.25 & 0.5 & 6 & 20.50 & 12 & 1.75 & & & 1.584 & 1.968 & Perforated \\
\hline 0.25 & 0.5 & 6.5 & 22.21 & 13 & 1.75 & & & 1.609 & 2.466 & Perforated \\
\hline 0.25 & 0.5 & 7 & 23.92 & 14 & 1.75 & & & 1.627 & 2.964 & Perforated \\
\hline 0.25 & 0.5 & 7.5 & 25.62 & 15 & 1.75 & & & 1.641 & 3.463 & Perforated \\
\hline 0.25 & 0.5 & 8 & 27.33 & 16 & 1.75 & & & 1.652 & 3.963 & Perforated \\
\hline 0.25 & 0.5 & 0.5 & 1.71 & 1 & 1.5 & 0.589 & 1.177 & 0.000 & 0.090 & \\
\hline 0.25 & 0.5 & 1 & 3.42 & 2 & 1.5 & 1.083 & 1.083 & 0.000 & 0.102 & \\
\hline 0.25 & 0.5 & 1.5 & 5.12 & 3 & 1.5 & 1.578 & 1.052 & 0.000 & 0.112 & \\
\hline 0.25 & 0.5 & 2 & 6.83 & 4 & 1.5 & 2.081 & 1.040 & 0.000 & 0.117 & \\
\hline 0.25 & 0.5 & 2.5 & 8.54 & 5 & 1.5 & 2.604 & 1.041 & 0.000 & 0.119 & \\
\hline 0.25 & 0.5 & 3 & 10.25 & 6 & 1.5 & 3.167 & 1.056 & 0.000 & 0.120 & \\
\hline 0.25 & 0.5 & 3.5 & 11.96 & 7 & 1.5 & 3.815 & 1.090 & 0.000 & 0.121 & \\
\hline 0.25 & 0.5 & 4 & 13.67 & 8 & 1.5 & 4.709 & 1.177 & 0.000 & 0.134 & \\
\hline 0.25 & 0.5 & 4.5 & 15.37 & 9 & 1.5 & & & 0.644 & 0.225 & Perforated \\
\hline 0.25 & 0.5 & 5 & 17.08 & 10 & 1.5 & & & 1.066 & 0.564 & Perforated \\
\hline 0.25 & 0.5 & 5.5 & 18.79 & 11 & 1.5 & & & 1.203 & 1.031 & Perforated \\
\hline 0.25 & 0.5 & 6 & 20.50 & 12 & 1.5 & & & 1.269 & 1.521 & Perforated \\
\hline 0.25 & 0.5 & 6.5 & 22.21 & 13 & 1.5 & & & 1.310 & 2.017 & Perforated \\
\hline 0.25 & 0.5 & 7 & 23.92 & 14 & 1.5 & & & 1.337 & 2.515 & Perforated \\
\hline 0.25 & 0.5 & 7.5 & 25.62 & 15 & 1.5 & & & 1.357 & 3.014 & Perforated \\
\hline 0.25 & 0.5 & 8 & 27.33 & 10 & 1.5 & & & 1.373 & 3.514 & Perforated \\
\hline
\end{tabular}


TABLE D2. VARIOUS PENETRATION PARAMETERS FOR FRAGMENTS IMPACTING A 2-INCH THICK HSLA-100 STEEL PLATE WITH A CONSTANT FRAGMENT $D=0.75 \mathrm{CM}$

\begin{tabular}{|c|c|c|c|c|c|c|c|c|c|c|}
\hline $\begin{array}{l}\text { Radius } \\
(\mathrm{cm})\end{array}$ & $\begin{array}{c}\text { Diameter } \\
(\mathrm{cm})\end{array}$ & $\begin{array}{l}\text { Length } \\
(\mathrm{cm})\end{array}$ & $\begin{array}{c}\text { Mass } \\
(g)\end{array}$ & $\begin{array}{c}\text { L/D } \\
\text { Ratio }\end{array}$ & $\begin{array}{c}\text { Velocity } \\
(\mathrm{km} / \mathrm{s})\end{array}$ & $\begin{array}{c}\text { Depth of } \\
\text { Penetration } \\
(\mathrm{cm})\end{array}$ & $\begin{array}{c}P / L \\
\text { Ratio }\end{array}$ & $\begin{array}{c}\text { Residual } \\
\text { Velocity } \\
(\mathrm{km} / \mathrm{s})\end{array}$ & $\begin{array}{l}\text { Residual } \\
\text { Length } \\
\text { (cm) }\end{array}$ & REMARKS \\
\hline 0.375 & 0.75 & 0.75 & 5.77 & 1 & 2 & 1.353 & 1.804 & 0.000 & 0.108 & \\
\hline 0.375 & 0.75 & 1.5 & 11.53 & 2 & 2 & 2.428 & 1.618 & 0.000 & 0.108 & \\
\hline 0.375 & 0.75 & 2.25 & 17.30 & 3 & 2 & 4.430 & 1.969 & 0.000 & 0.111 & \\
\hline 0.375 & 0.75 & 3 & 23.06 & 4 & 2 & & & 0.770 & 0.126 & Perforated \\
\hline 0.375 & 0.75 & 3.75 & 28.83 & 5 & 2 & & & 1.393 & 0.264 & Perforated \\
\hline 0.375 & 0.75 & 4.5 & 34.59 & 6 & 2 & & & 1.732 & 0.884 & Perforated \\
\hline 0.375 & 0.75 & 5.25 & 40.36 & 7 & 2 & & & 1.822 & 1.605 & Perforated \\
\hline 0.375 & 0.75 & 6 & 46.12 & 8 & 2 & & & 1.865 & 2.342 & Perforated \\
\hline 0.375 & 0.75 & 0.75 & 5.77 & 1 & 1.75 & 1.141 & 1.521 & 0.000 & 0.117 & \\
\hline 0.375 & 0.75 & 1.5 & 11.53 & 2 & 1.75 & 2.094 & 1.396 & 0.000 & 0.122 & \\
\hline 0.375 & 0.75 & 2.25 & 17.30 & 3 & 1.75 & 3.198 & 1.421 & 0.000 & 0.127 & \\
\hline 0.375 & 0.75 & 3 & 23.06 & 4 & 1.75 & 4.827 & 1.609 & 0.000 & 0.138 & \\
\hline 0.375 & 0.75 & 3.75 & 28.83 & 5 & 1.75 & & & 0.894 & 0.225 & Perforated \\
\hline 0.375 & 0.75 & 4.5 & 34.59 & 6 & 1.75 & & & 1.389 & 0.692 & Perforated \\
\hline 0.375 & 0.75 & 5.25 & 40.36 & 7 & 1.75 & & & 1.526 & 1.390 & Perforated \\
\hline 0.375 & 0.75 & 6 & 46.12 & 8 & 1.75 & & & 1.585 & 2.121 & Perforated \\
\hline 0375 & 0.75 & 0.75 & 5.77 & 1 & 15 & 0.933 & 1244 & 0000 & 0134 & \\
\hline 0.375 & 0.75 & 1.5 & 11.53 & 2 & 1.5 & 1.742 & 1.161 & 0.000 & 0.146 & \\
\hline 0.375 & 0.75 & 2.25 & 17.30 & 3 & 1.5 & 2.629 & 1.168 & 0.000 & 0.155 & \\
\hline 0.375 & 0.75 & 3 & 23.06 & 4 & 1.5 & 3.703 & 1.234 & 0.000 & 0.165 & \\
\hline 0.375 & 0.75 & 3.75 & 28.83 & 5 & 1.5 & 5.530 & 1.475 & 0.000 & 0.204 & Bulging \\
\hline 0.375 & 0.75 & 4.5 & 34.59 & 6 & 1.5 & & & 0.924 & 0.453 & Perforated \\
\hline 0.375 & 0.75 & 5.25 & 40.36 & 7 & 1.5 & & & 1.187 & 1.067 & Perforated \\
\hline 0.375 & 0.75 & 6 & 46.12 & 8 & 1.5 & & & 1.281 & 1.777 & Perforated \\
\hline
\end{tabular}

TABLE D3. VARIOUS PENETRATION PARAMETERS FOR FRAGMENTS IMPACTING A 2-INCH THICK HSLA-100 STEEL PLATE WITH A CONSTANT FRAGMENT $D=1.0 \mathrm{CM}$

\begin{tabular}{|c|c|c|c|c|c|c|c|c|c|c|}
\hline $\begin{array}{c}\text { Radius } \\
(\mathrm{cm})\end{array}$ & $\begin{array}{c}\text { Diameter } \\
(\mathrm{cm})\end{array}$ & $\begin{array}{l}\text { Length } \\
(\mathrm{cm})\end{array}$ & $\begin{array}{c}\text { Mass } \\
(\mathrm{g})\end{array}$ & $\begin{array}{l}\text { L/D } \\
\text { Ratio }\end{array}$ & $\begin{array}{c}\text { Velocity } \\
(\mathrm{km} / \mathrm{s})\end{array}$ & $\begin{array}{c}\text { Depth of } \\
\text { Penetratio } \\
(\mathrm{cm})\end{array}$ & $\begin{array}{l}P / L \\
\text { Ratio }\end{array}$ & $\begin{array}{c}\text { Residual } \\
\text { Velocity } \\
(\mathrm{km} / \mathrm{s})\end{array}$ & $\begin{array}{c}\text { Residual } \\
\text { Length } \\
(\mathrm{cm})\end{array}$ & REMARKS \\
\hline 0.5 & 1 & 1 & 13.67 & 1 & 2 & 2.104 & 2.104 & 0.000 & 0.143 & \\
\hline 0.5 & 1 & 2 & 27.33 & 2 & 2 & 4.186 & 2.093 & 0.000 & 0.143 & \\
\hline 0.5 & 1 & 3 & 41.00 & 3 & 2 & & & 0.788 & 0.170 & Perforated \\
\hline 0.5 & 1 & 4 & 54.66 & 4 & 2 & & & 1.614 & 0.567 & Perforated \\
\hline 0.5 & 1 & 5 & 68.33 & 5 & 2 & & & 1.802 & 1.480 & Perforated \\
\hline 0.5 & 1 & 6 & 82.00 & 6 & 2 & & & 1.864 & 2.453 & Perforated \\
\hline 0.5 & 1 & 7 & 95.66 & 7 & 2 & & & 1.896 & 3.439 & Perforated \\
\hline 0.5 & 1 & 8 & 109.33 & 8 & 2 & & & 1.916 & 4.431 & Perforated \\
\hline 0.5 & 1 & 1 & 13.67 & 1 & 1.75 & 1.734 & 1.734 & 0.000 & 0.154 & \\
\hline 0.5 & 1 & 2 & 27.33 & 2 & 1.75 & 3.390 & 1.695 & 0.000 & 0.162 & \\
\hline 0.5 & 1 & 3 & 41.00 & 3 & 1.75 & & & 0.318 & 0.191 & Perforated \\
\hline 0.5 & 1 & 4 & 54.66 & 4 & 1.75 & & & 1.221 & 0.475 & Perforated \\
\hline 0.5 & 1 & 5 & 68.33 & 5 & 1.75 & & & 1.504 & 1.310 & Perforated \\
\hline 0.5 & 1 & 6 & 82.00 & 6 & 1.75 & & & 1.586 & 2.270 & Perforated \\
\hline 0.5 & 1 & 7 & 95.66 & 7 & 1.75 & & & 1.627 & 3.251 & Perforated \\
\hline 0.5 & 1 & 8 & 109.33 & 8 & 1.75 & & & 1.651 & 4.240 & Perforated \\
\hline 0.5 & 1 & 1 & 13.67 & 1 & 1.5 & 1.402 & 1.402 & 0.000 & 0.174 & \\
\hline 0.5 & 1 & 2 & 27.33 & 2 & 1.5 & 2.728 & 1.364 & 0.000 & 0.191 & \\
\hline 0.5 & 1 & 3 & 41.00 & 3 & 1.5 & 4.645 & 1.548 & 0.000 & 0.221 & \\
\hline 0.5 & 1 & 4 & 54.66 & 4 & 1.5 & & & 0.773 & 0.402 & Perforated \\
\hline 0.5 & 1 & 5 & 68.33 & 5 & 1.5 & & & 1.167 & 1.080 & Perforated \\
\hline 0.5 & 1 & 6 & 82.00 & 6 & 1.5 & & & 1.290 & 2.003 & Perforated \\
\hline 0.5 & 1 & 7 & 95.66 & 7 & 1.5 & & & 1.345 & 2.970 & Perforated \\
\hline 0.5 & 1 & 8 & 109.33 & 8 & 1.5 & & & 1.376 & 3.951 & Ferforated \\
\hline
\end{tabular}


This report has been reproduced directly from the best available copy. It is available electronically on the Web (http://www.doe.gov/bridge).

Copies are available for sale to U.S. Department of Energy employees and contractors from:

Office of Scientific and Technical Information P.O. Box 62

Oak Ridge, TN 37831

(865) 576-8401

Copies are available for sale to the public from: National Technical Information Service

U.S. Department of Commerce

5285 Port Royal Road

Springfield, VA 22616

(800) 553-6847 
